Illinois State University

ISU ReD: Research and eData

Theses and Dissertations

$5-19-2016$

\title{
Elementary District-Level And Building-Level Leadership Practices That Promote And Sustain Professional Learning Communities
}

Nathaniel Cunningham Jr.

Illinois State University, airfrce80@me.com

Follow this and additional works at: https://ir.library.illinoisstate.edu/etd

Part of the Elementary and Middle and Secondary Education Administration Commons, and the Elementary Education and Teaching Commons

\section{Recommended Citation}

Cunningham Jr., Nathaniel, "Elementary District-Level And Building-Level Leadership Practices That Promote And Sustain Professional Learning Communities" (2016). Theses and Dissertations. 565. https://ir.library.illinoisstate.edu/etd/565

This Dissertation is brought to you for free and open access by ISU ReD: Research and eData. It has been accepted for inclusion in Theses and Dissertations by an authorized administrator of ISU ReD: Research and eData. For more information, please contact ISUReD@ilstu.edu. 


\section{ELEMENTARY DISTRICT-LEVEL AND BUILDING-LEVEL LEADERSHIP PRACTICES THAT PROMOTE AND SUSTAIN PROFESSIONAL LEARNING COMMUNITIES}

Nathaniel Cunningham, Jr.

\section{Pages}

This study examined the relationship between building-level and district-level leadership in sustaining Professional Learning Communities (PLCs). The study attempted to reveal the relationships of building-level and district-level leadership in sustaining level PLCs. The study also sought to determine the impact of relational trust between building-level and district-level leadership practices within professional learning communities. The Professional Learning Community Continuum (PLCC) was administered in order to identify those districts that were operating at the sustaining stage for PLCs. Approximately 46 district and building-level leaders participated in the study. A non-random sampling of three sustaining-stage PLC districts participated in the second stage of the study.

The relationships of central office and building leadership in sustaining-level PLCs, using values coding, were investigated, resulting in a culture picture. The study was carried out in three phases: the first two phases consisted of a selection process aimed at the identification of sustaining-level PLC elementary school districts in the 
northeastern portion of the state of Illinois. The final phase focused on a qualitative analysis of the relationships of central office and building leadership in those PLCs.

In Phase I, the researcher chose to survey the districts in the northeastern section of Illinois because more than $50 \%$ of the state's elementary school districts are located in the four northeastern counties. The researcher surveyed 916 administrators from 134 elementary school districts. In Phase II, the researcher utilized the information gathered with the PLCC to identify sustaining stage PLCs. Phase III included visits and interviews with both building-level and district-level leadership. The data gained with the visits, interviews, and document review enabled the researcher to answer the research questions The analysis of Phase III centered upon coherence across the interviews of the three districts' central office and building leadership. The study identified relational trust as a factor in sustaining level PLCs.

KEY WORDS: Building-Level and District-Level Leadership, Professional Learning Communities, Relational Trust 


\title{
ELEMENTARY DISTRICT-LEVEL AND BUILDING-LEVEL LEADERSHIP \\ PRACTICES THAT PROMOTE AND SUSTAIN \\ PROFESSIONAL LEARNING COMMUNITIES
}

NATHANIEL CUNNINGHAM, JR.

\author{
A Dissertation Submitted in \\ Partial Fulfillment of the Requirements \\ for the Degree of \\ DOCTOR OF PHILOSOPHY \\ Department of Educational Administration and Foundations \\ ILLINOIS STATE UNIVERSITY \\ 2016
}


Copyright 2016 Nathaniel Cunningham, Jr. 


\section{ELEMENTARY DISTRICT-LEVEL AND BUILDING-LEVEL LEADERSHIP PRACTICES THAT PROMOTE AND SUSTAIN PROFESSIONAL LEARNING COMMUNITIES}

NATHANIEL CUNNINGHAM, JR.

COMMITTEE MEMBERS:

Neil Sappington, Chair

Guy Banicki

Lydia Kyei-Blankson

Elizabeth Timmerman Lugg 


\section{ACKNOWLEDGMENTS}

Though the path to complete my work has been circuitous, it is without hesitation that I give all praise and honor to God Almighty, for He provided the strength to move me to this place.

Over the past 8 years I have received love, patience, support and encouragement from a great number of individuals. My advisor, professor, department chair, and dissertation advisor extraordinaire, Dr. Neil Sappington, continued to encourage, be patient, and support my efforts. To him, I am forever grateful. He stayed with me through three job changes and four relocations. To my dissertation committee-Dr. Guy Banicki, Dr. Lydia Kyei-Blankson and Dr. Elizabeth Timmerman Lugg — thank you for your work, patience and persistence. My committee members provided a plethora of knowledge. I am forever grateful for their support over the past 2 years, as I moved from an idea to a completed study, and it was their continued guidance and support that enabled me to complete my work successfully.

I would be remiss not to mention Ms. Pat McCarney, for her skills, aid, and true guidance. Your help was imperative in assuring all of the pieces of my work fit together, for the completion. Thank you to Dr. Richard Voltz, mentor and friend, for deepening my understanding of the world of education, providing needed encouragement, and for sharing your profound insight.

I would like to thank my colleagues, the schools, and the district leaders who took part in this study, allowing fruitful discussions and for generously sharing their time and ideas. I have learned much though our conversations. A huge thank you for those prayer warriors who uplifted me when my mind, body, and spirit were so tired. 
Finally, my family played a major part of this, more than they know. Thanks to my parents who always encouraged me to stretch to reach my best and for teaching me to be curious. Thank you to my two boys who always asked how they could help and were understanding during my time of writing and research. My joy knows no bounds for my wife and best friend. She pushed, pressured, and stood by me to the end. Thank you for sacrificing and for believing that I would get here.

N. C. 


\section{CONTENTS}

Page

ACKNOWLEDGMENTS

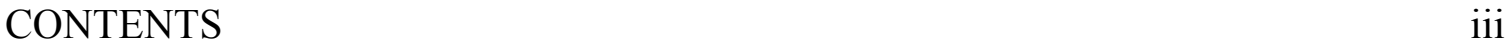

TABLES vii

CHAPTER

I. THE PROBLEM OF THE STUDY AND ITS CLARIFYING COMPONENTS 1

Introduction 1

Statement of the Problem 11

Statement of the Purpose $\quad 12$

Specific Research Questions $\quad 13$

Conceptual Framework $\quad 13$

Study Design 14

Data Collection $\quad 14$

$\begin{array}{ll}\text { Data Analysis } & 17\end{array}$

$\begin{array}{lr}\text { Significance of the Study } & 18\end{array}$

Assumptions 18

$\begin{array}{ll}\text { Delimitations } & 19\end{array}$

$\begin{array}{ll}\text { Limitations } & 19\end{array}$

Definitions and Technical Terminology 19

Organization of the Study 22

II. REVIEW OF THE LITERATURE 24

The Birth of the School District 25

The Process of Educational Change 27

Social Upheaval Causes Waves of Reform 30

The Learning Organization 41

The Professional Learning Community 44

Instructionally Effective School Districts (IESD) 47

Loose and Tightly Coupled Organizations to District-wide PLCs 52

Administrator Professional Development 56 
Conclusion

III. METHODS OF STUDY 64

Purpose of the Research $\quad 64$

Research Questions $\quad 65$

Positionality of the Researcher 66

Characteristics of Qualitative Research $\quad 67$

Participant Selection $\quad 69$

$\begin{array}{ll}\text { Instrumentation } & 72\end{array}$

Interview Protocol 73

Observation Protocol 73

$\begin{array}{ll}\text { Data Collection Procedures } & 74\end{array}$

Study Reliability and Validity $\quad 76$

$\begin{array}{ll}\text { IV. ANALYSIS OF RESULTS } & 77\end{array}$

$\begin{array}{ll}\text { Phase I } & 78\end{array}$

$\begin{array}{ll}\text { Phase II } & 78\end{array}$

Phase III Subgroup Identification $\quad 79$

$\begin{array}{ll}\text { Participant Profiles } & 79\end{array}$

$\begin{array}{ll}\text { Grandview District } & 80\end{array}$

Dr. Chievers $\quad 81$

$\begin{array}{ll}\text { Mrs. Marks } & 82\end{array}$

Mrs. Red $\quad 82$

Huntington District $\quad 83$

$\begin{array}{ll}\text { Dr. Daly } & 83\end{array}$

$\begin{array}{ll}\text { Mrs. Farmer } & 84\end{array}$

Mrs. Jackie $\quad 84$

Findings from the Study $\quad 86$

Research Question $1 \quad 86$

Six characteristics of a sustained PLC 86

Mission vision, values, and goals $\quad 87$

Collaborative culture $\quad 90$

Collective inquiry 93

Action orientation $\quad 95$ 
Commitment to continuous improvement 96

Results orientation $\quad 98$

Defined autonomy $\quad 99$

Deprivatization of practice 101

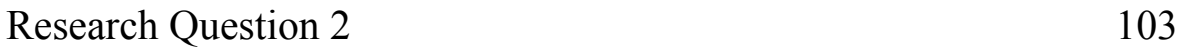

Accountability 103

$\begin{array}{ll}\text { Capacity building } & 107\end{array}$

$\begin{array}{ll}\text { Research Question } 3 & 110\end{array}$

$\begin{array}{ll}\text { Social respect } & 111\end{array}$

Personal regard 113

Competence in core responsibilities $\quad 115$

Personal integrity 116

$\begin{array}{ll}\text { Summary } & 118\end{array}$

Research Question 1 Findings $\quad 118$

Research Question 2 Findings $\quad 119$

Research Question 3 Findings 119

V. ANALYSIS, FINDINGS, IMPLICATIONS,
AND RECOMMENDATIONS

$\begin{array}{ll}\text { Introduction } & 120\end{array}$

$\begin{array}{ll}\text { Overview of the Study } & 120\end{array}$

Summary of Results 123

Research Question 1 123

Research Question 2 125

Research Question $3 \quad 126$

$\begin{array}{ll}\text { Conclusions } & 127\end{array}$

Implications for Practice and Analysis of Results 127

Process $\quad 128$

Communication 129

Limitations $\quad 130$

Recommendations for Future Research 130

REFERENCES 134 
APPENDIX B: Recruitment E-mail

APPENDIX C: Recruitment Phone Script_-If Individual Answers Phone

APPENDIX D: Recruitment Phone Script_-If Leaving Voicemail

APPENDIX E: Informed Consent Letter

APPENDIX G: Confirmation Email—Demographic Questions to Complete Prior to Interview

APPENDIX H: Interview Guide: Building Leadership Interview Questions Based on the Research Problem

APPENDIX I: Interview Guide: District Leadership Interview Questions Based on the Research Problem

APPENDIX J: Recording_-Video, Audio, Still Image, Digital 


\section{TABLES}

Table $\quad$ Page

1. Survey Participant Stages $\quad 79$

2. Study Districts and Participants $\quad 80$

3. Grandview and Huntington District Student Demographics 85

4. Grandview, Huntington and State Teacher Demographics 86 


\section{CHAPTER I}

\section{THE PROBLEM OF THE STUDY AND \\ ITS CLARIFYING COMPONENTS \\ Introduction}

“America needs to improve its public schools" (Moe, 2006, \1). The second half of the $20^{\text {th }}$ century and the beginning of the $21^{\text {st }}$ century were filled with calls for school reform. Sputnik, Brown v. Board of Education, Johnson's War on Poverty, the Effective Schools Movement, the Nation at Risk Report, the Excellence Movement, the Standards Movement, the Restructuring Movement, the No Child Left Behind legislation, and Race to the Top have all been attempts or included attempts to improve the nation's schools. These legions of attempts to improve the nation's schools have one thing in commonthe attempts left the core of the rigid bureaucratic educational system in place.

American schools have been in a constant state of reform and improvement for the last 60 years. The fifties, sixties, seventies, eighties, and nineties saw the emergence of social issues of reform. Brown vs. the Board of Education of Topeka in the fifties changed the social makeups of many of our schools (Hughes \& Snauwaert, 2010). Also in the fifties, fear of being second place in the cold war with the launch of the Russian artificial satellite pulled national dollars and interest into the local school for curriculum to ensure the United States School System was the best in the world.

The sixties had Johnson's War on Poverty. The seventies saw the rise of school improvement through the effective schools research (Edmonds, 1982). The eighties 
experienced the Excellence movement and unsuccessful top down school improvement.

The nineties saw the Restructuring Movement and unsuccessful grassroots improvement. Currently, the No Child Left Behind legislation and Race to the Top funding are the latest federal attempts at school improvement.

Schlechty (2005) says, "When America's schools were created it was never intended that all students would learn at high levels" (p. xi). According to Wald and Castleberry (2000), "The charge of public education system was to provide education to the masses..." (pp. 3-4). The education system adapted the factory system for use in the schools (Wald \& Castleberry, 2000). The schools' mission was to provide an opportunity for students to be educated (Callahan, 1962). According to Glanz (1991), "Throughout most of the $19^{\text {th }}$ century, schools were controlled by loosely structured, decentralized ward boards.... Beginning in the late $19^{\text {th }}$ century, educational reformers sought to transform schools into a tightly organized and efficiently operated centralized system" ( $\mathrm{p}$. 37). This structural change moved the American school system into a bureaucratic structure (Lortie, 1977). Bidwell (1965) states:

School systems are to some degree bureaucratic including the following four items: a functional division of labor, the definition of staff roles as offices, the hierarchic ordering of offices, providing an authority structure based on legally defined and circumscribed power of officers, a system of adjudication of staff disputes by reference to superiors, and regularized lines of communication and operation according to rules of procedure, which set limits to the discretionary performance of officers by specifying both the aims and modes of official action. (p. 974)

This bureaucratic system was established in the late $19^{\text {th }}$ century by reformers known as schoolmen (Callahan, 1962). Teachers were the labor and were changed in and out like parts. The focus of the system never included collaboration. The schools as they grew 
became one-room schoolhouses connected by hallways (Lortie, 1977). The individual teachers work from the one-room schoolhouse changed very little except for the addition of supervisors: the principal and the superintendent. The work of teaching stayed relatively the same (Lortie, 1977).

"Bureaucracy...is a social invention perfected during the Industrial Revolution to organize and direct the activities of the firm" (Bennis \& Bennis, 1993, p. 3). Bureaucracy was considered an answer to social ills at the beginning of the Industrial Revolution. "Throughout most of the $19^{\text {th }}$ century, schools were controlled by loosely structured, decentralized ward boards" (Glanz, 1991, p. 37). According to Bennis and Bennis (1993), "Bureaucracy...was developed as a reaction against the personal subjugation, nepotism, cruelty, emotional vicissitudes, and subjective judgment which passed for managerial practices in the early days of the Industrial Revolution” (pp. 4-5). Glanz (1991) states, "Beginning in the late nineteenth century, educational reformers sought to transform schools into a tightly organized and efficiently operated centralized system” (p. 37). Bureaucracy was the model used for the transformation. According to Glanz (1991), Reformers attempted to persuade the American people that a highly complex system of schooling would best serve the interests of all. Bureaucracy, a byproduct of the reform efforts, brought order and organization to an otherwise chaotic, corrupt, and inefficient school environment. (p. 37)

For the $19^{\text {th }}$ century, the bureaucratic system was the answer to their problems; for the $20^{\text {th }}$ century, the bureaucratic system has become part of the problem.

The bureaucratic school system performed its mission well until the 1950s (Callahan, 1962). The mission that had been established in the early $20^{\text {th }}$ century included ensuring all majority students had the opportunity to learn at a public school (Cubberley, 
1919). The challenges of new social expectations - desegregation, new curriculumSputnik, new expectations - the War on Poverty, and new research — the Effective Schools research created new expectations. Bureaucratic schools could not meet these expectations. In order to meet the new needs and expectations of modern America, a new structure for schooling was needed.

"Contemporary American educators confront the most daunting challenge in the history of public schooling in the United States" (DuFour \& Marzano, 2011, p. 5). Educators are asked to raise academic achievement standards to the highest level in history for all students (DuFour \& Marzano, 2011; Schlechty, 1994). It has been argued that decades of school reform have made very little impact and most, if any, through structural and curriculum initiatives, while failing to significantly impact classroom practice in any telling way (Elmore, 2004). What America needs is school improvement (Moe, 2006). Hopkins, Ainscow, and West (1994) define school improvement as “...a distinct approach to educational change that enhances student outcomes as well as strengthening the school's capacity for managing change" (p. 3). The new mission of schools is to ensure all students learn at high levels (DuFour, 1998). The change is required because schools today, as opposed to when the highly bureaucratic American school system was established during the first two decades of the $20^{\text {th }}$ century, are serving the knowledge society (Hargreaves, 2003); the bureaucratic system no longer meets the needs of our students, employees, or stakeholders.

As previously stated, many attempts have been made to rehabilitate individual parts of the educational system, including schools, teachers, and classrooms (Edmonds, 1982; Rosenholtz, 1989; Joyce \& Showers, 1995). These attempts lead to research to 
improve schools that discovered the most important aspect of student achievement is the quality of the teacher (Shulman, 1983; Sanders, 1997; Rosenholtz, 1989; Marzano, 2003). Once it was widely understood and agreed that the quality of the teacher was the most important factor in improving student learning, the focus on that direct aspect of research and application increased. The focus of school improvement became the classroom teacher or the school.

The focus of improving student achievement has been on individual schools (Fullan, 2006; Lezotte, 2008). The effective schools movement was able to document that schools make a difference in student achievement (Edmonds, 1982). Researchers discovered learning-enriched and learning-impoverished schools were related to school districts as much as they were related to individual schools (Rosenholtz, 1989). Attempts to use the research and work within the system to improve student achievement have been successful in some areas and unsuccessful in others. DuFour and Eaker have had great success in a one-school school district using Professional Learning Communities (PLCs) to improve student achievement based on system change (DuFour \& Eaker, 1998). In a larger venue, the San Diego Public Schools, Anthony Alvarado attempted to use system change and aggressive professional development to improve student achievement, but slight elementary improvement and significant pushback doomed those efforts (Hubbard, Mehan, \& Stein, 2006).

Although the quality of the teacher has the most powerful effect on student achievement, there are many other important factors such as at other levels (Marzano, 2003). In most cases, the other factors are needed to support the quality of the classroom teacher. Those factors impact student achievement indirectly. If school improvement is to 
be successful, the factors at all levels - the district, school, and classroom, direct and indirect - must all be considered and understood (Marzano \& Waters, 2009; Fullan, 2010). "Leaders will increase their effectiveness if they continually work on the five components of leadership — if they pursue moral purpose, understanding the change process, develop relationships, foster knowledge building, and strive for coherence-with energy, enthusiasm, and hopefulness" (Fullan, 2001, p. 10).

Oxley (2008) states, “...coherence relies on teachers collaborating across content areas and grade levels with the aim of adopting common instructional strategies and systematically building on learning in multiple contexts" (p. 1). Oxley is describing coherence across a school building. Coherence from the district level to the classroom would involve district administrators, building administrators, and teachers collaborating and adopting common strategies. According to Supovitz (2006), "Districts, whether improving or not, are at the crux of our American system of education. The district sits at the intersection of state policy and the work of schools" (p. 11). At that intersection, the battle for school improvement will be won or lost.

American education was established as a local entity under states' rights (Cubberley, 1909). With new problems looming, Tyack (2002) states, "Reformers often bypass local boards or regarded local control as more the problem then the solution. Remedy for faults lay up the chain of command, not down" (p. 10). As the many challenges bombarded the local school boards, elected trustees, and superintendents in the fifties, sixties, seventies, eighties, and nineties, Americans began to see the district and its leaders as the problem, instead of the solution. According to Tyack (2002), "Critics have periodically concluded — usually in times of social stress — that elected 
school boards and local districts are ineffective and obsolete and therefore should be abolished" (p. 10). According to Supovitz (2006),

[the] common scenario in which district leaders for all intents and purposes cede instruction on to school leaders, who in turn may pass it on to individual teachers. The result of this vacuum of instructional leadership at the district level is huge variability in the quality of learning opportunities children received from school to school and from classroom to classroom. Hence the inequities in student opportunity to learn. (pp. 1-2)

This lack of coherence led some researchers to conclude that the district didn't matter in school improvement (Lezotte, 2008).

The industrial revolution began in the $19^{\text {th }}$ century and lasted until the middle $20^{\text {th }}$ century, at most. The chief system for organization during that time was bureaucracy. As the world changed, the needs of business and education were no longer met by the system of bureaucracy. Business and education have entered what has been coined 'the knowledge society' (Hargreaves, 2003). According to Bimber (1993), "Many of the difficulties that plague US schools are typical of public bureaucracy: the focus on rules and complying with procedure rather than outcomes; inertia; lack of initiative; and unresponsiveness to changing external needs" (pp. 2-3). The study of organizations and organizational learning led to Peter Senge's book, The 5th Discipline, which turned organizational learning into the learning organization where collaboration, reflection, and teaming were more important than bureaucratic hierarchy. Senge (2006) states, "When people and organizations focused only on their position [bureaucratic model], they have little sense of responsibility for the results produced when all positions interact...[when] the results are disappointing...All you can do is assume that someone screwed up"(p. 19). The systemic process of the learning organization is designed to maximize progress 
through learning and collaboration (Senge, 2006).

Business is moving away from the bureaucratic system's one head for decisions with many arms for labor. Best practice for business has moved to collaborative agreement on mission, vision, and values driving the organization to meet its function (DuFour \& Eaker, 1998). Collaboration, as in co-labor, was the opportunity to use many hands to lighten the load. The learning organization labors to ensure that the organization learns both individually and organizationally what it takes to be successful (O'Neil, 1995). The learning organization of business is called a Professional Learning Community (PLC) in education (Hord, 1997).

The concept of the PLC was first officially coined by Shirley Hord (1997) with her work with the Southwest Educational Development Laboratory (SEDL). The work was based upon many different researchers including Rosenholtz (1989), Newmann (1994), and Kruse, Louis, and Bryk (1994). Hord's (1997) work was extended by DuFour and Eaker (1998), Hargeaves (2003), Blankstein (2004), DuFour, Eaker, and DuFour (2005), and Fullan (2006), to name a few. In DuFour, Eaker, and DuFour (2005), an unprecedented 21 educational reformist came together to state that PLCs are the best hope for educational reform. According to Lieberman and Miller (2008), "Like all phenomena, professional learning communities are embedded within a context. In this case, the context is the long history of staff development as it has evolved" (p. 7). PLCs are a process for staff development. This process, when completed correctly, uses vision, values, goals and staff commitment to develop best practice (DuFour \& Eaker, 1998; Blankstein, 2004). 
The reformers of the late $21^{\text {st }}$ century identified the problem of school improvement as an issue with 'Loosely Coupled System". In the learning organization, it is postulated that today's problems come from yesterday's solutions - solutions that just shift the problem to another part of the system (Senge, 1990). The reformers attempted to solve the issues of the loosely coupled system by bringing back a more tightly coupled bureaucratic system. "The latter half of the $21^{\text {st }}$ century saw an array of reform efforts designed to improve the educational system and achieved other, often ideological goals. These reforms operate within a system that is highly institutionalized..." (Sunderman, 2010, p. 226). These changes created more bureaucratic top down system. Sunderman (2010) says, “...reform has expanded the federal and state role in education, transformed the organization of interest, and created a national political culture where educational policy priorities increasingly are established nationally...the result has been greater bureaucratization of the educational system..." (p. 226). The cure can be worse than the disease - using an intervener; shifting the burden to someone else and needing to always rely upon this solution-likened to an addiction (Senge, 1990). Even with calls for greater decentralization, the system went back to what was best known, bureaucracy. Bureaucracy failed again to create the needed changes for school improvement.

PLCs and learning organizations have at their core, as opposed to bureaucracy, common purpose, mission, vision and values. The common purpose, mission, vision and values move a community of learners to the point where their effort is driven by the social expectations of their colleagues. Conzemius and Morganti-Fisher (2011) state, "Much has been written about the nature of systems (Buffum, Mattos, \& Weber, 2009; Davidovich et al.; Dolan, 1994; Fullan, 1991; Hall \& Hord, 2011; Schlechty, 1991; 
Senge, 1990; Wheatley, 1992), yet we continue to struggle with finding a formula that really works when it comes to education"'(p. 10). The work process and expectations that are generated by a true PLC focus on learning. The work expectations that are not required in a bureaucracy are completed at high levels in a PLC because it is the norm of the group (Cowan, 2006). According to Lieberman and Miller (2008), “Teachers in professional learning communities develop new identities as group members” (p. 13). This new identity creates a shift from a focus on teaching to a focus on learning (DuFour \& Eaker, 1998). This focus on learning creates a system that focuses on actions to ensure learning for all students (DuFour \& Eaker, 1998).

Pfeffer and Sutton (2007) suggest evidence-based management for the discovery of the practices that improve success. Educators must discover the best practices that enhance student achievement and ensure that they are implemented and sustained at every level. It is very important that every level in a school system be defined as the district, the schools, and the classrooms. The PLC works to unite teachers in a common goal and uses their collaboration to promote learning. According to Senge (2000), "The organizations that will truly excel in the future will be the organizations that discover how to tap people's commitment and capacity to learn at all levels in an organization" (p. 14). The question becomes, "Is the district-wide PLC that future organization?" Much of the research on school improvement focuses on the individual school (Edmonds, 1983; Cuban, 1984, Elmore, 1993). New research shows that this focus might be flawed (Marzano \& Waters, 2010; DuFour \& Marzano, 2011). According to McLaughlin and Talbert (2002), "For better or worse, districts matter fundamentally to school reform outcomes and without effective district engagement, school-by-school 
reforms are bound to disappoint"(p. 173). Currently, there are a great number of best practices published for the classroom and the school, but best practices at the district level are not common. In order to have successful school improvement, best practices must be identified and enacted at all levels. School improvement, when it is successful, systemically affects changes at all levels including the district, the school, and the classroom. Successful school improvement should be defined as successful change at all levels of the system that support individual student achievement (Fullan, 2006). As we shall see through other research, changes at the classroom level require changes at higher levels; therefore, the school and district level must systemically support classroom improvement/student achievement: learning for the student, the teacher, and the administrator (Purkey \& Smith, 1983). In the development of school reform, the school district has become a forgotten player (Tyack, 2002).

\section{Statement of the Problem}

The research on the role of the school district in school improvement is thin (Firestone, 2009). This researcher endeavored to describe the role of relationships between the central office and building leadership in successful school improvement. For this research project, the problem was discovering the role of relationships between the central office and the building in school district improvement. According to Firestone (2009),

We may never be able to show statistically the school district's contribution to student achievement, but we know the district plays a key role in improving teaching and learning. Without adequate district support, changes that focus solely on the school...efforts, often fail or only limp forward. (p. 670) 
It is universally understood through research and practice that the purpose of school improvement is increasing student achievement at the classroom level (Shulman, 1983; Sanders, 1997; Rosenholtz, 1989; Marzano, 2003). The researchers, politicians, and practitioners have worked so hard to directly influence student achievement by way of the classroom that they may have missed the opportunity to powerfully influence the classroom indirectly. Rosenholtz (1989) states,

...if we look only at the outputs of school and not at the structures and processes influencing them, we will never learn why organizations such as schools work, and how positive outcomes are brought about. We suggest, then, that a more expansive definition of school success, one that addresses social organization, will help us better understand how it works. (p. 2)

This research-based project was an attempt to determine how the relationship between district and building leadership affects school improvement as measured by the student achievement. In this study, the focus was on school districts that were engaged in learning organizations or professional learning communities as described by Hord (1997).

\section{Statement of the Purpose}

The purpose of this study was to discover the nuances of the best practices of systemic school improvement in view of the relationships between district and building level leadership. The continued focus on the building as the focal point of school improvement may ignore important factors related to school improvement. The rising popularity of PLCs provides an opportunity to measure the success of the district through the definition of a successful professional learning community. It was important that the study answer questions like: What factors need to be considered by the leadership team to drive school improvement district wide? and What role does leadership play in establishing trust between the district and the buildings? 


\section{Specific Research Questions}

1. How does the relationship between the district-level leadership and the building-level leadership impact the implementation and sustainment of a successful professional learning community?

2. What district-level and building-level leadership practices within professional learning communities ensure the establishment of a culture of improved student achievement?

3. How does relational trust impact district-level and building-level leadership practices within professional learning communities?

\section{Conceptual Framework}

According to DuFour (2004), “...improving schools by developing professional learning communities is currently in vogue. People use this term to describe every imaginable combination of individuals with an interest in education...the term has been used so ubiquitously...it is in danger of losing all meaning” (p. 6). Oliver (2003) states, "The complexity that exists in identifying schools as PLCs offers a challenge for researchers, principals, staff, parents, and other stakeholders" (p. 67). The conceptual framework used in this study properly delineates the differences between a pre-initiating, initiating, implementing, developing, and sustaining PLC based on the tenants of a PLC as described by Hord (1997), DuFour (1998) and Blankstein (2004). The conceptual framework of this study was the Professional Learning Communities at Work Continuum (DuFour, 2010). The Professional Learning Communities at Work Continuum is contained in Richard DuFour's (2010) Learning by Doing: A handbook for professional learning communities at work. It measures a PLC based on shared mission, shared vision, 
shared values, common school goals, purpose, priorities, and communication.

\section{Study Design}

A qualitative research design was applied in this study. According to Cresswell (2007), “The research design process in qualitative research begins with philosophical assumptions that the inquirers make in deciding to undertake a qualitative study" (p. 15). The assumptions in this study begin with an interpretivist approach. According to Crotty (1998), “The interpretivist approach...looks for culturally derived and historically situated interpretations of the social life-world" (p. 67). The approach seeks to reveal individual perceptions of experiences that are culturally or historically based (Crotty, 1998). The study of district-wide PLCs requires a well-defined view, because PLCs have a distinct culture that is very different from traditional schools (Hord \& Sommers, 2008). "Across the country, school districts from Maine to California are adopting PLCs as a strategy to increase student achievement by creating a collaborative school culture focused on learning" (Feger \& Arruda, 2008, p. 1). This study examined how the relationships between district and building leadership in district-wide PLCs at the sustaining stage affect school improvement from their perspectives. It is a basic interpretivist study design. Research design incorporated a three-phase study including survey, interviews, and an analysis of documents and artifacts. Basic interpretivist research was an appropriate choice because of the strategies used in exploring and understanding the varied perspectives of the study participants (Crotty, 1998).

\section{Data Collection}

Data were collected by interviewing district and building administrators, as well as collecting documents and processes used in the PLC process. This portion of the study 
delved deeper into how the relationship between district and building administrators affect school improvement. Each leader was asked interview questions that focused on mission, vision, values, and goals of the professional learning community. The questions also focused on the relationship between the district office and the buildings. At the end of the interview, the administrators were asked directly about district support in the process of school improvement. The questions probed for suggestions for improvement and areas of success.

The researcher intended to use three phases to complete this study. The state of Illinois has three types of districts: Unit District—-kindergarten through grade 12; Elementary School District, which includes kindergarten through grade 8, and High School District, which typically includes grade 6 through 12. In Phase I, Elementary School Districts were surveyed to ascertain the stage of the PLC process of the districts. A survey was sent to suburban elementary school districts in four northeastern counties in the State of Illinois to help determine the stage of PLC of the individual districts. The four counties have more than $50 \%$ of the state's Elementary School Districts. The information collected focused on the mission, vision, values and goals of the district PLC. Each district was assessed through a survey based on the Professional Learning Community Continuum as being in the pre-initiation, initiation, implementation, developing, or sustaining stage. In Phase II, the "sustaining stage leadership" subgroup was created based on the results of data retrieved from the first phase of the study. The "sustaining stage leadership" subgroup was composed of district and building leadership in districts that had reached the highest stage in the development of the PLC process. Phases I and II utilized quantitative techniques for research design. 
In Phase III of the study, the researcher visited the districts of subjects identified for the "sustaining stage leadership" subgroup and conducted in-depth interviews regarding their experiences. Both the district-level and building-level leadership in that district were interviewed for the study. The researcher used the information from the interviews, observations in the school district buildings and classrooms, and document analysis to develop a data-based picture of the relationships between district and building leadership that affect school improvement. Qualitative techniques were used in Phase III to analyze the relational experiences based on the concept of relational trust from Anthony Bryk encountered in the PLCs by "sustaining stage leadership" and their perceptions of these relationships impact on school improvement.

For the purposes of this study, it was important that the researcher acknowledge that experiences of the district and building leadership might vary greatly according to the phase of the PLC process a district inhabited. In order to eliminate any complexities associated with the different phases of PLC, this study included only the district and building leadership that were in the sustaining stage of the PLC process. This led to the development of the "sustaining stage leadership" subgroup which was used for the third phase of the study.

In Phase II of the study, the sample was reduced to a subset containing only those districts who met the intended requirements of the subgroup identified in Phases I and II. This subset was narrowed to a total of six elementary school districts for the purposes of moving into Phase III of the study. According to the availability, three to six elementary districts from the northeastern part of the state were selected to participate in the qualitative portion of the study. The study used the northeastern part of the state, the 
Chicago suburbs, because of the concentration of the elementary school districts in that area and the expectation that some districts in this area were in the sustaining stage of PLC development. The selected districts had attained the sustaining stage of the PLC process. The study kept consistent grade level experiences in order to reduce any possible variation effect that could be introduced by using different classifications of districts.

\section{Data Analysis}

Qualitative data analysis of interview recordings and related documents were reviewed and categorized in order to make determinations concerning how district and building relationships affect school improvement in PLCs. The words of the "sustaining stage leadership" subgroup helped to develop assumptions related to the appropriate interaction between district and building leadership. The study also documented the relational experience by the "sustaining stage leadership" subgroup to determine if their work was shown in school improvement.

In summary, the researcher attempted to ascertain the effects of district and building leadership relationships on school improvement, specifically student achievement, in a school district that was in the sustaining stage of district-wide PLCs. According to Vescio et al. (2008), "Although, teachers' perceptions about the value of PLCs are both valid and valuable, understanding the outcomes of these endeavors on teaching practice and student learning is crucial, particularly in today's era of scarce resources and accountability" (p. 81). Leading school is both a district and building responsibility; it cannot be completed without both district support and building work (Rosenholtz, 1989). The PLC process is a systemic process that is designed to create cultures of continuous improvement (Fullan, 2006). Fullan (2006) postulates that PLCs 
are often viewed as short-time transport innovative ideas that are implemented on an individual school-by-school basis rather than as a strategy for systemic change designed to create long-term improvement. This study examined districts that were focused and successfully achieving cultural change through the PLC process. It examined the relationships between district and building leadership and how those relationships affect school improvement. In addition to other questions asked in this study, the researcher attempted to identify some of the individual district practices that aid school improvement.

\section{Significance of the Study}

The second half of the $20^{\text {th }}$ century to the present has seen researchers and practitioners search for factors related directly to student achievement through school improvement. Many factors have been discovered. The application of the factors requires a nuance that is not always understood. This study was designed to acquire knowledge and understanding of the nuances of indirect factors that relate to school improvement in order to help districts, schools, and classrooms improve.

\section{Assumptions}

The assumption made in relation to this study was that school districts with higher levels of PLC practices will be more systemic than schools without them. According to Firestone (2009), although each district has its own culture, three are quite typical: loosely coupled culture, accountability culture, and student learning culture. Districts that have used PLCs to move from loosely coupled to a student learning culture have become systemic organizations with a culture of continuous improvement. 


\section{Delimitations}

This study focused on factors that indirectly relate to school improvement. Although the relation between these factors can be measured, there is no direct connection to student achievement. These factors are connected to leadership and leadership has been connected to student achievement. While student achievement can be related to leadership, the factors studied are only indirectly related to student achievement.

\section{Limitations}

With 869 school districts in the state of Illinois, it was virtually impossible to gauge the improvement of each district by the factors in this study. Therefore, this study is not generalizable to all of the districts in the state. It is not even generalizable to all elementary school districts in the state.

\section{Definitions and Technical Terminology}

The following definitions were utilized in this study.

Accountability cultures are districts that have "more agreement on basic assumptions than do those with a loosely coupled culture...Instructional problems are more likely viewed outside authorities" (Firestone, 2009, p. 672).

Collaboration "...is a natural outgrowth of reflective dialogue and deprivatization of practice"...it is the sharing of expertise with one another in order to increase teachers' technical competence (Louis, Kruse, \& Marks, 1996, p. 183).

Community "...is about the experience of belonging. We are in community each time we find a place where we belong...to belong is to be related to and a part of something" (Block, 2008, p. xii). 
Defined autonomy is the expectation of the superintendent or district administration that building principals and all other administrators "lead within the boundaries defined by the district goals" (Marzano \& Waters, 2010, p. 8).

Deprivatization of practice is a way of professional reflection with feedback from trusted colleagues. Peers become a critical source of insight and feedback to improve reflective teachers' understanding of their own practice. By sharing uncertainties about practice, teachers learn new ways to talk about what they do. At the same time, they kindle new relationships that help to advance their work. (Louis, Kruse, \& Marks, 1996, p. 183)

Disruptive innovations are innovations that "require dramatic alterations in both the structure and the culture of the organization...require changes in beliefs, values, and commitments as well as changes in rules, roles, and relationships"...they require changes in the way vital organizational functions are carried out (Schlechty, 2005, p. xiii).

District-wide alignment is..."the intentional linkage of the work of schools and the school district to the work of collaborative teams in order to achieve a district-wide professional learning community" (Clay, Soldwedel, \& Many, 2011, p. 6).

Instructional Program Coherence is, according to Newmann, Smith, Allensworth and Bryk (2001), "a set of interrelated programs for students and staff that are guided by a common framework for curriculum, instruction, assessment, and learning climate and that are pursued over a sustained period" (p. 297).

\section{A Learning Organization is}

....an organization in which people at all levels are, collectively, continually enhancing their capacity to create things they really want to create. And most of the educators I talk with don't feel like they're doing this. Most teachers feel 
oppressed trying to confirm to all kinds of rules, goals and objectives, many of which they don't believe in, teachers don't work together; there's very little sense of collective learning going on in most schools. It is an organization that seeks continuous improvement through the gathering and understanding of new knowledge..." (O’Neil, 1995, p. 20)

A Loosely Coupled System is "a situation in which elements (parts of the school system/school) are responsive (to each other), but retain evidence of separateness and identity" (Orton \& Weick, 1990, p. 203). This theory explains how all of the school organization is somehow connected but not always under the control of one section or another.

Nested layers are

...organizational layers, each having a conditional and contributory relationship to events and outcomes occurring at adjacent layer... Our basic contention is that each level of school system organization has it is own core agenda even though certain activities are performed at more than one level. (Dreeban \& Barr, 1983, p. 84)

\section{A Professional Learning Community is}

...an inclusive group of people, motivated by a shared learning vision, who support and work with each other, finding ways, inside and outside their immediate community, to inquire on their practice and together learn new and better approaches that will enhance all pupils' learning. (Stoll, Bolam, McMahon, Thomas, Wallace, Greenwood, \& Hawkey, 2006, \1).

Relational trust is the social relationship between teachers, principals, students, and parents that fosters a set of organizational conditions, structural and others socialpsychological, that make it more conducive for individuals within the school to initiate and sustain the kinds of activities necessary to affect productivity improvements (Bryk \& Schneider, 2002).

School improvement is "a distinct approach to educational change that enhances student outcomes as well as strengthening the school's capacity for managing change" 
(Hopkins, Ainscow, \& West, 1994, p. 3).

Sustaining Stage Leadership: Leadership district and building leadership is deeply embedded in the culture of the district. The practices of shared mission, vision, values, and common school goals are embedded. It is a driving force in the daily work of staff. It is deeply internalized, and staff would resist attempts to abandon the principle or practice.

System is the "...perceived whole whose elements hang together because they continually affect each other over time and operate toward a common purpose" (Cowan, 2006, p. 597). In this study it includes school systems, building systems, and classroom systems of an organization.

System change is "...the alteration of rules, roles, and relationships of the culture in which they are embedded so that people can carry out critical functions' of the organization in dramatically different ways"(Schlechty, 2005, p. xiii).

School districts are "... geographic entities representing a designated area and a set of schools contained within the boundaries" (Hightower, Knapp, Marsh, \& McLaughlin, 2002, p. 1).

Values are collective commitments that clarify what each member will do to create such organizations (that embrace learning for all students), and they (the members of the community) use results-oriented goals to mark their progress (DuFour, DuFour, \& Eaker, 2008).

\section{Organization of the Study}

Chapter I provides an introduction of the materials and the overarching problem that drives the research elements behind this study. It provides the conceptual framework, definitions of technical terminology, and research questions providing the overarching 
framework of the research. It also provides a condensed overview of the methodology, the studies significance, assumptions, delimitations and limitations. Chapter II provides a review of literature relative to the concept of professional learning communities and their development. It also provides connection to process of school improvement. Chapter III explains the methodology and research design. Chapter IV provides the findings from data disaggregation and analysis of the study. Finally, the researcher presents his conclusions, discussions, and arguments regarding significant issues, and makes further recommendations for the field in Chapter V. 


\section{CHAPTER II}

\section{REVIEW OF THE LITERATURE}

This review of the literature establishes a context for the research of this twophase interpretive methods study of relational practices between district and building leadership in order to view the effect of relationships through the lens of a district-wide professional learning community. The first section reviews the historical roots of the bureaucratic school district, what it is, why it was developed, and how it is a key player in the education of students. The second section includes a review of the literature on educational change based on the work of Fullan and Blankstein. Section three presents a review of the literature on the three waves of educational change. The fourth section includes a review of the literature historical roots of professional learning communities. The fifth section includes a review of the literature how districts impact student learning including a review of Instructionally Effective School Districts (IESD). The sixth section is a review of school improvement through the lens of the district. The information in the review establishes that school districts are currently very similar to the bureaucratic organizations that were created in the early $20^{\text {th }}$ century. It also establishes that the bureaucratic school district was unable to handle the stresses that created by the Brown v. School Board Supreme Court case, the Sputnik Scare, and Johnson's War on Poverty. The school district that was sent reeling by those three challenges was considered unimportant when the process of school improvement was being constructed (Lezotte, 2011; Lortie, 2007). Done correctly, school improvement is a systemic process that 
requires school district guidance and support.

\section{The Birth of the School District}

"Local control of education is a distinctly American ideal. In virtually no other country does the local community maintain so much influence over the form, function, and funding of schools" (Supovitz, 2006, p. 1).

[School] districts are geographic entities representing a designated area and a set of schools contained within the boundaries.... [D]istricts are also legal entities required by state law to provide education to all students regardless of race and ethnicity socioeconomic background and stability within the attendance boundaries. (Hightower, Knapp, Marsh, \& McLaughlin, 2002, p. 1)

The legal entity, better known as the school district, was born in the early $20^{\text {th }}$ century during an era of reform.

The evolution of the school district has been a long process that included the decisions about the types of schools, school finance, and control (Cubberley, 1919). According to Foley and Sigler (2009), “Administrative Progressives, as this early band of reformers has become known, sought the "one best system" (Tyack, 1974) that would separate schooling from politics and produce assimilated, productive citizens as efficiently as Ford's factories produced cars" (p. 5). "Ellwood Cubberley and other architects of educational professionalism constructed a social scientific theory of educational administration consistent with this perspective" (Strange, 1987, p. 355). The bureaucratic school district with professional leadership became that one best system.

The early $20^{\text {th }}$ century saw the building of modern school districts. "School districts, which emerged in the early twentieth century, grew out of the social and organizational ideas that took hold during the Industrial Revolution" (Foley \& Sigler, 2009, p. 5). Glanz (1991) stated, "Throughout most of the nineteenth century, schools 
were controlled by loosely structured, decentralized ward boards" (p. 37). The schools controlled by boards were considered controlled by politics; issues of nepotism and corruption were widely reported by the press (Glanz, 1991). School districts were built to rescue education from politics (Tyack, 1974).

The rescue included the building of bureaucracy as the basis of the system (Cubberley, 1919). Bennis (1993) wrote: "Bureaucracy...is a social invention perfected during the Industrial Revolution to organize and direct the activities of the firm”(p. 3). Bennis (1993) went on to say that "Bureaucracy...was developed as a reaction against the personal subjugation, nepotism, cruelty, emotional vicissitudes, and subjective judgment which passed for managerial practices in the early days of the Industrial Revolution" (pp. 4-5). A bureaucracy includes the following:

(1) a division of labor based on functional specification, (2) a well-defined hierarchy of authority, (3) a system of rules covering the rights and duties of employees, (4) a system of procedures for dealing with work situations, (5) impersonality of interpersonal relations, and (6) promotion and selection based on technical competence. (Bennis, 1993, p. 5)

Glanz (1991) elaborated,

Reformers attempted to persuade the American people that a highly complex system of schooling would best serve the interests of all. Bureaucracy, a byproduct of these reform efforts, brought order and organization to an otherwise chaotic, corrupt, and inefficient school environment. (p. 37)

"At the turn of the century, bureaucracy was undeniably the dominant form of school organization across the nation" (Glanz, 1991, p. 79). Bureaucracy was ushered in during the process of professionalization of the school systems. "The bureaucratization of supervision, in particular, occurred as a result of the efforts of reformers to standardize, control, and restore order to an urban school system beset by incompetency, inefficiency, 
and political influence" (Glanz, 1991, p. 79).

Sunderman (2010) stated, "In important respects, we have 50 independent state educational systems with 15,700 local variations at the district level that are loosely regulated by the states" (U.S. Census Bureau, 2006, p. 155). The independent state educational systems have been with us since the inception of the modern school district (Sunderman, 2010). According to Strange (1987), "Though American states successfully claimed authority over education in the nineteenth century, the median size of state departments of education was only two in 1900" (National Education Association, 1931, p. 345). Although the professionalized educational system was widely accepted upon its inception, it was first applied to cities and most rural areas remained untouched by the new system (Strange, 1987). Sunderman (2010) elaborated,

Whereas legal authority over education resided with the states, operational responsibilities listed with local units of government. The system was decentralized and neither the federal nor state government exercise much control over many kinds of education decisions at the local level. (p. 228)

"In the 1930s and 1940s, the organizational structures developed for cities began to be applied outside urban areas" (Strange, 1987, p. 355). The professionalism of all school districts had begun. Sunderman (2010) added, "By the 1950s, local school boards and superintendents, particularly in large districts, held considerable decision-making authority and operated relatively autonomously from state or federal control" (p. 228).

\section{The Process of Educational Change}

Fullan (1993) maintained that "...the need for improvement in schools in the United States have been debated and tried since the turn of the century, only in the postSputnik era has the push for reform taken on national proportions" (p. 116). This need for 
improvement has spawned many different theories for improvement including: implementation research and practice, school improvement, effective schools, staff development, and education leadership (Fullan, 1993). From the 1960s to the 1990s, researchers from a wide variety of fields studied independently and started to approach some common understandings (Fullan, 1993). The researchers were looking for ways to improve schools through the process of change. The chief discovery during that time was that change is a process, not an event (Fullan, 1993).

In the opinion of Huffman and Hipp (2003), “...change will require a radical recapturing of the school as an institution, and the basic redesign of the teaching profession (Fullan, 1995, p. 230)" (p. 15). Fullan and Miles (1992) asserted that "Change is learning-loaded with uncertainty. Change is a process of coming to grips with new personal meaning, and so it is a learning process" (p. 744). The three broad phases of the educational change process are the Big 'I's: Phase I-Initiation, mobilization, or adaptation, Phase II-Implementation, or initial use, and Phase III-Institutionalization (Fullan, 2003). Initiation is the process that leads up to and includes a decision to proceed with a change; implementation is the first few years of process that involves the experiences of attempting to put reform into practice; and institutionalization is the process where the reform is built into an ongoing part of the system (Fullan, 2007). The key to school improvement is change.

Major studies show that the local implementation process at the district level is essential if substantial improvement is the goal (Fullan, 2007). Effective teacher development and effective change processes are one and the same (Fullan, 1991). The challenging task of improving teaching and learning in all schools might be accomplished 
more effectively if schools choose from rigorously researched and well-documented reform designs that provide networks of support for implementation (Slavin \& Fashola, 1998). Research suggests that a district-wide professional learning community could be the well-documented reform that takes into consideration the change process to ensure student improvement.

Once there is an understanding of change, there has to be an understanding of levels of change. The levels of change include the following: level one- - techniques and strategies, level two — structures and systems, level three — culture and organizational values behavior, and level four-guiding philosophy and emotional connections through engagement (Blankstein, 2007). Elmore (2007) stated:

Reforms wash over schools in successive waves, creating the illusion of change on the rolling surface of policy making, but deep under this churning surface, the fundamental conditions of teaching and learning remain largely unchanged in all but a small proportion of classrooms and schools. (Cuban 1984, p. 194)

Level one, techniques and strategies, are curricular changes that were attempted in the 1960s and 1970s. Level two, structures and systems, are changes in structure and systemic changes that were attempted in the 1980s and 1990s. Level three, culture and organizational values behavior, and level four, guiding philosophy and emotional connections, are part of the district-wide PLC.

Understanding the change process and change level is very important to school improvement. Elmore (2007) specified:

Every organization has certain core processes that define its work. In schools... what is taught and to who, how students are grouped for purposes of instruction, how content is allocated to time, how teachers relate to each other in their work with students, and how student learning is judged by students, teachers, and external authorities. (p. 195) 
Hipp and Huffman (2010) added, "Change efforts that do little or nothing to affect what occurs in classrooms will have little or no effect on student achievement" (p. 67).

Districts need to be able to move from initiation to institutionalization while moving through the four levels of change to effect student achievement. The school alone does not have the ability to push these changes without district support. These understandings are important before reviewing the waves of reform.

\section{Social Upheaval Causes Waves of Reform}

Schlechty (1997) detailed:

Ignorance of the history of America's schools leads many to seek solutions where solutions cannot be found. Some would return to a past golden era when all parents were supportive and most children learned what it was intended that they These people do not seem to know that there never was a golden era. (p. 1)

The history of the modern school district can be appropriately traced to the early 1900 s. According to Cubberley (1916), “....schools first started as local independent entities and later became state supported and controlled" (p. 163). The evolution from common schools to publicly supported school districts that supported the education of all students started before the birth of the nation and continued to the early 1900s (Cubberley, 1916). Cubberley (1919) stated, "The history of our education evolution...clearly revealed to the reader how completely local the evolution of schools has been with us. Everywhere development has been from the community outward and upward, and not from the state downward" (p. 155). Cubberley (1916) added, "The communities were usually very willing to accept the state aid offered, but many of them resented bitterly any attempt to curb their power to do as they pleased, or forced them to make reports and meet general state requirements" (p. 165). In 1929 Cubberly elaborated, 
All children in different schools of the town are provided with an equal length of term, high schools and special-school advantages are open equally to all, special subjects of instruction and special supervision go to all schools, the school property is all under one board of control, and the cost of maintaining the school system of the towns is spread equally over the property of the entire town. (p. 56)

The establishment of the district's Chief Executive Officer, the superintendent, was the next step in the evolution of the school system. The school superintendent became focused with the business community and began to work to create efficiency in the school systems. The district controlled the buildings, the curriculum, attendance, and employment. Until national issues began to dominate schools, the locally controlled school district was the power in education. The first issue was curricular, with the advent of the Russian Satellite. Almost instantly, the schools were thought to be inferior to those of the Soviet Union. Next, the battle for civil rights and the inability for local politics to deal with the issue landed the decision in the hands of the Supreme Court of the United States. The landmark decision of Brown vs. Board of Education reduced the power of the school district. During the same time, the advent of powerful teacher unions reduced the power of the superintendent and the boards of education. The requirement to negotiate reduced the power of the school board. The national War on Poverty created the Elementary and Secondary Education Act (ESEA), which created a federal money stream with strings attached that again, reduced the power of the school district. When the ESEA was passed, no local school board members or superintendents were invited. They were considered to be part of the problem and not part of the solution.

The national issues that hit school districts in wave after wave reduced their control of the schools but did not eliminate it. The most prominent research on school improvement, the effective schools research, the excellence movement, and the 
restructuring movements, considered the school district to be unimportant. School improvement has always been a school-by-school focus. The school-by-school waves of school improvement have not been successful. Even the latest system for school improvement, the professional learning community, needs the assistance of the district.

At the conclusion of the social upheavals, public education went through three major reform movements: the Effective Schools Movement, the Excellence Movement, and the Restructuring Movement. The school district was not included as a solution in these issues because of its inability to handle the social upheavals (Lezotte, 2010). After the social upheaval, the citizenry, politicians, and scholars began to complain about the quality of the education that was being delivered to the highest percentage of its students. Sappington (1995) affirmed that "Criticisms of the educational system in America centered on the inability of the schools to produce students that could compete in a global economy" (p. 1). As economic difficulty grew, so did the number of critics of the school system and the number of politicians who would claim to be saviors of the institution.

The first movement was not started per se by the economic concerns of the nation. The Effective Schools movement began with the reported results of the Equality of Educational Opportunity report. The report, also known as the Coleman Report, was, according to the Association for Effective Schools (n.d.), “...a federal paper was written to discuss the effectiveness of American education. The paper was funded by the U.S. Office of Education and written by James Coleman, a prominent education researcher." The report focuses on the individual school. According to Marzano (2003),

The [Coleman] report had a profound impact on public perceptions of schooling in the United States. Specifically, it dealt a veritable deathblow to the belief that schools could overcome students' backgrounds. Perhaps the most publicized 
finding from the report was that schools account for only about 10 percent of the variance in student achievement the other 90 percent is accounted for by student background characteristics. (p. 2)

The first resulting movement, the Effective Schools Movement, focused on individual school improvement, because the original data used in the Coleman Report focused on schools as a whole. The resulting review of the same data showed that individual schools did indeed make a difference (Edmonds, 1977). The birth of school improvement (by individual school) was not planned and, according to the Coleman Report, it was not possible. The researchers had focused on individual schools as they discovered the ability to make change. Edmonds (1982) elaborated:

Three types of school improvement programs have resulted from the school effectiveness research: (1) programs that are organized and administered within schools and school districts; (2) programs that are administered by state educational agencies, which provide incentives and technical assistance to local schools and districts; and (3) programs of research, development and technical assistance usually located in a university. (p. 5)

When asked "What is the role of the central office, superintendent or board of education in creating effective schools?" Lezotte (2008) replied, "Initially, we responded by saying that they were irrelevant" (p. 13)! Bjork (1993) stated,

... research findings on the effective schools have focused on the individual school and suggests that the capacity for improvement and change the sides at building level. Although these studies made important contributions to the educational reform literature and administrative practice, the instructional leadership role of superintendents, those at the other end of the school hierarchy, has been largely ignored. (p. 249)

The Effective Schools Movement first identified that there were effective schools.

Second, they attempted to find out what made schools effective. Finally, they attempted to create effective schools. Clearly, the focus of the movement was on individual schools. In the beginning the researcher totally ignored or missed the role of the school district in 
school improvement in spite of the findings of Rosenholtz (1989). Clearly the preponderance of successful schools came from successful school districts, and without district support schools were 'stuck' (Rosenholtz, 1989).

The second major educational reform movement of the second half of the $20^{\text {th }}$ century, the Excellence Movement, began in 1983. Kingston (1986) explained, "Among educators, 1983 understandably became known as the 'Year of the Report.' Under a variety of auspices, major reports came out in a flurry. All documented deficiencies in American education, especially in secondary schools, and proposed reforms" (p. 633). The Excellence Movement of the 1980s that was spurred by the Nation At Risk Report tried to provide a successful top-down reform movement. This movement focused on requiring more from schools: higher standards, more hours, and more requirements. It is logical that this type of movement, different from the effective schools movement, would focus on the central office. "In his state of education address in 1987, Secretary of Education William Bennett attached the nickname 'the blob' to administrators and the administrative system in public schools” (Marzano (2009, p. 1). Marzano wrote: “...the term blob is an acronym for bloated educational bureaucracy" (p. 1). Tyack (2002) explained: “...Chester E. Finn declared school boards in their districts to be dinosaurs. They no longer raised the bulk of school funds, lagged behind in reforms, were irrelevant to national or state standards, and hassled school-site reform" (p. 10). The district was not the focus of school improvement and was quickly labeled the problem. "Even casual observers could see that a flurry of activity was taking place in states where governors wanted to improve school systems in order to sustain economic growth to satisfy demands of citizens with higher expectations for education" (Wayson, 1988, p. 7). 
According to Kingston (1986), “...the desire to systematically identify academic success creates an unresolved tension between equity and excellence" (p. 634). There was a lot of action but not many results.

By the beginning of 1985, the federal initiatives and state mandates seemed repetitive and somewhat rhetorical. The movement had levered greater funding for schools in some states. Many had added new requirements and monitoring devices. But the effect on children's education had been mixed, unclear, and debated. (Wayson, 1988, p. 7)

In the end, Wayson (1988) explained that "The Excellence Movement is plagued by many of the same mistakes that were made in the reforms between 1957 and 1980. A fundamental mistake made in the War on Poverty [was] massive reform could be affected from the top down" (p. 12). In the Excellence Movement, top down was from state/federal government to the schools. The central office again was not a part of the process. Not only were they not part of the process, the central office was accused of being the problem, even though they were specifically excluded from the process (Tyack, 2002).

Educational movements were started in many different areas. One of the movements that started early and gained momentum late was the Consolidated School Reform (CSR) movement. "Comprehensive school reform, or CSR, is among the waves of improvement efforts that radiated from the 1983 report $A$ Nation at Risk...CSR focuses on improvements schoolwide, encompassing everything from curriculum to school management" (Education Week, 2004, p. ). An early CSR model is School Development Program (SDP), which was developed by Dr. James P. Comer and his colleagues at the Yale Child Study Center in 1968. Other CSR programs included Theodore Sizer's Coalition of Essential Schools (CES), Henry Levin's Accelerated 
Schools, Adams and Engelmann's Direct Instruction, and Salvin's Success for

All. According to Slavin (2007), “Comprehensive school reform occupies a middle position in the spectrum of reforms proposed for schools, between teacher-by-teacher change strategies and systemic district, state, and national strategies" (p. 4). These models were strengthened in 1991 when business, more specifically IBM and Xerox, helped to form the New American Schools Development Corporation (NASDC) and developed \$100 million to support CSR (Slavin, 2007). Boreman, Hewes, Overman and Brown (2003) stated,

The latter half of the $20^{\text {th }}$ century was marked by recurring efforts at school reform and improvement in the United States. Yet, as Slavin (1989) observed, this cycle of reforms - like a pendulum swing - has continued to move from one fad to another with little evidence of national progress. (p. 125).

The money from NASDC helped motivate districts, individuals, and the government to support CSR (Education Week, 2004; Savin, 2007). An Education Week (2004) article stated, "The basic principle of CSR is that instead of a fragmented approach to addressing achievement issues, schools must overhaul their systems from top to bottom” (p. ) According to Vernez, Karam, Mariano, and Demartini (2006), “... by the early 1990s, changes in Title I of the Elementary and Secondary Education Act allowed high-poverty schools to use Title I funds to implement CSR models, including payments to consultants external to the school to assist in their implementation" (p. 2). Pockets of success and research included it in the beginning with NCLB but in the end the government and the public has moved on to another new shinny rock. Boreman et al. (2003) add: "The latter half of the $20^{\text {th }}$ century was marked by recurring efforts at school reform and improvement...this cycle of reforms - like a pendulum swing - has continued to move 
from one fad to another with little evidence of national progress" (p. 125). The CSR model has gone the same way as every other popular reform model in the rise and fall of a fad. Zavadsky (2013) elaborated,

A district central office is better positioned than schools to coordinate and align the crucial reform elements within and across schools. The CSR results support this theory: the program's limited success was attributed to lack of capacity at the school level to change structures and practices that most impact teaching and learning. (p. 2)

The final movement, the Restructuring Movement, sought to correct the schools problems through restructuring and moving from a top-down system to a bottom-up system. It sought to correct issues through the understanding of schools as loosely coupled systems (Weick, 1976). The tool used for bottom up systemic improvement was Site- Based Management (SBM). Educational Research Service (ERS) (1991) opined: "[SBM] can be viewed as a response to the many reforms following A Nation At Risk. These reforms...tended to do so in a sweeping, centralized fashion. A second wave of reports has developed focusing on the individual school” (p. 2). In the opinion of DuFour, DuFour, and Eaker (2008), “...demise of the top-down excellence movement prompted the restructuring movement, a new, two-pronged approach to school improvement based on establishing national goals and providing site-based local autonomy to achieve these goals" (p. 35). Local site-based autonomy was attempted with Site-Based management. Russo (2010) added: "Site-based management, or school-based decision making (SBDM), as it is more commonly known, is an innovative reform that swept the nation during the 1990s in an attempt to allow building level decision making for curricular and other educational issues" (p. 829). According to Hill and Bonan (1991), 
The purpose of site-based management, like the movement toward participatory management in business, is to improve performance by making those closest to the delivery of services - teachers and principals - more independent and therefore more responsible for the results of their school's operations. (p. 23)

Hill and Bonan (1991) added, "Site-based management... involves shifting the initiative in public education from school boards, superintendents, and central administrative offices to individual schools" (p. 23). Brocato (1990) stated, "Site-based management is more than a change in the organizational chart. It is a change in the total organizational culture that will require redefining of roles and interpersonal relationships within the organizational structure” (ף12). Brocato (1990) continued, “As legislatures across the nation instituted reforms, they also instituted greater centralized control of schools. This creates a situation which is a direct contrast to the bottom-up approach of site-based management" (\25). Site-based management has been instituted in large urban areas, Chicago, Detroit, and New York City. Site-based management was also instituted in the state of Kentucky, but in all areas it has failed to show a relationship between itself and improved student achievement (Russo, 1990; Honig, \& Rainey, 2012). Again, the school district's central office was left out of the process of improvement. In this case, power was specifically sent to the individual buildings to spawn school improvement.

Elmore (1990) wrote that the restructuring movement had at least three reasons for restructuring America's schools, including: economic improvement, social justice, and improving teacher quality (pp. 1-2). President Bush, along with other political leaders, saw restructuring as a way to empower teachers to improve the educational system by empowering them to cut the red tape of bureaucracy. Conley (1993) stated, "In education, the term restructuring is as notable for its ambiguity as for its meaning" (p. 7). 
The challenge of the movement that was pushed by politics to empower teachers through a general term to do things that have never been done in education was a very tall order. This movement focused on empowering the local schools and teachers and discovered a great many secrets to how the schools must be run. Elmore (1990) maintained that "the motive for restructuring schools is often couched in the language of economic competitiveness and materials well-being...economic growth, competitiveness, and living standards depend heavily on making investments in human capital. That means attending to the state of America's schools" (p. 1). According to Conley (1993), "In the private sector the term (restructuring) has come to mean a process of rapid adaptation prompted by the need to maintain or regain competitiveness. The restructuring process has been called a radical reaction to product or market changes” (p. 7). Conley (1993) detailed: “...three levels of change occurring sometimes simultaneously in public schools; renewal, reform and restructuring, what might be referred to as the 'three R's' of change in education" (p. 7). In the end, the movement discovered that restructuring alone does not solve issues with student achievement or change within the school or district (Newmann, 1996). The third wave of educational reform again focused on schools, classrooms and power relationships. Again, the school district central office was not considered a player in school improvement. It seems simple that, without an understanding of the system, improvement attempts continue to fail.

Within each of the major movements, many research projects helped evolve the knowledge base of school improvement (Purkey \& Smith, 1983; Murphy \& Hallinger, 1988; Rosenholtz, 1989; Newmann, 1996; Marzano, 2003). Today our nation understands that schools and teachers make a significant difference in the ability of students to 
achieve academically (Marzano, 2003). Knowledge, understanding, and political crisis have pushed our society to reach for school improvement. Our evolution has improved our knowledge of how to help students achieve at higher levels.

There is nothing wrong with learning from experience and developing proficiency at certain strategies and tactics. We ought to learn from experience and use that experience to get better at what we do and develop specialties and talents that we can execute with consummate skills. (Pfeffer \& Sutton, 2007, p. 9)

Pfeffer and Sutton (2007) added that managers are not as successful as they could be because they do not rely on evidence. They rely on their experiences over solid research and they miss the opportunity for lasting success. It is evident that educators have not been able to use their knowledge gained from experience because the cause and effects have been so far apart (Senge, 2006).

After years of being ignored, the school district has again become the center of new thoughts about reform. Rothman (2009a) stated, "Over that past few years, educators and policymakers have paid increasing attention to school districts" (p. 1). Rothman continued, "For decades, school districts have been vilified as impediments to reform... reformers in the 1980s and 1990s sought to bypass districts; standards-based reforms was originally designed as a system in which schools would be accountable to the states..." (p. 1). The strong and increasing pressure to improve academic achievement for all students has focused educators' attention on student learning (Rothman, 2009b). "More than ever before, teachers and administrators at every level are aware they must do something to ensure that all students attain challenging standards" (Rothman, 2009b, p. 44). “...less clear is what school districts should do to ensure all schools are affected virtually all districts can point to a few schools that are successful and to schools that have made 
impressive gains" (Rothman, 2009b, p. 44). After being vilified for years, the importance of the school district is becoming clearer.

In Rothman's opinion (2009b), “...no district can say that every school in its borders is high achieving. And most school districts are struggling to provide the right mix of policies and support to ensure that every school succeeds" (p. 44). Rothman (2009b) elaborated, "As a part of the systemic instructional improvement program the districts have pursued strategies designed to yield large-scale instructional improvement and to ensure that every aspect of their operations support schools and students" (p. 44). Rothman (2009b) added:

Lessons learned (from the research) include: it's teaching that matters, systemic improvement does not move in a straight line, measuring progress at midpoint is critical but challenging, external assistance is crucial, external resources need to be adapted to local circumstances, accountability matters, creating ownership and common language is critical, improvement means breaking norms of isolation for everyone. (p. 46)

The work of the district is central to school improvement; support from the district is not suggested, it is required.

\section{The Learning Organization}

The learning organization is based on the principles of organizational learning. Triangulation of the three major theories of the learning organization includes: Peter Senge, Bob Garratt, and Pedler, Boydell, and Burgoyne. In reading Pedler, Boydell, and Burgoyne (1989), there is a reference to Peters and Waterman's (1982) In Search of Excellence. The reference implies that the way to organize for action and innovation is to create a learning organization. Although the three theories are not exactly the same, they share some significant commonality and make up a great deal of the foundation of the 
learning organization. Bob Garratt was the first of the three to publish with The Learning Organization in 1987. In 1989, Pedler, Boydell, and Burgoyne published The Learning Company. In 1990, Peter Senge published The Fifth Discipline. Many consider The Fifth Discipline to be the seminal work of the learning organization. The work of these theorists spawned a movement in business and education: the learning organization in business and the professional learning community in education.

Coopey (1995) specified: "Learning has a long history as a concept in organizational theory. The essential concern is to enhance processes of learning which can be used within organizations to improve individual and collective actions...” (p. 193). The three models that make up the foundation of the learning organization have some differences in how they deal with ideology, decision-making, and power and control. In reviewing the ideology, Coopey (1995) wrote that Senge and Garratt delineate roles for their managers. Senge gave managers the responsibility for learning, while Garratt saw managers as the vehicle to improve effectiveness through their learning. Pedler et al. considered managers like Senge except employees are more involved. In decision making, Senge viewed leaders as the key decisions makers with review by stakeholders based on shared resources (Coopey, 1995). In contrast, Pedler et al. believed in shared decision making that included exterior stakeholders. Finally, Garrett believed in high transparency in the decision making process. The leaders were to make the decisions based upon their shared knowledge and information.

Bob Garratt (1999) defined the learning organization as having: “...frequent inputs of learning and continuous critical review of what is happening within and without the organizational boundaries, to allow its adaptation to changing environments" (p. 205). 
The identified benefits of becoming a learning organization are as follows: the personal and group growth resulting from learning together, the establishment of sustainable knowledge assets within the organization, and productivity and profitability (Garratt, 1999). Garratt (1999) considered that a learning organization is a more humane place to work. He stated, "[it] reinforces the informed, conscious and discriminating choices that underpin democracy" (p. 206).

Pedler et al. (1989) defined the learning company as "an organization which facilitates the learning of all of its members and continuously transforms itself"' (p. 2). Pedler, Boydell, and Burgoyne (1997) later described the 11 characteristics of a learning company as follows: (a) A Learning Approach to Strategy; (b) Participative Policy Making; (c) Informing; (d) Formative Accounting and Control; (e) Internal Exchange; (f) Reward Flexibility; (g) Enabling Structures; (h) Boundary Workers as Environmental Scanners; (i) Inter-company Learning; (j) A Learning Climate; (k) Self-development Opportunities for All (p. 15). The definition and characteristics focus on the importance of the learning culture to the success of the learning company. They also help us understand that training is not learning and thus focusing on job embedded learning for improvement. According to Pedler et al. (1997), “...in the last 20 years we have learned a lot about helping individuals to learn; now the challenge is to understand and master the art of corporate learning" (p. 6).

Senge (1990) defined learning organizations as, “organizations where people continually expand their capacity to create the results they truly desire, where new and expansive patterns of thinking are nurtured, where collective aspiration is set free, and where people are continually learning how to learn together" (p. 5). Peter Senge's 
seminal work listed five disciplines vital to the effective enterprise of organizational success: personal mastery, mental models, building a shared vision, team learning, and systems thinking. All disciplines complement each other and are needed for success. None is more important than the other. Senge (1990) stated,

From a very early age, we are taught to break apart problems, to fragment the world. This apparently makes complex tasks and subjects more manageable, but we pay hidden, enormous price. We can no longer see the consequences of our actions; we lose our intrinsic sense of connection to a larger whole. (p. 3)

Senge's organizational learning model is based on the whole, not individual parts. In order to learn, all five disciplines together and the whole of the system must be understood. PLCs focus on Senge's vision of the learning organization as the foundation. The system in this research is the school district/community, and it cannot be broken apart

\section{The Professional Learning Community}

The professional learning community, also known as the PLC, is a systemic school improvement process that Shirley Hord (1997) was the first to research, develop, and name. The PLC process is not trademarked or specifically defined by one author or set of researchers. Feger and Arruda (2008) wrote,

Translating the ideas of a learning organization from the world of business to a learning community and education, board refines a set of characteristics based on the work of the Astuto (1994). Astuto and her colleagues studied the interactions of educators in schools where there was ongoing exchange around issues of teaching and learning to improve practice and student learning. (p. 3)

Robert Eaker, Richard DuFour, Michael Fullan, Andy Hargreaves, Shirley Hord, Douglas Reeves, Milbrey McLaughlin, Dennis Shirley, Mike Schmoker, and Joan Talbert have all written about professional learning communities. DuFour (2010) maintained that 
"PLC...is an ongoing process in which educators work collaboratively in recurring cycles of collective inquiry and action research to achieve better results for the students they serve" (p. 11). This process has become very popular without becoming well defined. Many believe (DuFour \& DuFour, 2005) that it has the power to improve education. The PLC process has normally been applied to individual schools. In this research project, the PLC process was established as a lens to view school improvement with a focus on the district level.

The concept of professional learning communities began at Southwest Educational Development Laboratory (SEDL). The concept was developed from effective schools research and the learning organizations systems approach that was developed by Peter Senge (Hord, 1997a). According to Hord (1997a),

Reports in the literature are quite clear about what academically successful professional learning communities look like and act like. The requirements necessary for organizational arrangements that produce such outcomes include: (1) the collegial and facilitative participation of the principal who shares leadership — and thus, power and authority - through inviting staff input in decision making, (2) a shared vision that is developed from an unswerving commitment on the part of staff to students' learning and that is consistently articulated and referenced for the staff 's work, (3) collective learning among staff and application of the learning to solutions that address students' needs, (4) the visitation and review of each teacher's classroom behavior by peers as a feedback and assistance activity to support individual and community improvement, (5) physical conditions and human capacities that support such an operation. (p. 24)

From 1995 to 1997, Shirley Hord worked in SEDL's Creating Communities of Continuous Inquiry and Improvement project (CCII) (Huffmann \& Hipp, 2003). The research from this project led to the development of the professional learning community model. The research clearly focused on collaboration, vision, mission, values, and goals. Huffman and Hipp (2003) elaborated: 
Practitioners and researchers alike have provided organizations a myriad of images as to how these learning communities should look, but few have formed these visions into reality because little has been documented as to how to create, much less sustain, these communities of learning. (p. xvii)

It is easier to identify PLCs than it is to discover how to create, or sustain them (Huffman \& Hipp, 2003). Hord (1997b) stated: “The literature on professional learning communities repeatedly gives attention to five attributes of such organizational arrangements: supportive and shared leadership, collective learning, shared values and vision, supportive conditions, and shared personal practice" (p. 2).

The team of DuFour and Eaker extended the vision of PLCs. This superintendent and professor combination completed their first book, Fulfilling The Promise of Excellence, in 1987. "In developing recommendations we have attempted to integrate two important bodies of research that have emerged over the past decade...the first is research on effective schools... the second...the study of effective business practices (the learning organization)" (DuFour \& Eaker, 1987, p. xvi). The DuFour and Eaker extension included the following six characteristics: (a) shared mission, vision, and values; (b) collective inquiry; (c) collaborative teams; (d) action orientation and experimentation; (e) continuous improvement; and (f) results orientation (DuFour \& Eaker, 1998). In extending their own work, they were joined by two additional authors. To represent elementary and middle schools, they gave examples of systemic application of PLCs to all levels of schooling (DuFour, DuFour, Eaker, \& Karhanek, 2004). According to DuFour et al. (2004),

Psychologists tell us that we share certain fundamental needs-the need to feel successful in our work, the need to feel a sense of belonging, and the need to live a life of significance by making a difference. The PLC speaks to each of these needs. (p. 6) 
School systems are groups of individuals acting as a system, and DuFour et al. (2004) proposed that the school be a system that systemically supports student and teacher learning. DuFour et al. (2004) elaborated: “...a PLC will not leave this critical question to each teacher to resolve (individually). PLC will...create a school-wide system of interventions that provides all students with additional time and support when they experience initial difficulty in their learning" (p. 7).

Although Shirley Hord completed much of the research on PLCs at Southwest Educational Development Laboratory (SEDL), DuFour and Eaker are better known for the system of school improvement. The system is based on the work of Effective Schools and Organizational Learning. The goal is to create a collaborative community of learners who are dedicated to continuous improvement to increase student learning. It is based on four basic pillars: shared mission, vision, values, and goals. A collaborative staff works together daily to improve student learning. In Richardson’s (2011) opinion,

...[Richard DuFour] transformed Adlai Stevenson High School in suburban Chicago from a good school to one of the most highly honored high schools in the country; that's no small task considering that the American high school is traditionally an institution nearly immune to change. (p. 28)

If the PLC can change the American high school, maybe it can change the American school district. It is clear in the research that schools cannot change alone. Stevenson High School is a one-school district. It houses all of the power of the school district within the school, meaning the building and district administration work closely together.

\section{Instructionally Effective School Districts (IESD)}

Wood (1985) explained, "For school-based improvement to make a real difference, however, we need to realize that while the unit of change in education is the 
school, schools are not independent of a school system" (p. 63). All of methods of school improvement have focused on the most direct ways to improve student achievement — the school/teacher. Although research from the classroom and school levels (Marzano, 2003) is clearly of higher impact than that of the administrator (Marzano, 2005) and the district level (Marzano, 2011), it is clear that the effects are systemic: meaning both school and district wide. According to Wood (1985), "The central office administrators must understand and support school-based improvement. This includes learning the roles necessary to support decision-making at the school level, rather than at the district level" (p. 66). School improvement is part of a whole, meaning district improvement and all parts must be understood. Wood (1985) stated, "The principal, as a key leadership person in school improvement, must learn how to facilitate improvement in the school, particularly in areas of instruction, shared decision-making, and managing change" (p. 66).

It is understood that someone has to support the principal. It is the district that must support the building administration. In reviewing the literature of the school district and school improvement, a good starting point is the study Characteristics of Instructionally Effective School Districts. The goals of the study were threefold: to develop a better understanding of (a) the factors and processes that characterize IESD (instructionally effective school districts), (b) the role of the superintendent in promoting IESD, and (c) the methods used by district offices to coordinate and control the work activities of school level personnel, especially principals. Murphy and Hallinger (1988) offerred a vision of school improvement that includes the following three conditions: labor peace, board support, and community acceptance. The districts in this study were at peace with the larger communities in which they operated. "There has been little analysis 
of the educational effects produced by district level activities..." (Murphy \& Hallinger, 1975, p. 175). The authors were perplexed that “...because of the growing acceptance of studying organizations as 'nested layers' (Barr, Dreeben, \& Wiratchai, 1983), continued absence of attention to district level activities is difficult to explain" (p. 175). Murphy and Hallinger (1988) identified a number of patterns that characterized the environment or culture of these districts which emerged during analysis, including the following: (a) productivity focus - improving student learning was the top priority in these districts; (b) improvement focus - although the 12 districts were already among the most instructionally effective in the state, a systematic improvement efforts were evident in all of them; and (c) problem-solving focus - just as in effective classrooms (Brophy \& Good, 1986) and schools (Murphy \& Hallinger, 1985). In these effective districts, problems were viewed as issues to be solved or circumvented rather than as barriers to action. Murphy and Hallinger (1988) stated that a number of the districts closely parallel factors found in studies of instructionally effective schools. The locus or impetus for these factors is found at the district level rather than at the individual school. This supports the proposition that districts can undertake more active roles than the facilitative and catalytic ones generally prescribed for them in the area of school improvement (Murphy, Hallinger, \& Mesa, 1985). The goal of the study was to describe some of the variables and factors that characterize a sample of IESD in California. Murphy and Hallinger (1988) made it clear that the picture presented did not represent the majority of districts around the country. They also showed that the districts were different from other school systems and that their research discovered some of the reasons why these districts are more instructionally effective than others. 
Bjork (1993) stated, "Researchers found that the manner in which superintendents and that their management role may influence the quality of instruction in their districts. This suggests that superintendents have opportunities to serve as the instructional leaders at the district level" (p. 247). Bjork's focus on the role of the superintendent as an educational leader focused on the findings of the three waves of reform from the 1980s. According to Bjork (1993),

...reports identified individual schools as the locus of reform and contain widely divergent recommendations for school improvement and reform, including a more prominent role for state level leaders, decentralization, increased training for teachers, allowing teachers more professional discretion, defining a pivotal leadership role for principles, focusing on children, increasing the involvement of parents in the community, and engaging in collaboration with businesses and universities. (p. 248)

Bjork (1993) added, "The identification of the importance of instructional leadership and school improvement has raised questions about its locus in characteristics at different levels in the school's hierarchy" (p. 249). This research focuses on the role of the superintendent. Bjork (1993) explained,

Leadership at this level involves sending messages and roll tunes to participants and lower levels in the organization, not only through clearly stating the organizational goals, but also demonstrating their importance by making appropriate structural changes and rewarding participants who support those goals....The school superintendent may be able to have a more direct influence in changing the behavior [of] principals and teachers at building and classroom levels. (p. 251)

Therefore, the behavior of the district leadership is important in directing instructional improvement. Bjork (1993) continued, "Superintendents give principals messages during regular meetings that serve as by the role cues that identify what was important and where focused on improving the districts instructional programs at the building level" 
(p. 253). Leadership and support at the district level is important to school improvement.

Pajak and Glickman (1989) wrote: "In districts that have sustained improvements in student achievement for three years, we found a continuing instructional dialogue, the foundation of supervisory support, and instructional leadership from various sources" (p. 61). In their 1989 study, Pajak and Glickman found that "In each of the districts... the superintendent and the central office supervisors were key figures in stimulating and facilitating efforts to maintain and improve the quality of instruction" (p. 62). Pajak and Glickman added, "What is important is to create district expectations of professional dialog and support so that educators in all positions in a school system can share in the innovativeness and express that commitment" (p. 64). It is the district that sets the focus for academic improvement. The superintendent sets the focus and the district administrators and principals follow.

Togneri and Anderson (2003) completed a study on how high-poverty districts improve; "...the study sought to build greater understanding of what improving districts were doing to support the instructional work of teachers and principals" (p. 12). The study sought to understand how districts created the will to begin instructional reform, the ways the district changed their approaches to professional development, how interactions among the stakeholders facilitated or hindered instructional reform, and how leadership was distributed across stakeholders to facilitate improvement. Togneri and Anderson (2003) concluded that, “...the study revealed a strikingly similar set of strategies used across these districts" (p. 13). A summary of the findings are as follows: the districts acknowledged poor performance and sought solutions; the districts focused intensively on improving instruction and achievement; the districts build a system-wide framework 
of instructional supports; the districts redefined and redistributed leadership roles and no single stakeholder tackled reform alone. The districts made professional development relevant and useful, and finally the districts recognized that there are no quick fixes (Togneri \& Anderson, 2003). Again, the key to school improvement was understanding and support for the schools at the district level.

\section{Loose and Tightly Coupled Organizations to District-wide PLCs}

In 1976 Karl Weick published "Educational Organizations as Loosely Coupled Systems." It was a discussion of organizations that were described as tightly or loosely coupled. According to Green and Swanson (2011) “...Weick's 1976 article from Administrative Science Quarterly is commonly cited as the foundational statement on organizations as loosely coupled systems" (Orton \& Weick, 1990; Robson, 1998; Gumport \& Sporn, 1999; Weick \& Quinn, 1999; Johnson, 2002; Pajak \& Green, 2003) (p. 377). The article states that educational organizations are not as rigidly structured as it would seem, and that this, in fact, is the beauty of the entity. Some parts of the organization are rational while other parts are not. Weick (1982) wrote that loose coupling can be defined as "anything(s) that may be tied together either weakly or infrequently or slowly or with minimal interdependence" (p. 239). Loose coupling is essential to educational organizations because it shows the identity as well as the separateness of elements that are temporarily attached (Weick, 1982). Weick (1982) explained:

The goals in education are also intermediate, which makes them difficult to use as hard standards to use to evaluate individual performance. Administrators and instructors work on variable raw material with little control over the supply; they have no firm standards by which to judge the impact of their work and no clear theory of causation that specifies the effects of the things they do. (p. 673) 
From around 1976 until the 1990s, the school was thought of as a loosely coupled system. This theory had replaced the focus on individual schools that labored under bureaucracies from the late sixties and early seventies. It included nested systems where the classroom was nested in the school, while the school was nested in the district and the district was nested within the state. Loosely coupled systems also allowed the examination of top-down reform and its failure, which may have spawned the restructuring movement.

To take advantage of the positives of the loosely coupled system, some systems chose to restructure. In the opinion of Marzano and Water (2009), "The natural consequence of loosely coupled districts and schools is to move toward site-based management" (p. 22). Site-based management was a process included in restructuring. DuFour and Marzano (2011) stated,

The site-based school improvement model was based on the premise that if educators were given unfettered autonomy in their schools, innovation and creativity would flourish. Educators would approach their challenges with renewed sense of enthusiasm, ownership, and commitment if they were given freedom to identify the problems in their own schools and were empowered to develop their own solutions. (p. 28)

This strategy did not work. DuFour and Marzano (2011) added that educators with sitebased management were no more likely to engage in the tough work of school improvement than any other educator.

Marzano and Waters (2009) reviewed the work the work of Weick. Their review included a discussion of tight coupling as well as loose coupling.

...tightly coupled organizations have four defining characteristics: (1) they are self-correcting rational systems with highly interdependent components; (2) they have consensus on goals and the means to accomplish those goals; (3) they can coordinate activity by disseminating information, and (4) they have predictable 
problems and the means to address those problems. (Marzano \& Waters, 2009, p. 13)

The description of the tightly coupled organization describes the PLC. Vescio (2008) explained, "Learning communities are grounded in two assumptions. First, it is assumed that knowledge is situated in the day-to-day lived experiences of teachers and best understood through critical reflection with others who share the same experience" (Buysse, Sparkman, \& Wesley, 2003, p. 81). Roy and Hord (2006) added” "The PLC requires that educators act and interact differently from the traditional mode. These interactions are intended to enhance the knowledge and skills of teachers and, in turn, affect student learning" (p. 496).

Schools on their own do not have the ability to create tight couplings (Marzano \& Waters, 2009). How schools organize and how they interact with their communities has a lot to do with their success or failure (Bryk, 2010). Bryk (2010) identified five essential supports for school improvement: (a) a coherent instructional guidance system; (b) the school's professional capacity; (c) strong parent-community-school ties; (d) a studentcentered learning climate; and (e) leadership that drives change. Even with the essential supports a school cannot sustain school improvement alone (DuFour \& Marzano, 2011).

A principal and key staff could help a school improve student achievement through heroic effort, but they could not sustain the improvement or survive the departure of key leaders without the support of the district and a commitment at that level to promote effective schooling practices (Lezotte, 2008). (p. 28)

According to DuFour and Marzano (2011), “...district leadership has been found to have a measurable effect on student achievement (Marzano \& Waters, 2009, p. 12)" (p. 28). The district is central in school improvement (Lezotte, 2008; DuFour, DuFour, \& Eaker, 
2008; Marzano \& Waters, 2009; DuFour \& Marzano, 2011).

Marzano and Waters (2009) focused on the leadership effects of the district.

“...[research] findings suggest that when district leaders are carrying out their leadership responsibilities effectively, student achievement across the district is positively affected" (Marzano \& Waters, p. 5). Marzano and Waters' (2009) research identified the following leadership responsibilities as central to effecting student achievement at the district level:

1. Ensuring collaborative goal setting

2. Establishing nonnegotiable goals for achievement and instruction

3. Creating board alignment with and supporting support of district goals

4. Monitoring achievement and instruction goals

5. Allocating resources to support the goals for achievement and instruction.

These items become very important when you reflect them against loosely coupled systems, individual professional learning communities, and tightly coupled systems. The loosely coupled system is the traditional educational system. The individual professional learning community is the individual school building that through heroic effort establishes a PLC. The tightly coupled system is the district-wide professional learning community. Specifically, the focus on nonnegotiable goals, alignment, and monitoring do not reflect a loosely coupled system they are more reflective of a tightly coupled system. They specifically fit into a tightly coupled system (Marzano \& Waters, 2009). The district-wide professional learning community is a tightly coupled system that has a coherent instructional guidance system, builds the school's professional capacity, enhances strong parent-community-school ties, promotes a student-centered learning 
climate, and creates leadership that drives change. It is a system that promotes school improvement through systemic application of leadership, collaboration, and focus on learning.

\section{Administrator Professional Development}

Barth (1984) wrote: "Central office administrators, State Department officials, and university researchers have come to recognize what most teachers, parents, and students have known all along - the quality of the school is related to the quality of it's leadership" (p. 93). Other researchers have agreed with Barth. Sarason (1996) stated it this way,

To put it succinctly as possible, if you want change and improve the climate and outcomes of schooling for both students and teachers, there are features of the school culture that have to be changed, and if they are not changed, your wellintentioned efforts will be defeated. (p. 340)

If we know that it is the quality of the leadership that improves instruction through the work of culture, we must go about improving leadership. Barth (1984) explained, “...the more the principal learns, the better the principal performs. The better the principal performs, the better teachers and students will perform" (p. 94). These statements explain that principal professional development improves student achievement indirectly through the cultural improvement.

If culture is part of the improvement process, what is culture? Schein (2004) elaborated, "...we can think of culture as the accumulated shared learning of a given group, covering behavioral, emotional, and cognitive elements of the group members' total psychological functioning" (p. 17). This means leadership, professional learning communities, the learning organization, and culture are all related. Schein (2004) added, 
...the only thing of real importance that leaders do is their ability to understand and work with culture; and that the unique talent of leaders is their ability to understand and work with cultures and that it is an ultimate act of leadership to destroy culture when it is viewed as dysfunctional. (p. 11)

DuFour and Eaker (1998) explained that "The structure of an organization is founded upon its policies, procedures, rules, and relationships...culture...is founded upon the assumptions, beliefs, values, and habits that constitute the norms for that organizationnorms that shape how its people think, feel, and act" (p. 131). The culture, as it has been explained, is one of the building blocks of an organization. Schein (2004) also wrote, "Once a group has a culture, it will pass elements of this culture on to new generation of group members" (p. 18). This is an example of how learning is a part of culture in an organization.

Wells and Keane (2008) explained that "Principles for professional development policy, practice, and initiative that come from nearly two decades of U.S. education reform underscore our conclusion that teacher learning communities constitute the best context for professional growth and change (McLaughlin \& Talbert, 2001, p. 135)" (p. 24). Thee authors go on to say that superintendents can make several conclusions about PLCs from the research:

(1) It is essential that schools and school districts evolve as learning organizations; (2) The development of Professional Learning Communities (PLCs) is an essential step in creating and sustaining a learning organization; (3) District leadership must be involved in the change process; individual schools attempting these changes are not enough. (McLaughlin \& Talbert, 2001, p. 24)

The research tells us that systemic professional development of principals is important and that it should be completed by the superintendent and the district office staff. Together the district office and the building administration establish the culture of the 
district. The hard work of establishing culture cannot be left to chance, but if there is no professional development for the building administration - culture, how things are done around here - is left to chance. Wells and Keane (2008) opined that "The tasks needed to transform schools or school districts to a PLC are complex, and they require unique knowledge, skills, and behaviors for the administrators leading those changes" (p. 28). Professional development of principals is not only necessary, it is required for school/district improvement because of the complexity of the process.

Marzano and Waters (2001), drawing from 35 years of studies, explained critical leadership principles that every administrator needs to know:

1. Twenty-one leadership responsibilities that have a significant effect on student learning and the correlation of each responsibility to academic achievement gains;

2. The difference between first-order and second-order change and the leadership responsibilities — in rank order — that are most important for each;

3. How to choose the right work to focus on to improve student achievement;

4. The advantages and disadvantages of comprehensive school reform models for improving student achievement;

5. Eleven factors and 39 actions that help you take a site-specific approach to improving student achievement; and

6. A 5-step plan for effective school leadership that includes a strong team, distributed responsibilities, and 31 team action steps.

Marzano, Waters, and McNulty (2005) added: "Leadership has long been perceived to be important to the effective functioning of organizations ...our metaanalysis of 35 years of research indicates that school leadership has a substantial effect on 
student achievement and provide guidance ...administrators" (p. 12). In reviewing the research on building leadership, Marzano and Waters (2005) discovered well-researched 21 leadership responsibilities: “...the 21 responsibilities identified in our meta-analysis are not new to the literature on leadership. Each one has been mentioned explicitly or implicitly by a host of researchers and theorists" (pp. 61-62). Marzano et al. (2005) explained that the 21 responsibilities of the building administrator cannot be completed by one individual. The principal has to develop a leadership team and distribute those responsibilities. Again, this fits appropriately into the PLC. Distributive leadership is a large part of the PLC model; it is evident that no one person can do all that is required for leadership in a learning organization. It is the responsibility of a team.

\section{Conclusion}

A variety of research from the 1980 s to the present documents the importance of the district in school improvement. The birth of school improvement in the 1970s started with a focus on the most direct manner of improving student achievement—schools and classrooms. According to Robert Marzano (2003), "The schools that are highly effective produce results that almost entirely overcome the effects of student background" (p. 7). There is no doubt that the most important direct factor for educating students is the teacher. For more than 40 years, researchers, practitioners, and school improvement zealots have been working to improve schools through the Effective Schools Movement, the Excellence Movement and the Restructuring Movement, to name a few projects. These projects have consistently failed because they have not taken into account the value of the indirect factors that included in distributive leadership. 
Educators have been working very hard for more than 40 years on improving individual schools one at a time. Researchers and practitioners have spent most of the time focusing upon individual schools and teachers. The focus of the action for improvement has been on the most direct factors of learning. As the old song says, you can't get there from here. The schools have worked over and over to focus on direct factors that influence school achievement. These direct factors without leadership have failed to bring about the changes that are needed to support student achievement. As Marzano (2005) noted, "[the] research over the last 35 years provides strong guidance on specific leadership behaviors for school administrators and those behaviors have welldocumented effects on student achievement" (p. 7). The individual teacher cannot sustain the type of effort needed to cause improvement across the system without assistance from leadership. The individual leader cannot do all the necessary things to ensure success for all students. School improvement gurus have worked for nearly 50 years on school systems and schools without combining all of the necessary items.

Currently, the American system of education is improving instruction based on individual school improvement. The school systems attempt to improve one teacher at a time in one school at a time. The American system for improving schools is also based on improving one school at a time. The systems are flawed in both cases. Senge (1994) implored, "What makes an airplane cannot be found in the parts" (p. 25). Likewise for schools: what produces a well-educated student cannot be found in the parts (p. 28). "Principles for professional development policy, practice, and initiative that come from nearly two decades of U.S. education reform underscore the conclusion that teacher learning communities constitute the best context for professional growth and change 
(McLaughlin \& Talbert, 2001, p. 135)” (p. 24). When working with PLCs, the emphasis is on the interrelatedness of the goals and vision for success for every student. Instead of looking for the quick fix approach to solving a problem in isolation, the system is reviewed for its connections and solutions are formed from that deeper understanding ( $\mathrm{p}$. 28). The work that it takes to improve individually at the teacher and school levels cannot be sustained without support from the district.

We must build the capacity for school districts to become systems that empower instructional improvement while improving schools. According to Wells and Keane (2008),

research shows us: (1) It is essential that schools and school districts evolve as learning organizations; (2) The development of Professional Learning Communities (PLCs) is an essential step in creating and sustaining a learning organization; (3) District leadership must be involved in the change process; and (4) individual schools attempting these changes are not enough. (p. 24)

District-wide PLCs are required to improve instruction and schools at the level we have sought for more than 40 years.

Purkey and Smith (1983) elaborated:

Following Barr and Dreeben (1981), we view school systems as 'nested layers' in which each organizational level sets the context and defines the boundaries for the layers below (though there is a reciprocal influence). If the locus of the educational process is at the lowest structural level, the classroom, it is nevertheless the adjacent layer, the school, the forms the immediate environment in which the classroom functions. The quality of the process at the classroom level will be enhanced or diminished by the quality of activity at the level above it. (p. 428)

In order to successfully improve schools, we have to start at the next higher level, simply stated, at the district level. We cannot improve schools one at a time. We must improve school systems. Senge (1990) explained that when you push on the system it pushes back, 
and to tinker with one part of the system is to become the victim of another. We must stop tinkering and set about understanding and working with the system we have in order to improve it. We must design the school system to be learning organizations that are focused on Hord's (1997) characteristics of a professional learning community: (a) supportive and shared leadership; (b) shared basic values and vision; (c) collective learning and the application of that learning; (d) shared practice; and (e) supportive conditions for the maintenance of the learning community. Wells and Kean (2008) explained that "The tasks needed to transform... school districts to a PLC are complex, and they require unique knowledge, skills, and behaviors for the administrators leading those changes. In addition to the "laws" of systems thinking" (p. 28), it is time that the educational profession worked to acquire the unique knowledge, skills, and behaviors to transform our systems into learning organizations for the betterment of our students, community, and society.

The information in this review has established that school districts are currently very similar to the bureaucratic organizations that were created in the early $20^{\text {th }}$ century. The school district, with its bureaucratic structure, was unable to handle the stresses that created by the various social issues of the decades of the fifties through the present. The school district and its leadership went from being the center of a successful system to the being unimportant.

Since the early 1950s, the American System of Education has been in a constant state of reform. New idea after new idea or wave after wave of reform has washed over the system and no matter the power of the wave, the system remained relatively untouched. Senge (1990) explained that when the system is pushed, there is an equal push 
back from the system. His theory concerning the learning organization explains that only an understanding of the system can lead to change and success. School improvement done correctly is systemic process that requires school district guidance and support.

The review of literature establishes that PLCs were developed from organizational learning and through the field of learning organizations. It is not just a system that was implemented from business, it is a system that is also based on the knowledge gained through years of reform. It deals with the issue of teacher isolation that was identified by Lortie (1974) with collaboration. It encompasses professional community that has been shown to improve student achievement (Cuban, 1992; McLaughlin, 1992; Louis, Marks, \& Kruse, 1996; Louis, 2006). It is a systematic solution that includes knowledge from business, effective schools research, and professional community. The PLC is touted as the best hope for school improvement (DuFour, 2004).

The PLC was developed in the early nineties and it is nearly 20 years old. There have been many individual research projects how to develop a PLC, describing PLC, and describing effects of a PLC. Through the research, articles, and books, the term PLC has become very popular; many organizations claim to have established PLCs. DuFour (2004) cautioned, "the term has been used so ubiquitously that it is in danger of losing all meaning”( (12). In order to prevent the PLC model from the same dismal fate as other well-intentioned reform efforts, recommends that educators continually reflect on the ways they are working to embed student learning and teacher collaboration into the culture of the schools (DuFour, 2004). This research project used the perceptions of its leadership to measure the relationships of a sustaining PLC as defined by DuFour (2004). The work will help define the role of leadership relationships in a successful PLC. 
CHAPTER III

\section{METHODS OF STUDY}

This chapter reviews the procedures and methodologies used to study how the relationship practices between district and building leadership affect school improvement as measured by the professional learning community model of school improvement. I will employ a basic interpretivist study utilizing inquiry strategies and associated processes for data collection regarding the relationships of administrators and analyzed data for patterns and relationships. In addition, this chapter includes a description of the method used to select sites for the study, including the description of a survey tool used in the selection of typical professional learning communities. This chapter also includes a description of the methods used to analyze and validate the findings. Lastly, a discussion of potential ethical issues is included.

\section{Purpose of the Research}

The purpose of this study was to explore how district and building leaders work together affect school improvement in a professional learning community. Hopkins, Ainscow, and West (1994) state, "...school improvement is a distinct approach to educational change that enhances student outcomes as well as strengthening the school's capacity for managing change" (p. 3). For this purpose, school improvement is defined as the purposeful interaction, communication, and connection between school personnel directly related to accomplishing teaching and learning objectives. According to Hord (1997), five characteristics define a professional learning community: supportive and 
shared leadership, collective creativity, shared values and vision, supportive conditions, and shared personal practice. A professional learning community may be limited to a team of teachers or be as large as a school or district. For this study, the professional learning community included the whole district. For the purpose of answering the research questions posed in the study I conducted interviews and observations and collected artifacts from selected districts that had been identified as professional learning communities. The resulting understanding of the working relationships between the district and building administrators in the professional learning communities and how this relationship leads to school improvement were sought. Insights into how the relationship guides, impedes, or accentuates school improvement successes, failures, challenges, and rewards were explored through this study and each finding can aid districts in defining expectations for relationships between district and building administrations in sustaining their professional learning communities.

\section{Research Questions}

This study was driven by the following research questions:

1. How does the relationship between the district-level leadership and the building-level leadership impact the implementation and sustainment of a successful professional learning community?

2. What district-level and building-level leadership practices in the professional learning community ensure the establishment of a culture of improved student achievement?

3. Does relational trust impact district-level and building-level leadership practices within professional learning communities? 


\section{Positionality of the Researcher}

As a former principal of a suburban high school and a current district administrator who has engaged in the process of becoming a professional learning community, I acknowledge a favorable bias toward professional learning communities and district support of school improvement. It is important to acknowledge that I am an advocate of the principles and practices of professional learning communities. Personal experience as a principal and as a district administrator engaged in the process of becoming a PLC gives me experiences and knowledge of specific successful and unsuccessful strategies in developing professional learning communities. There is no doubt that those experiences contributed to my choice of topic: examining how relationships between district and building administration affect school improvement in the professional learning community model. Personal experience and the literature review provided a critical lens through which to analyze data that were collected throughout the study and to verify whether the attributes stated by those interviewed were observable. Additional bias may have been present as a result of the limited experience of the researcher in urban settings; although I have experience with diversity in my administrative positions, I do not have experience in high poverty urban settings. As a minority researcher, my lens may be different than a majority researcher, but bias is still present in my race (black) and sex (male), since my personal and professional experiences are different from those in the study. Experience as an administrator in districts with the Illinois Education Association may have been a bias as well. Abiding by the IRB processes and procedures may have reduced the possibility of my biases unduly influencing the research findings. This study focused on gaining understanding, analysis, 
and interpretation of the research data, thus adding to the research base for school improvement.

\section{Characteristics of Qualitative Research}

The overarching goal of this study was to gain a deeper understanding of how relationships of district and building administration affect school improvement. The most appropriate process in achieving this goal was qualitative research, because it allowed the researcher, through human interaction, to understand the various perspectives of the administrators involved in this process. Patton (2002) described qualitative data:

Qualitative data describes. It takes us, as readers, into the time and place of the observation so that we know what is like to have been there. It captures and communicates someone else's experience of the world in his or her own words. Qualitative data tells a story. (p. 47)

A qualitative approach allows the researcher to achieve the goal of understanding the experiences of the teachers within the context of their developing professional learning communities.

Each member of a developing professional learning community interprets his or her experience in a unique way. A basic interpretivist study is most appropriate in exploring and understanding these varied perspectives. An interpretivist approach seeks to reveal individual perceptions of experience that are culturally or historically based (Crotty, 1998). The characteristics of qualitative inquiry were appropriate for the goals of this study. Merriam (1998) stated that "qualitative researchers are interested in understanding the meaning people have constructed, that is, how they make sense of their world and the experiences they have in the world" (p. 6). Four other characteristics of qualitative research described by Merriam were also relevant to the design of this study. 
The first described the researcher as "the primary instrument for data collection and analysis" (p. 7). The role of the researcher in the study was to be the exclusive eyes and ears for data collection.

Merriam (1998) described the importance of fieldwork and the employment of an inductive research strategy. Using qualitative methodology, I explored the leadership practices and guiding values of a professional learning community through fieldwork, making observations, and interviewing in two schools where I listened to the stories and experiences of teachers. Through reflection and analysis, themes and concepts were inductively derived. "Qualitative researchers build toward theory from observations and intuitive understandings gained in the field" (Merriam, 1998, p. 7).

Another characteristic described by Merriam identified the product of qualitative research as richly descriptive. These characteristics of qualitative research were consistent with the goals of this study. My research provides a rich description of the experiences of teachers and administrators as they worked to develop professional learning communities.

Qualitative research methods were best suited to this study, especially in terms of the interactive nature of professional learning communities. While student achievement, a chief goal of professional learning communities, can be viewed quantitatively, the collaborative interaction of teachers is best understood through observations of the lived experiences of the interpersonal experiences of teachers. Creswell (2003) explained that qualitative researchers "seek to build rapport and credibility with the individuals in the study" (p. 181). Among the methods available to the qualitative researcher are observations, interviews, and artifacts created by teachers in the schools to be studied. 


\section{Participant Selection}

The participant districts were selected using purposive sampling. Tongco (2007)

described purposive sampling in this way:

The purposive sampling technique...is the deliberate choice of an informant due to the qualities the informant possesses. It is a nonrandom technique that does not need underlying theories or a set number of informants. Simply put, the researcher decides what needs to be known and sets out to find people who can and are willing to provide the information by virtue of knowledge or experience (Bernard 2002; Lewis \& Sheppard 2006). (p. 147)

Samples were chosen based on the belief that they could produce for the researcher the most knowledge for answering the research questions. According to Merriam (1998), “...[purposive] sampling is based on the assumption that the investigator wants to discover, understand, and gain insight and therefore must select a sample from which the most can be learned" (p. 61). Using this technique, districts were selected based on the extent they were engaged as per DuFour's (2010) The Professional Learning

Communities at Work continuum. The continuum rubric categorizes districts based on the characteristics of a professional learning community. The categories are: preinitiating, initiating, implementing, developing, and sustaining.

Districts in the pre-initiating stage are discussing the process in preparation for implementation. "... not yet begun to address the...practice of a PLC" (DuFour et al., 2010, p. 42). Districts in the initiating stage have begun the process of implementation. "An effort has been made...but [it] has not yet begun to impact a critical mass of staff members" (DuFour et al., 2010, p. 42). Districts in the implementing stage have gone through the first two stages and are developing systems and understanding. "A critical mass of staff members is participating in implementing [the PLC], but many approach the 
task with a sense of compliance rather than commitment. There is some uncertainty regarding what needs to be done and why it should be done" (DuFour et al., 2010, p. 42).

Districts in the developing stage have gone through developing systems and are working to the place where the system is self-sustaining. "Structures are being altered to support the changes, and resources are being devoted to moving them forward. Members are becoming more receptive to [the practices of the PLC] because they have experienced some of its benefits" (DuFour et al., 2010, p. 42).

Districts in the sustaining stage have established that the process is how things are done in the district. "[The PLC] is deeply embedded in the culture...It is a driving force in the daily work of staff. It is deeply internalized, and staff would resist attempts to abandon the... practice" (DuFour et al., 2010, p. 42). The processes are established and the system is intertwined with the workings of the district. For the purposes of this study, only districts at the sustaining level were selected for inclusion.

The PLC process is a systemic job embedded process of professional development designed to focus on improving student achievement through organizational learning. "One of the most persistent findings from research on school improvement is, in fact, the symbiotic relationship between professional development and school improvement efforts" (Hawley \& Valli, 1999, p. 129). In developing the research process, it was discovered that although many levels of schools have attempted school improvement, by far the most difficult to improve has been the American high school. Good (1989) explained: "Cogent arguments illustrate the dynamic relations in schools, offering a sophisticated view of differences in functioning between schools that are changing and improving ("moving" schools) and those that are not ("stuck")" (p. x). In a 
study of 78 schools, including 27 elementary schools, 18 middle/junior high schools, and 18 high schools that were categorized as stuck, limited connections, transitional and systemic, the vast majority $(82 \%)$ were in the bottom two categories of stuck and limited connection (Sappington, Pacha, Baker, \& Gardner, 2012). In the study, only 3 schools (4\%) achieved the systemic level; all three of the schools were elementary schools (Sappington et al., 2012). This information led to the choice of elementary schools as the focus of our study. Fullan (2000) wrote that it takes less time to improve an elementary school than any other school. The state of Illinois has three major types of schools districts: (a) Unit Districts - that include all levels of schools, elementary, middle, and high school; (b) High School Districts—-that include only high schools; and (c) Elementary School Districts - that include pre-k to grade 8 students. In an attempt to gather the highest number of districts in the sustaining stage - based on research on schools - the research project included only Elementary School Districts.

The Illinois Interactive Report Card [http://iirc.niu.edu] identified 862 school districts in the state of Illinois: 387 unit school districts, 100 high school districts, and 375 elementary school districts. The participant districts were selected with a 2 -step process. The first step identified up to three to six districts for more intensive study. The second step was a more intensive study of the relationships between the district level and building level leadership, including a district-wide professional learning community.

The first step started by using a survey for principals and district-level administrators based on DuFour's (2010) Professional Learning Community Continuum. The survey placed the districts in one of five stages as professional learning communities based on the characteristics of a professional learning community: Pre-initiation Stage, 
Initiation Stage, Implementing, Developing Stage, and Sustaining Stage.

The participant districts were selected using DuFour's PLC Continuum. The group of districts that had reached the highest level was placed in the Sustaining Leadership Group. This group of PLC districts had the characteristics that represent those most widely cited in the literature. The next step in the study sites was to interview the identified key informants: school and district administrators, and teacher leaders who would have firsthand knowledge of their schools and the work. The data gathered from the interviews were used to help the researcher choose building and district documents for review in the research process.

The research focused on those schools that had established themselves as sustaining level PLC organizations. Selected districts were atypical of most school districts that had labeled themselves as professional learning communities as indicated by their survey results and as compared to the prevailing models in the literature. In addition, the interview tool revealed relationships between the building and district leadership.

\section{Instrumentation}

The development of an instrument to measure the status of a PLC started with the development of the model with Shirley Hord in 1995 (Huffman \& Hipp, 2003). Huffman and Hipp took the next few steps in developing an instrument to measure a PLC after Hord in designing what was called the Professional Learning Community Organizer (Huffman \& Hipp, 2003). "Rather than determining that a school is or is not functioning as a PLC, it is more useful to assess its progress along a continuum... Such analysis can be enhanced by assessment of organizational variables related to PLC development..." (Huffman \& Hipp, 2003, p. 29). Their work utilized Fullan's (1990) three phases of 
change: initiation, implementation, and institutionalization. From the Professional Learning Community Organizer, Olivier extended and created The Professional Learning Community Assessment (PLCA) (Oliver, 2003). This survey was designed to assess where a school was on the PLC continuum. The survey used in Phase I was a closed survey with 47 questions that was developed by DuFour (2006) in Learning by Doing. This survey was designed to evaluate both the district and the building. The survey divided questions into eight sections: focus, shared mission, collective commitments (shared values), purpose, communication, teaming, monitoring, and intervention. The questions were designed to help ascertain where the district or school was on the PLC continuum. For this study, the closed survey was used to define our study group of multibuilding elementary school districts in the sustaining stage of PLC development.

\section{Interview Protocol}

Following the interview protocol as required by the IRB, I met for one-on-one interviews with the superintendents, building principals, and teacher leaders (if they could be identified). These meetings included 25 open-ended questions concerning district vision, mission, and values. An example question would be: Who was involved in building the district vision? Other items in the interview included questions about trust and relationships between the district office and the buildings. The questions were designed to build a picture of administrative relationships in the district and how they impact PLCs.

\section{Observation Protocol}

Observations in the district included administrative meetings. The three meeting types I was most interested in observing included meetings with the district leadership, 
meetings building leadership teams, and meetings with the district and building leadership teams. I reviewed the agenda and took notes on the types of interactions, including engagement, meeting type and leadership style. The meetings added to the process of building a picture of administrative relationships in the district and how they impact PLCs.

\section{Data Collection Procedures}

The data for this study were collected in three phases. In Phase 1 of the study I used the information about school districts listed on the publicly available Illinois Interactive Report Card (iirc) website. The iirc lists sizes of districts, labeling districts with similar sizes, structures, and geographic locations as "large," "suburban," and "unit." The information in iirc was used to gather all of the large elementary districts in the northeastern section of Illinois. In Phase 2 of the data collection, the districts identified in Phase 1 were surveyed to determine their status on the professional learning community spectrum: pre-initiating, initiation, developing, or sustaining stage. The result of the first two phases narrowed down the pool of districts significantly from 862 , identified by the state, to 3 through random sampling upon approval of the IRB. The individual participating school leaders within those randomly identified districts were selected for interview based on convenience sampling.

Contact information to inquire about availability for participation was acquired through public school district websites. Individuals in the roles identified as the focus of this study were contacted via email addresses and/or work phone numbers available on the district websites. Participants were recruited for Phase III of the study initially with a email from the co-principal investigator and then a follow-up letter of invitation. If 
contact was never made with the prospective subject, a new subject was selected for the study and this subject was sent the letter of invitation.

Participants of this study were expected to answer a series of questions related to their experiences with school improvement through the professional learning communities. Prior to the interview and as a confirmation of the interview time, date, and location, participants were emailed basic questions and asked to have the answers to those questions available during the interview. As part of their responsibility as a building or district administrator, it was also their responsibility to keep ongoing records of their school improvement data. These documents were also reviewed and shared with the researcher for purposes of this study. Participants were expected to respond to a series of approximately 25 interview probes using a semi-structured format. The order of the probes was adjusted in order to maintain a conversation quality to the interview. Following the interview probes, participants were asked to participate in two activities, neither of which required physical movement or risk beyond standard questions.

Data were collected through interview, observation, and document review. The data collected were kept on my computer in my locked office at work or home. When scheduling the interviews, I allowed the participants to choose a place at a location that they would find comfortable and familiar. I offered to meet at the district offices of the participant, the school of the participant, or a quiet public location, e.g., a public library or quiet restaurant. Interviews conducted on school sites were conducted in offices or rooms with closed doors to maintain privacy. The locations offered were tailored to the geographic location of each participant. I took any and all precautions necessary to provide confidentiality to the participants. 


\section{Study Reliability and Validity}

The researcher conducted on-site interviews with each of the leaders from the selected districts. The data were gathered using three qualitative methods: interviews, observations, and document review. Data gathered from these visits enabled the researcher to analyze and determine the relationships between district and building leadership in sustaining stage PLCs within the conceptual framework of the study. 


\section{CHAPTER IV}

\section{ANALYSIS OF RESULTS}

This study investigated the relationships of central office and building leadership in sustaining level elementary school district PLCs and explored the leadership practices that encouraged a culture of improved student achievement in those schools. In this chapter, the themes identified from the data gathered from the study will be presented with a summary analysis of the results through the lens of the Sustaining Level PLC as described by DuFour (2010).

The study was carried out in three phases. The data collection and analysis procedures were focused on answering the three research questions associated with this study:

1. How does the relationship between the district-level leadership and the building-level leadership impact the implementation and sustainment of a successful professional learning community?

2. What district-level and building-level leadership practices within professional learning communities ensure the establishment of a culture of improved student achievement?

3. How does relational trust impact district-level and building-level leadership practices within professional learning communities? 


\section{Phase I}

In Phase I, I used the Illinois Interactive Report Card (iirc) to identify all of the elementary school districts in the state of Illinois. Next, I eliminated all elementary school districts that were not in Cook, Dupage, Lake, and Will Counties. Finally, I screened the districts in those four counties for districts with multiple buildings. In this phase I identified 916 administrators from 134 elementary school districts-134 superintendents and 782 principals.

\section{Phase II}

In Phase II, I utilized the data gathered in Phase I from the 916 building and central office administrators that were identified in multiple building elementary school districts. I used the Professional Learning Community Continuum (PLCC) to sort the districts into the four categories of the PLCC: Pre-initiation, Initiation, Developing, and Sustaining Stages. I chose to survey the districts in the northeastern section of Illinois because more than $50 \%$ of the state's elementary school districts are located in the four northeastern counties of Cook, DuPage, Lake, and Will. The districts were surveyed in the Spring of 2015. Thirty-seven administrators responded-24 principals and 13 superintendents, representing 29 districts. Of these, five districts were determined to be at the sustaining stage. Of the five districts, three agreed to participate in the interviews. Initial contact and electronic correspondence were sent to the individual administrators in the three districts after gaining permission from the superintendent. The survey participants included 4 districts in the pre-initiation stage, 5 districts in the initiation stage, 15 districts in the developing stage, and 5 districts in the sustaining stage (see Table 1). 
Table 1

Survey Participant Stages

\begin{tabular}{lccccccc}
\hline Stages & $\begin{array}{c}\text { Number of } \\
\text { Districts }\end{array}$ & $\begin{array}{c}\text { Greater than } \\
50 \% \text { Low } \\
\text { income }\end{array}$ & $\begin{array}{c}\text { Less than 50\% } \\
\text { Low Income }\end{array}$ & Cook & Dupage & Lake & Will \\
\hline $\begin{array}{l}\text { Pre- } \\
\text { initiation }\end{array}$ & 4 & 3 & 1 & 4 & 0 & 0 & 0 \\
Initiation & 5 & 3 & 2 & 3 & 2 & 0 & 0 \\
Developing & 15 & 8 & 7 & 8 & 3 & 2 & 2 \\
Sustaining & 5 & 2 & 3 & 3 & 1 & 1 & 0 \\
\hline
\end{tabular}

\section{Phase III Subgroup Identification}

Data collection began after participation agreement was secured from the superintendent and one building administrator from the three participating districts. Pseudonyms were used for the purpose of confidentiality for participants, buildings, and districts of responsibility. Interviews were set up for the fall of 2015. During the interviews, it was determined that one of the district's PLCs did not meet the sustaining level as previously reported; therefore, that district was eliminated from the study, leaving participants from only two districts.

\section{Participant Profiles}

The participants of the study were district administrators (superintendents) and building administrators (principals) in two elementary school districts with PLCs at the sustaining level PLCs. To ensure the anonymity of the districts, schools, and participants, pseudonyms were assigned. All participants had 2 or more years of experience in the district (see Table 2). 
Table 2

Study Districts and Participants

\begin{tabular}{lccccccc}
\hline District & County & $\begin{array}{c}\text { Super- } \\
\text { intendent }\end{array}$ & $\begin{array}{c}\text { Years } \\
\text { in } \\
\text { position }\end{array}$ & $\begin{array}{c}\text { Elementary } \\
\text { Principal }\end{array}$ & $\begin{array}{c}\text { Years } \\
\text { in } \\
\text { position }\end{array}$ & $\begin{array}{c}\text { Middle } \\
\text { School } \\
\text { Principal }\end{array}$ & $\begin{array}{c}\text { Years } \\
\text { in } \\
\text { position }\end{array}$ \\
\hline Grandview & Cook & $\begin{array}{l}\text { Dr. } \\
\text { Chievers }\end{array}$ & 3 & Mrs. Red & 2 & Mrs. Marks & 3 \\
Huntington & Lake & Dr. Daly & 6 & Mrs. Jackie & 6 & $\begin{array}{l}\text { Mrs. } \\
\text { Farmer }\end{array}$ & 3 \\
\hline
\end{tabular}

\section{Grandview District}

Grandview is an elementary school district with 27 school buildings (22

elementary schools and 5 middle schools). The district covers 31 square miles and has a population of 133,000 people. The job of the superintendent in this district is creating capacity for the district to achieve its vision while working on the district's mission in collaboration with the board of education. The superintendent is the chief executive officer of the district. The previous superintendent started the PLC model in the district. The district is currently in year 12 of its PLC journey.

The district has a little over 14,000 students. Thirty-one percent of the students in the district are low income. According to Superintendent Chievers, 80 languages are spoken in the district. This elementary school district is $42 \%$ White, $25 \%$ Hispanic, $23 \%$ Asian, 7\% Black, and 3\% other (two or more races) (iirc, nd). The performance of the district on Illinois School Achievement Testing (ISAT) had been at least 90\% meets standards until the state made some scoring adjustments in the last 2 years. About $22 \%$ of the students in the district are English Language Learners, and the district has a mobility rate of $11 \%$. 
Three administrators from Grandview District agreed to participate in the face-toface interview for this study: Dr. Chievers (superintendent), Mrs. Marks (middle school principal), and Mrs. Red (elementary school principal).

Dr. Chievers. Dr. Chievers is superintendent of Grandview School District; he worked through the system and now finds himself at the helm. He has been an educator for 22 years. He started as a high school teacher and moved to administration. He entered the district as an assistant principal and progressed through the ranks, serving as a principal and an assistant to the superintendent. He served as an assistant superintendent for 6 years under the former superintendent. The district has been working on its PLC for more than 10 years. It was started under the former superintendent and continues under Dr. Chiever's leadership. This is his third year as superintendent.

Dr. Chievers' job includes capacity building. He was well prepared for capacity building, having served 6 years as the assistant superintendent of Human Resources. He was part of constructing the system for hiring in the district. He is continuously working on ensuring that the learning in the district is not only available to all but is used by all. He is constantly looking to ensure that he is building succession plans. The two building leaders from his district related respect for him and his work in the district.

The district has been on the PLC journey since 2002 and has implemented an early release schedule for PLC work. Once a week the staff meets during the early release to collaborate to improve student learning. The staff members work on many different activities through the year including assessment review, lesson study, and curriculum review. The plan is constructed the year before by the administrative team with staff input. The finalized plan is submitted to the school board and accepted as the blueprint 
for staff development work in the district.

Mrs. Marks. Mrs. Marks is the principal of Grandview Middle School. Grandview Middle School has an enrollment of just over 600 pupils in grades 7-8. Nineteen percent of the students at the school are considered low income. The performance of the school on Illinois School Achievement Testing (ISAT) has been above the state average for the last 4 years. The school has outperformed the district average for the last 4 years.

Mrs. Marks is responsible for running the building professional development and being a part of building the professional development plan at the district level. Mrs. Marks has been an administrator for 6 years. She spent 3 years as the assistant for the building before moving into the principal position for the last 3 years. Mrs. Marks was a special services teacher before becoming an administrator.

Mrs. Red. Mrs. Red is the principal of Grandview Elementary School and has held the position for 2 years. Grandview Elementary School has an enrollment of just over 400 pupils in grades K-6. Thirteen percent of the students at the school are considered low income. The performance of the school on Illinois School Achievement Testing (ISAT) had been $90 \%$ or higher until the state made some scoring adjustments in the last 2 years. The school has outperformed the scores of the district and the state. Mrs. Red is responsible for running the building professional development and being a part of building the professional development plan at the district level. She has been a principal for 10 years, spending those 10 years in three different buildings in the district. She spent a year in the district office as an assistant superintendent but returned to the building to strengthen the administration's team. 


\section{Huntington District}

Huntington is a K-8 school district in Lake County in a suburb of Chicago. The elementary school district has a little more than 3,100 students. The district covers 18 square miles and has a population of 23,683 . This district is composed of seven schools: one kindergarten center, four elementary schools, and two middle schools. In Huntington, $9 \%$ of the students in the district are low income. This district is $60 \%$ White, $27 \%$ Asian, $8 \%$ Hispanic, $1 \%$ Black, and $4 \%$ other. The district is $11 \%$ English Language Learners and has a mobility rate of $8 \%$. They are in year 16 of their PLC journey. Three administrators from Huntington District agreed to participate in the face-to-face interview for this study: Dr. Daly (superintendent), Mrs. Farmer (mmiddle school principal), and Mrs. Jackie (elementary school principal).

Dr. Daly. Dr. Daly is superintendent of Huntington School District; she was recruited from a neighboring district to strengthen curriculum in Huntington district. She was an associate principal and associate superintendent in a high school district prior to coming to Huntington district. This is her $26^{\text {th }}$ year in education, starting in special education and moving into administration. She wasn't planning to be a superintendent, but the district tapped her on the shoulder and she took the helm. This is her $6^{\text {th }}$ year as superintendent; she spent the 5 previous years in the role of assistant superintendent and has a total of 11 years in the district. The district has been working on the PLCs for more than 15 years and has been on the PLC journey since 2000.

Dr. Daly's job includes capacity building. She and the previous superintendent believe in the PLC concept. Their work didn't begin with culture changes; it began by defining behavior and letting culture change happen after behavior change was required. 
As superintendent, Dr. Daly is constantly working to ensure that learning in the district is not only available to all but is used by all. According to her staff members, she is constantly looking to ensure that she is building succession plans; the staff members call it the chess board. Her staff, although stable, is excellent and there are opportunities in other districts to take on new leadership roles as the district builds the capacity of its employees. She must be and is ready to fill the next opening with a person who has the capacity not only to do the job but to keep the learning going.

Mrs. Farmer. Mrs. Farmer is the principal of Huntington Middle School. Huntington Middle School has an enrollment of just over 500 pupils in grades 6-8. Five percent of the students at the school are considered low income (iirc, nd). The performance of the school on Illinois School Achievement Testing (ISAT) had been 90\% or higher until the state made some scoring adjustments in the last 2 years. The school has outperformed the scores of the district and the state.

Mrs. Farmer started her career as a special education teacher. She has teaching experience in both Chicago Public Schools and the suburbs. She is a 16-year educator who began her work as an administrator in 2010. Mrs. Farmer is responsible for running the building professional development and being a part of building the professional development plan at the district level. She has held the position for 6 years.

Mrs. Jackie. Mrs. Jackie is the Huntington Elementary School principal. Huntington Elementary School has an enrollment of just over 400 pupils in grades 1-5. Twenty-nine percent of the students at the school are considered low income (iirc, nd). The school has performed just under the scores of the district while surpassing the scores of the state. 
Mrs. Jackie began her career as an elementary school teacher. As principal, she is responsible for running the building's professional development and being a part of building the professional development plan at the district level. She has been an educator for 16 years. She is a certified elementary educator, English as a Second Language instructor, and a Spanish teacher. She has held the principalship position for 6 years prior to which she was an assistant in the district for a year. Table 3 shows a summary of student demographics for Grandview and Huntington School Districts, while Table 4 shows a summary of district teacher demographics as reported in the Interactive Illinois Report Card (IIRC).

Table 3

Grandview and Huntington District Student Demographics

\begin{tabular}{lccccccc}
\hline Type & Students & White & Black & Hispanic & Asian & $\begin{array}{c}\text { Other (2 or } \\
\text { more races) }\end{array}$ & $\begin{array}{c}\text { Low } \\
\text { Income }\end{array}$ \\
\hline $\begin{array}{l}\text { Grandview } \\
\text { District }\end{array}$ & 14,268 & $31 \%$ & $7 \%$ & $25 \%$ & $23 \%$ & $3 \%$ & $31 \%$ \\
$\begin{array}{l}\text { Grandview } \\
\text { Elementary }\end{array}$ & 407 & $42 \%$ & $1 \%$ & $9 \%$ & $31 \%$ & $17 \%$ & $13 \%$ \\
$\begin{array}{l}\text { Grandview } \\
\text { Middle School }\end{array}$ & 623 & $54 \%$ & $5 \%$ & $15 \%$ & $23 \%$ & $3 \%$ & $18 \%$ \\
$\begin{array}{l}\text { Huntington } \\
\text { District }\end{array}$ & 3,140 & $58 \%$ & $1 \%$ & $8 \%$ & $27 \%$ & $6 \%$ & $9 \%$ \\
$\begin{array}{l}\text { Huntington } \\
\text { Elementary }\end{array}$ & 404 & $47 \%$ & $3 \%$ & $20 \%$ & $23 \%$ & $7 \%$ & $29 \%$ \\
$\begin{array}{l}\text { Huntington } \\
\text { Middle School }\end{array}$ & 623 & $54 \%$ & $5 \%$ & $15 \%$ & $23 \%$ & $3 \%$ & $5 \%$ \\
\hline
\end{tabular}


Table 4

Grandview, Huntington and State Teacher Demographics

\begin{tabular}{lrllllll}
\hline Type & Teachers (FTE) & White & Black & Hispanic & Asian & Other & PARCC \\
\hline Grandview District & 1,050 & $85 \%$ & $1 \%$ & $6 \%$ & $4 \%$ & $4 \%$ & $62 \%$ \\
Huntington District & 241 & $95 \%$ & $1 \%$ & $2 \%$ & $0 \%$ & $2 \%$ & $72 \%$ \\
State & 129,668 & $83 \%$ & $6 \%$ & $6 \%$ & $1 \%$ & $4 \%$ & $33 \%$ \\
\hline
\end{tabular}

\section{Findings from the Study}

\section{Research Question 1}

How does the relationship between the district-level leadership and the buildinglevel leadership impact the implementation and sustainment of a successful professional learning community?

Three main themes were generated from the qualitative interview data from the school administrators from Grandview and Huntington School Districts: Characteristics of a Sustained PLC, Defined Autonomy, and Deprivatization of Practice.

Six characteristics of a sustained PLC. Both central office and building level administrators talked about various items related to the establishment of PLCs, work relationships, mission, vision, values, roles, trust, understanding, expectations and time. The subthemes or Characteristics of Sustained PLCs generated under this theme include: (a) shared mission, vision, values, and goals, (b) collaborative culture, (c) collective inquiry, (d) action orientation/experimentation, (e) commitment to continuous improvement, and (f) results orientation. The administrators from Grandview and Huntington School Districts used a common vocabulary when discussing their professional learning community. 
These characteristics become the pattern of shared assumptions learned by a district as it solves its problems. The districts in the study have used these characteristics to construct a sustainable level PLC. Both school systems began focusing on the six characteristics with their board, community, and administration. Collaboratively, they found a way to define and institute the six characteristics into their districts.

Mission vision, values, and goals. The first building block-mission/purposeanswers the question, Why do we exist? The second building block is vision. It answers the question, What do we hope to become? The third building block is values. It answers the question, How must we behave to make our shared vision a reality? The fourth and final building block is goals. It answers the question, what steps will we take first, and when? These four items together are the foundation of a professional learning community (DuFour, 2004).

In the Grandview district, parents, community members, board members, administration, and teachers were involved in creating the shared mission, vision, values and goals. Dr. Chievers related that, in the community meetings in 2006 and 2012, the board of education convened a collaborative committee. The committee was tasked to look over the needs and numbers of the district. Dr. Chievers stated, "The collaborative efforts of the committee and the board of education allowed the district to pave the way for successful implementation of the PLC model.” Mrs. Marks added,

...it's not one individual, it's not the superintendent saying this is my vision and you are going to adopt it, it's a group of administrators, board members, teachers that come together with students and parents that have input...it's a collective group of people. 
Once the mission, vision, values and goals were developed, they were followed by the district. Dr. Chievers believes that, "The mission, vision, and values document is the heart and soul of the Grandview district." It is the mission of Grandview School District to ensure student success. According to Ensuring Student Success (2015), "[the district is] supporting a culture of high expectations for both staff and students" (p. 1). Grandview School District demonstrates a commitment to the mission of "Ensuring Student Success" by supporting a culture of high expectations for both staff and students. Institute Day One (2015) states, “The goals are ensure students success by (1) getting to grade, (2) closing the [achievement] gap, and (3) performing in the top $10 \%$ nationally" (p. 9) Getting to grade is ensuring all students who have attended Grandview for at least one year will be at grade level in reading and math upon entering the third grade as measured by Measures of Academic Progress (MAP). Closing the gap is having each district school close the achievement gap for all students in reading and math as measured by both district and state assessments. Finally, top $10 \%$ is ensuring each school will perform at or above the ninetieth percentile nationally in meeting individual student growth targets in reading and math as measured by MAP. The district pledged to sustain and grow this culture to achieve their vision and goals. The vision is used to guide all that the district does from assessment to curriculum to instruction to student learning. Mrs. Red added, "the mission was built collaboratively...they looked at data and sent surveys out to gain input on the big areas. They worked together to build the mission document and the overarching statement of ensuring student success." A collaborative inclusive committee of school and community members built a blueprint of what they wanted their schools to be for their students. 
Huntington School District has completed a process similar to Grandview. Mrs. Farmer stated, "The visioning committee started in 2005 after a contentious election." The focus of this district begins with the vision, which is based upon the PLC language of DuFour and Eaker (1998). According to Dr. Daly, "A contentious board election in 2000 brought in a board that had a focus on moving together." The vision of the Huntington School District is to become the premier elementary school district in the nation. Mrs. Jackie stated, "a visioning committee included board members, community members, staff, etc., all the various stakeholder groups that created our vision mission values and goals." The committee was built by the prior board and superintendent. Dr. Daly said, "The committee built a vision that focused on the district becoming a premiere district in the nation." She added, “...it is a stretch goal that is a continually moving target." Dr. Daly focuses her energy on getting to the vision. She feels that the mission of most school districts is very similar if not the same. The difference is the vision-Huntington has a robust vision and they are focused on attaining it. The mission of the district is to ensure that every child achieves his or her maximum potential. Dr. Daly also stated,

We have to be careful working on the mission, it is the job of the district to get students to their maximum potential but it is not the job of the district to define the maximum potential of our students.

In Dr. Daly's opinion, "Values are the behaviors that we need to see on a regular basis to make progress towards the vision." The values for the district are as follows: model for others what we expect from others, every child, every school, every day; best practice, not first practice; learning has no boundaries; and celebrate success. If you ask where the vision, values, and goals come from, you will hear a standing joke from the district. Mrs. Jackie indicated that, "[goals are] refined and we joke, because people we'll 
say 'come October' and we're in October now, the staff will say who dreamed up these goals anyway, in a system where people are very much involved." According to What's Right about Huntington School District, "[a goal indicator is to] continue to enhance instructional practices across content areas through professional development and curricular implementations" (p. 21). Indicators and measures are used to monitor progress towards goals. Input and collaboration are not sought, they are required. Dr. Daly stated, "You can't talk people into beliefs, you have to ask them to try new behaviors and, as the behaviors become accepted, you see attitudes change."

The work on the vision, mission, and values was completed in 2005 and updated in 2010. Currently, the superintendent is preparing for the next update of the review of the vision, mission, values, and goals of the district. The process will include board of education, community, and district staff members. The district looks at the vision as the GPS of the district. According to Mrs. Farmer, "Top priorities are to live out the vision, mission, values; I would say to differentiate for all kids, use best practices with data to support what we do, to communicate, communicate and collaborate." The district believes that if they do not follow the behaviors suggested by the vision they will never get to their destination; they work daily to get to their destination.

Collaborative culture. The research has shown that "Good teaching matters... a lot" (Haycock, 1998, p. 11). According to Odden and Wallace (2003), improving teaching is "the prime factor to produce student achievement gains" (p. 64). The research on the quality of the teacher continues to state that it impacts the learning of our students, but it is not the individual quality (Newmann \& Wehlag 1995; Darling-Hammond, 2000). It is the quality of the collective staff working together that matters in a school. The 
districts in this study believe wholeheartedly in this practice. They all use a half day a week to work collaboratively to improve the quality of their professional skills. DuFour and Marzano (2011) state that the best strategy for improving adult strategy is “...developing the results-oriented collaborative culture of a strong PLC, a culture committed to building the collective capacity of the staff to fulfill the purpose and priorities of their...district" (p. 67). The districts in this study believe in this wholeheartedly. They have built and continue to work to sustain a collaborative culture that works together to ensure student academic success. They believe that the best way to improve the quality of staff members is to learn together. Both districts have designed systems of professional development that support collaborative cultures.

Grandview uses its early release days to meet with their teams' groups by grade and subject. Mrs. Marks stated, "It's our collective commitments and it crosses over many different areas, so then all of our buildings obviously follow through with them." While the teachers meet by grade and by subject, the administrators in the district lead discussions, and professional development. Mrs. Red added, "The success our students continue to experience is the result of Grandview's strong collaborative culture as defined in the commitments made by our students, families, community members, Board of Education and employees." The professional development has been designed and practiced with the assistance of district and building administration. The administration has also used input from their building leadership teams to decide what subjects to discuss and train upon. The use of the teams, discussion of the topics, and transparency of the process ensures that there are no surprises for the teachers and often the district is able to deliver instruction for professional development just as the district needs support. 
The March 2015 Board of Education report included the following statement: "Based on direction from the Board of Education, the superintendent and cabinet worked collaboratively with building administrators, teachers, and support staff to build consensus around the recommended district and building staffing plans" (p. 1). The district, with the support of building leadership, used its three goals to create a collaborative staffing plan for the district that supports student learning. The process involves everyone. Everyone at the district and building level willingly fulfills their roles.

The Huntington school district system for early release and professional development is designed to support the learning needs of the administration and teachers. The district has developed this process over the years. Mrs. Farmer stated,

As far as PD, we have the most extensive opportunities of districts I've ever seen and worked in. We have my learning plan, which is our kind of system that has so many classes all year, offered all summer, an incredible amount of writing, curriculum writing and assessment opportunities for teachers over the summer, and unreal amount of release time for our teachers that we are able to provide.

Providing the opportunities is one thing and getting people to take advantage of the opportunities is another. Dr. Daly explained that, "In the beginning it is a challenge to make collaborative meetings meaningful for everyone. Protocol and practices are needed to help everyone use the process successfully." The superintendent stated that the district takes collaboration to another level. It is a condition of employment. Dr. Daly added, "the district can teach employees how to teach the important aspects of helping students become successful but they cannot teach teachers how to become collaborative." She also said, "If a teacher cannot or will not collaborate they will not last at Huntington." Huntington uses what is called Job Alike Groups (JAGs) as their unit for discussion and 
professional development. These JAGs, as they are called, are made up of teams of people who share similar jobs. Mrs. Jackie explained that, "I participate in a principal job alike group, so all the elementary principals get together every other week, so twice monthly, where we make sure we're not leading in totally different directions." The discussions include curricular improvement, classroom expectations, interventions, and review of data. The district PD plan from the September 2015 meeting included the district's key concepts of a PLC: (a) focus on student learning, (b) collaborative culture, and (c) results orientation. These concepts work together to improve student achievement. This work is woven into the culture of the district - that is how things are done in the Huntington School District.

A collaborative culture is working in teams with a common purpose. According to Zepeda (1999), "Effectiveness in school leadership is characterized by an orientation toward continuous learning and tailored to the school's context" (p. 33). The two districts are all focused on learning and supporting that learning at the buildings. They have established successful job embedded staff development that includes adult learning concepts, trust, and time.

Collective inquiry. Administrators and teachers in a learning community relentlessly question the status quo and seek new methods of teaching and learning. The interviews left no doubt that the focus of the three districts is the improvement of student learning.

In the Grandview district, the administrators use data to describe the challenges and then seek solutions for those challenges. The administrators meet twice a month and discuss data about students, programs, and expectations. The meetings include data 
review. This data are the basic building block of the district's school improvement program. The challenges and solutions that are developed by the building leadership teams are brought to the district office with the data for discussion. Mrs. Farmer stated, "We have a lot of direct say in the professional development it's with our job-alike, which is typically twice a month." The administrators work together while the teachers work together. Dr. Chievers believes that, "One of my biggest challenges in a district this size is establishing consistency while allowing needed autonomy." The monthly discussions are collected and used to construct the school improvement plan. The gathering of data from individuals, groups, and buildings are a part of the communication plan that moves information from the top to the bottom and back again. In Mrs. Marks' opinion, 'It's all a task force of a variety of different people." In these meetings, the district uses data to describe their issues and determine plans to correct them. The team provides the superintendent with the data, discussions, plans and solutions for discussion with the board of education. The plan for school improvement is developed through collective inquiry.

The Huntington school district has several systems in place to assist with school improvement planning. Huntington uses the administrative meetings just as the first two districts do, but they also use their JAGs to help focus on challenges. According to Dr. Daly, "The administrative team meetings include all building principals and district administrators." They meet once a week for a half day to discuss issues and challenges of the district. Mrs. Jackie elaborated:

The cabinet gets together. We have admin council twice a month, which is the [superintendent, assistant superintendents, and directors] and all of the principals, and each principal group has their own meeting too, so middle school principals and assistant principals get together and elementary teams get together too. 
The discussions are systemic and the entire group is required to be involved. The JAGs allow the district's principals to work together, flush out issues, and suggest solutions and how to implement those solutions. Each of the building administrators works to solve problems together. The process of developing solutions for the many problems that each administrator faces helps reduce stress because it is not how we handle individual problems individually but how we collectively handle our collective problems. The administrators, teachers and employees in this district support each other.

Action orientation. Members of PLCs constantly use the knowledge gained by their experimentation or collective inquiry to actively improve student learning. It is a process; the learning of individuals becomes the learning of all. The teams work together to share knowledge and improve learning processes.

Grandview district has collected data since it began the process of becoming a PLC. Each year the administrative team reviews the yearly data and develops SMART Goals to improve student learning. The data are collected and reviewed monthly. The information is used to develop a school improvement plan. The plan is developed by the entire group of district administrators. Dr. Chievers stated, "We are only as successful in the district as my 28 principals are in leadership; you can't micromanage this place." The plan is then presented to the board of education. The board approves the plan and the cycle begins again.

The Huntington School District has a formal process for developing their school improvement plans. The district and the buildings work together to develop professional development plans, school improvement plans, and budget plans. Dr. Daly stated, "The district uses JAG, Professional Learning Teams (PLT), and the District Team to come to 
consensus on district school improvement plans." The process includes input from buildings with team leaders, from administration with all principals, and input from the central office from the cabinet. Mrs. Farmer added,

Starting with the superintendent, she has feedback sessions with the staff in April. She would come to the building and really hear what the staff has to say about district initiatives, our previous goals, previous work, kind of where we're heading.

The input from the team leader meetings, job-alike meetings, staff meetings, and administrative meetings are gathered to build the school improvement plan. The plan is built in what is called Chautauqua. Mrs. Farmer explained:

[Chautauqua] which is at the end of the year...is a representation of all seven buildings and district administration. So there's about seven people per building and on the district administration coming together for kind of a recap of the year... what's good about the work we've done, celebrating successes, and we have a lot of time to reflect on the feedback and kind of crafting the goals.

Once completed, the plan is presented to the board of education. Dr. Daly described the process. She also talked about the way that the process builds upon itself. In a PLC, the learning is shared and built upon in a yearly process. This process is action oriented to focus improving student learning.

Commitment to continuous improvement. DuFour and Eaker (2002) stated, "A persistent discomfort with the status quo and a constant search for a better way characterize the heart of a professional learning community" (p. 28). Once a district has stated its shared mission, vision, values, and goals, they are used to move a district forward. It must face, as DuFour, Eaker, and DuFour (2011) said, “...a constant search for a better way to achieve goals and accomplish the purpose of the organization are inherent in the PLC culture" (p. 17). In this study, it is evident that each district reviews 
data. As mentioned in the previous section, the districts review data to find opportunities for improvement. The information is shared and discussed district wide. The three districts designed their systems to support student learning.

Dr. Chievers, Grandview superintendent, and his team work together to develop processes that ensure continuous improvement. Their processes are data-based. Dr. Chievers gathers part of data through building walk-throughs. The other information is gathered from leadership teams and JAG. According to Mrs. Red,

I think a big way that [trust] is established is during our leadership meetings; it happens twice a month, we always have a reflection at the end. They [district leadership] really try to meet our needs with the reflection session at the very end, we discuss the meetings and future topics we need to discuss and how could we improve the meeting.

The process is designed to ensure that information flows from the top down and bottom up. The information is used to build the school improvement goals and processes. Mrs. Marks explained, "The superintendent and our cabinet members really are focusing on being clear with us, responding to us, communicating with us, being visible in our buildings and supporting our teachers, addressing the problems that come up." All are required to be a part of the process. No one is allowed to avoid the work.

Dr. Daly, superintendent of Huntington school district, uses her teams to analyze the impact of the changes of her school improvement plan. She explained, "The district uses about $2^{1} / 2$ hours a month to work on continuous improvement." She works to ensure that the team understands the change process. Mrs. Farmer stated, ...in order to build trust and honor the district mission, vision, values, the PLC, we're really focusing, now that this [the building] is a fabulous place, it's a celebration for me that we didn't need to focus on culture so we can move on to data/differentiation cycles. 
The process is sometimes messy but always necessary. According to Mrs. Jackie, "So it goes back to those administrative council and principal job alike meetings, that's where we are clarifying all the time what our goals are and what work we are doing is directly related to that, and then we have the flexibility as leaders in the building." The team ensures that the new knowledge is applied in the next cycle of school improvement. Dr. Daly recognizes that some of the district's success is due to the process of continuous improvement that the administrative team has continued and refined over the last 15 years.

Results orientation. All efforts of the six characteristics must be assessed on the basis of results rather than intentions. For years it has been the intention of communities to provide the opportunity for students to learn. In the new century, public schools were called on to deliver a new standard — one that was far away from opportunity — the standard of high levels of learning for all students (DuFour, Eaker, DuFour, \& Kanert, 2002). Each district in this study had focused on a results orientation.

The Grandview superintendent focused his school improvement goals on three things: (a) students who have attended Grandview for at least one year will be at grade level in reading and math upon entering third grade as measured by Measures of Academic Progress (MAP); (b) each school will close the achievement gap for all students in reading and math as measured by both district and state assessments; and finally, (c) each school will perform at or above the top $10 \%$ nationally in meeting individual student growth targets in reading and math as measured by MAP scores.

Mrs. Red, principal of Grandview Elementary School, worked with her teaching team to develop common assessments to ensure students met the challenge. Mrs. Marks, 
principal of Grandview Junior High School, worked with her teams to develop reading and math goals. The goals for reading were: fall to spring percent of students currently meeting or exceeds their individual growth targets of $71.5 \%$ for the whole building, $72 \%$ for seventh grade, and $71 \%$ for eighth grade.

Dr. Daly, superintendent of Huntington school district, focused on her school improvement goals: (a) maintain high levels of student growth, and (b) build capacity at all levels. The work that is done based on these two goals are action items determined by the buildings - the focus of understood loose tight relationships.

Defined autonomy. Any solution to sustainability must solve the centralizationdecentralization dilemma (Fullan, 2005). Each of the districts has district goals developed by a group comprised of the board of education, stakeholders, and administration. Defined autonomy is the 'what' the district gives the individual buildings so that the individual buildings can define the 'how.' Each building in each of the districts has the same 'what', but the 'how' is determined based on the needs of the individual building with the support of the district. It enables each building to deal with its individual students and the individual challenges of each of those students.

Dr. Chievers has established a system that defines the roles of the leaders in the district. The role of the leader is to be involved and assure that all others are involved. The previous example of how Grandview builds their school improvement program is based on the roles that have been established by the superintendent. The superintendent expects that everyone will be involved in the processes. He has set boundaries and expectations for building work. Those expectations are specific in that everyone is involved. Mrs. Marks explained, "The system is a great support; it provides guidelines for 
our work." The superintendent expects everyone to be a part of the process and they are. Mrs. Farmer added,

...we will meet and, you know, just go over items. We do like to keep the two middle schools very closely aligned. So if there's extra resources, we want to consider the other middle school... We want us to just have the same opportunities.

Everyone is involved and everyone works to move the district toward their vision while meeting the goals that the district has established. Everyone has a role and they all fulfill their roles. The special understanding about district goals is that the district, everyone, is involved in creating and reaching the goals.

Dr. Daly's JAGs are central to the system that defines the roles of employees in the district. The role of employees is to work together to meet the mission of the district. According to Dr. Daly, “...when it comes to establishing the district-level goals, there's really very little distinction between district-level leadership and building-level leadership participation. We participate in that process through our district administrative team." In the previous discussion, it was mentioned that collaboration is not just something that is done in Huntington school district; it is a job requirement. The work in the district is done in collaboration. Mrs. Farmer explained,

There are a great deal of tights that go along with the initiatives and the principals are the ones who are implementing that in the buildings through our coaches, through our team leaders, through leaders, trainers in the building, a lot-but a lot of tights, so our district has the same expectations of different schools.

Tights are district requirements; the loose is how the building decides to do the work. In Mrs. Jackie's opinion, the district is ...definitely more flexible than tight, but we do have a series of loose and tights. For example, we're committed to embedding collaborative team time into the school day. So it is an expectation when I design the special schedule, which then 
allows teachers to have that common time to meet. It's an expectation that I create the schedule to the best of my ability so that I can maximize team time to meet.

The district decides what is important, and the building level decides how the task is completed. Everyone is involved and everyone works to move the district toward its vision while meeting the goals that the district has established. The special understanding about district goals is that the district, everyone, is involved in creating and reaching the goals.

Deprivatization of practice. The three districts in the study are all working on the deprivatization of professional practice. The work of the district and building is done in collaborative fashion. Teams of teachers work together at least weekly on issues, data, and concerns. The school districts stop the important work of teaching for a half a day a week to work together. In order to do this required work, the buildings and the district have to be safe places for discussion and professional conflict. The participants do not describe this as a cookie cutter set up for standardization; it is an opportunity to work with others to solve classroom issues with the actual learners with the actual data.

In the Grandview school district, Mrs. Marks and Mrs. Red ensure that deprivatization of practice happens and learning is the result of the work. The work of creating professional development plans for the building is the role of the principal. The principals do not do it alone, but it is their role. Mrs. Marks explained, "It's our collective commitments and it crosses over many different areas, so then all of our buildings obviously follow through with what we have agreed to do." The principals bring the information concerns they receive from their buildings to the district office. The concerns are worked on collaboratively and solutions are sent back to the buildings. 
The superintendent is usually aware of many of the challenges because of his building walk-throughs. Mrs. Marks added, “...you have to believe in the PLC model to be successful." They know and trust each other, those above them and the system. Teachers are comfortable talking to Dr. Chievers, and he expects the discussion. Dr. Chievers stated, "It's important to establish solid professional relationships with the students and staff and the parents. I think that the active involvement of all of those individuals or those groups is critical to the functioning of the school." He works to ensure that everyone is involved and informed. The district is so informed that the standard joke is that no one knows what's going on- everyone does. Dr. Chievers believes that, "It's relational type communication, you know, purpose in what we do, you know, transparency, openness with parents and dialogue and open-problem solving when stuff goes wrong and if there's stuff to discuss." The information that is brought to the meeting is reviewed, and together the principals build, practice, and refine professional development plans for their schools. The structural and instructional priorities document for Grandview school district reads: "Grade level common planning allows for equity when planning and true collaboration on content."

In the Huntington school district, Mrs. Farmer and Mrs. Jackie also ensure deprivatization of practice happens and learning is the result of the work. In Huntington, like Grandview, the work of creating professional development plans for the building is the role of the principal. The system that the two districts have to ensure for deprivitization of practice is very similar. The Huntington School district board of education approved goals include "continue to enhance instructional practices across content areas through professional development and curricular implementations." These 
goals are the focus of professional development for the district. Dr. Daly also completes walk-throughs. Farmer and Jackie also bring the information, concerns, and needs to the district office that they receive from their buildings. The information brought to the meeting is reviewed, and together the principals build, practice, and refine professional development plans for their schools in their JAGs.

\section{Research Question 2}

What district-level and building-level leadership practices within professional learning communities ensure the establishment of a culture of improved student achievement?

From the semi-structured interviews and artifact data, two main themes were perpetuated in the data that focused on research question two: accountability, and capacity building. Research question two is focused around how things are done in the district to ensure continuous improvement. It is organized in order from curriculum, to people, and finally to culture. In this instance, as in research question one, the Grandview and Huntington School Districts used a common vocabulary when discussing their curriculum and capacity building.

Accountability. "The glaring absence of true accountability in education can be traced right back to the moment of our hiring. Educators rarely have real job descriptions ...It [the job description] does not detail what I am responsible for causing" (Wiggins, 2010, p. 7). In many instances, educators do not know what they were hired to do. In sustaining level PLCs, educators know what they are responsible for doing. Accountability in PLCs is based on continuous improvement of the curriculum, which is based on four questions that drive the curricular work of the community: 
1. Exactly what is it we want all children to learn?

2. How will we know when each student has learned it?

3. What happens when students don't learn?

4. How do we respond when students already know it?

These questions are central to learning and to the design of PLCs. Marzano (2003) identified five items necessary for impacting student achievement. The factor that has the biggest impact on student achievement is a Guaranteed and Viable Curriculum. The four questions help a district develop a Guaranteed and Viable Curriculum at all levels. It is the essential school curriculum, how it will be assessed and how students will receive intervention, and finally, how students will be accelerated? Togneri and Anderson (2003) state, "Structures such as system-wide curricula and a multi-measure accountability system provide a path for improvement and signal expected outcomes" (p. 11). As previously stated, the four questions are about curricular improvement. They define the expectations for students, the manner of measurement, plans for correction of students that aren't meeting expectations, and enrichment for students that are exceeding expectations. They are the foundation for accountability.

Dr. Chievers explained Grandview's induction program: “All our new hires spend a week in our induction program; the program teaches them the basics of Professional Learning Communities.” According to Mrs. Red, the objectives of Grandview's Induction Week are as follows: (a) build shared knowledge of core PLC components, practices, and beliefs, (b) provide research, support and practical applications of the PLC framework as it is implemented in Grandview, and (c) provide time for reflection on the PLC concepts presented. The district also presents its core commitment: All children can 
and will learn. Dr. Chievers stated, "During the Induction Week, all teachers are taught essential learning outcomes.” Mrs. Marks elaborated on the induction process: “... (the new hires are) buried there in their building for about a month and a half and they've already been part of the PLCs. So it's like they know all of the information because that's just kind of how our buildings have been functioning." After the work in the buildings, they are sent to induction week. Mrs. Marks added,

We have a whole week for new teachers before the school year starts and Dr. Chievers, Human Resources, and the cabinet members go through the nuts and bolts of PLCs, what our expectations are for them and what does it look like for them to be on a team.

Mrs. Red stated, “...looking at what central outcomes we are targeting, how we are going to be presenting those lessons to kids, how kids are broken up into more homogeneous groupings to meet their needs..." The learning outcomes are the core skills, concepts, and enduring understandings that all children must master before exiting a given grade level or course.

Grandview School District included the four questions in their school improvement and professional development plans. Induction Week included professional development on Common Formative Assessments (CFAs). Dr. Chievers clarified,

CFAs defined are ongoing assessments administered to all students in a grade level/course to determine student mastery of essential learning outcomes and inform instructional practice. The four questions helped each grade level and course build CFAs.

Once the CFAs are built, the teams can continue to review the data to see if the teaching is successful, assessing their work. According to Mrs. Red,

We look at the essential outcomes and we'll take the kids that have challenges and really dig deeper into some of those common core self-thinking, critical thinking, exchanges and all the way down to the kids that are struggling a little bit, that we 
need to get more direct instruction around that standard to get them to really start to understand it and then eventually apply it.

Wiggins (2010) explained, “A teacher in a school has three results-focused responsibilities: (a) cause successful learning..., (b) cause greater interest in learning than there was before..., and (c) cause greater confidence.... and intellectual direction of learners" (p. 11). The questions are used not only to check progress but also to identify learners who need intervention when their individual achievement is not meeting expectations. The districts use the questions to define expectations and check accountability of the system, the curriculum, school, and the teacher.

Huntington School District also has an induction program for its new teachers. The program is designed to teach the new teachers the basics of PLCs before they begin their work in the district. Huntington has embedded the training a little deeper. Dr. Daly elaborated: "Our district allows other districts to come in and visit our PLC. Each building hosts other schools and the staff takes them through the PLC process.” Mrs. Jackie said, "This is another way we deepen the learning, because not only do you have to know the process, but you have to explain it. Each grade level is part of facilitating the visits." In Huntington, the district has induction training, puts their staff members to work in the PLC process, and then has them explain the process to others during the monthly visits. Mrs. Jackie believes that "Behaviors precede beliefs — we are engaged in the work long before we realize the change in understanding and culture.” In Mrs. Farmer's opinion, "Modeling for others is what we expect-model for others what we expect from others, every child, every school, every day. Best practice, not first practice." 
Huntington School District includes the four questions in their school improvement and professional development plans. Mrs. Farmer stated that, “... [District] non-negotiable would be the four questions that drive everything we do. They're brought up in one-on-one coaching and planning for lessons; they are brought up for problem solving." In the interviews, the participants from the Huntington District refer and discuss the questions. Mrs. Jackie believes, "There is a lot of reflection and dialogue going on this this district." Mrs. Jackie went on to explain the process of reflection, which includes visits from the superintendent, discussions with the building leadership team and discussions with the cabinet. It was easy to see that they are well-established practices for the districts. The questions are used not only to intervene when individual students are having issues, but also to discover issues with the curriculum. In Mrs. Farmer's words, "We live the three critical concepts and the four questions; they are our biggest commitment." The districts use the questions to define expectations and, while they discuss the expectations, they discuss how to meet those expectations in common language. Mrs. Farmer added, "[District] non-negotiables would also be extending ourselves to provide what the students need. We really use every resource we can and build capacity before we look outside, whether it'd be student behavior, special programming, functional versus academic." That commitment is accountability for the staff and students of Huntington school district.

Capacity building. Developing professional learning communities seems to have considerable promise for capacity building for sustainable improvement (Stoll, Bolham, McMahon, Wallace, \& Thomas, 2006). The concept of PLCs is built on capacity building. The expectation for the staff of a PLC is that they are continuously learning to 
ensure students are academically successful. The learning is the capacity building for the system. Capacity building in the classroom is only a part of the requirement. Capacity building in leadership is a large part of the job. The district office staff in a PLC need to be capacity builders (Schlechty, 2009). Perconti explained that, “...central office administrators are charged with building capacity to focus on student learning in all aspects of the organization. Enabling and supporting rather than controlling...” (p. 30)

Employees resign, retire, and are terminated. Institutional knowledge must be kept in the organization and shared if organizations are to be sustained. In successful districts, leadership at the school and district levels is identified as crucial to success (Fullan, 2005). Grandview and Huntington school districts have succession plans for both building and district administration. Mr. Marshall admitted, "The district does not have any succession plans." Replacing leaders is a significant challenge for all districts, but most organizations do not plan for them (Hargreaves \& Fink, 2005).

The administrators in Grandview call the succession plan the chess board. Dr. Chievers was the assistant superintendent for human resources before becoming the superintendent. He worked with the board of education to fill the needs of the district and is constantly working with the board and administration to plan for the future needs of the district. According to Dr. Chievers, "For the stability of a PLC, you have to have the right people in the right spots." Dr. Chievers meets and discusses career progression with all of his administrators. Mrs. Marks stated,

... depending on where people are in their lives and turnover, people move, but there have been constant people within the cabinet and the buildings that are in leadership positions. So I guess it doesn't really matter what position they're in; they are stable people and people that we know that we can go to, no matter if they're in charge of instruction. 
Mrs. Red explained, "[succession plans add]... more stability in this district. I think we have —we all have goals that—we have a plan...we have a district plan...” Dr. Chievers did not admit to having a chessboard, but he did discuss how he planned for the future of the district: "In preparing for the position I did present to the board plans for filling open positions at that time and for the future."

Planning for district and building administration stability is only one part of capacity building. In fact, the previous discussion on induction is also a part of the capacity building system for Grandview School District. Grandview also uses its weekly collaboration meetings to build the capacity of its employees. The employees work in groups to create knowledge that is shared. The learning or capacity is used to create systems that help the district meet its identified goals.

Dr. Daly and her administrators have built an induction plan for their capacity building program. According to Dr. Daly, "Capacity building is central to the job of educating her students. Building capacity ensures the stability of the system." Each new teacher in Huntington is instructed in the PLC process during the district onboarding process.

Dr. Daly is also rumored to have a plan for administrative succession. Mrs. Jackie explained, "We have career discussions with Dr. Daly; we discuss plans for our careers and our expectations for the future.” These discussions help Dr. Daly keep her chess board up to date and address needs of the staff. Dr. Daly responded by saying, My staff is young and I have to coax them a bit in discussions because, if a person is not leaving, the person would find it hard to say that I want to be the assistant superintendent for curriculum, but we do discuss their goals for the future. 
The relationship Dr. Daly has built with her leaders helps her to move to topics about succession that are not always comfortable. Mrs. Jackie elaborated,

I might have a goal conference with Dr. Daly and we might be talking about my career path and thinking about potentially other people in the building that could do my job because I'm not going to be here forever... for plans and naturally nothings ever a guarantee or a plan, but I think it is a constant conversation, what's happening with the chessboard, so to speak.

Huntington School district also has goals for capacity building. These goals are designed to help the district reach for continuous improvement. Dr. Daly finds ways to help her leaders stretch themselves in their positions to reach to the future while ensuring that they identify the next person with the capacity to step up in leadership.

Huntington has a school district goal to build capacity at all levels. The Board of Education Approved Goals (2015) include:

(1) enhanced district learning environments to support deep levels of learning and high levels of engagement; (2) build system capacity to fully implement the Performance Evaluation Reform Act; (3) continue to enhance parent/community engagement; and continue to deepen communication across the organization. (p. 1)

These goals are designed to create continuous improvement by reaching for deep learning and engagement, improving feedback through evaluation, engaging parents, and communicating across the organization. The capacity building goal states, “...the District will focus on continuing to build capacity and engagement levels across the organization."

\section{Research Question 3}

How does relational trust impact district-level and building-level leadership practices within professional learning communities?

From the research interviews, a main theme focused on research question three: relational trust. Participants talked about relational trust without specifically saying it. 
According to Cranston (2011), "The existence of relational trust appears to have the effect of fostering collaboration and promoting willingness among staff to grow professionally" (p. 59). Relational trust is composed of social respect, personal regard, competence in core responsibilities, and personal integrity (Bryk, 2003).

Social respect. According to Bryk and Schneider (2003), "Respectful exchanges are marked by genuinely listening to what each person has to say and by taking these views into account in subsequent actions" (p. 42). The relationships in all three districts between the district leaders and the building leaders were all marked by respectful interactions. These relationships were more than respect for position; they included respect for individuals and their work. Social respect also includes how we treat people across the learning community (Bryk \& Schneider, 2003). In the school districts in this study, the participants treated each other with social respect by listening, learning, and taking into account the thoughts and feelings of each other, even if they didn't agree.

An example of social respect in Grandview School district is the time that it took to set up interviews. I worked for over 2 months to get interview times with the leadership team. Superintendent Chievers would not allow interviews until he knew that the team had their buildings running properly. The comfort of his team was very important. He respected the individuals, work, and needs of his team. He was happy to be involved in research on PLCs, but the research came after the job of educating his team, staff, students, and parents.

In the interviews, the respect of the principals for their leader was evident in how they spoke about him and his work. They were comfortable talking to the superintendent, but they did not refer to him by his first name. It was a respectful interchange. Mrs. 
Marks and Mrs. Red agreed that their leader respected them and their work. Mrs. Red gave an example of how Superintendent Chievers comes to the building and talks and listens to everyone. He brings the information that he receives back to the administrative team to triangulate the information brought to the team by building leadership teams. Mrs. Red explained that everyone knows the superintendent listens and that he will require everyone to participate. Both principals talked of how Dr. Chievers ensures that everyone is involved in the professional learning community model. Both principals explained how the superintendent over-communicates his message and requires participation in discussion.

The superintendent talked about his principals with respect of them as individuals and professionals. He feels it is his job to ensure that his employees are successful. He has a schedule of building visits. Dr. Chievers believes that, "You can't micromanage this job; you have to trust your people and hold them accountable." He goes often but he always stops in the office and lets them know he is in the building. He may or may not have a conversation with the principals due to the state of business in the office. He talks to teachers, support staff, and students during his visits. His visits are frequent enough that staff members are not surprised to see him. Mrs. Red said, "He [Dr. Chievers] talks to everyone and his conversations are always collecting data." Everyone sees him, his actions, and his work; his respect of others is shared district wide.

In Huntington School District, Dr. Daly shows the same type of respect for her employees and their work. Before she would allow me to interview her team, she interviewed me and reviewed my topic. In Dr. Daly’s opinion, “...trust was established through goal alignment and communication.” Dr. Daly has high expectations for her team 
and she makes sure that she protects their time so that they can meet her expectations. It is evident that she respects her staff's work, thoughts, and time. Her staff has the same type of respect for her. They listen to her and work to meet her expectations.

Mrs. Farmer and Mrs. Jackie both respect and care for Dr. Daly. It was evident in the respectful interactions that were observed between them. The interactions between Dr. Daly and other employees had the same type of feeling. Dr. Daly and I met at Huntington Middle School to complete her interview. I was around the corner in another room when she entered the building, but you could hear the excitement and respect when she came into the school from both the secretary, who she spent time talking to, and the new assistant principal. Neither conversation was one sided-you could tell by her answers to their questions that Dr. Daly was intently listening to them. Mrs. Farmer described the way that Dr. Daly established trust just as Bryk and Schneider (2003) noted, ... in the daily work and interactions among her employees. Mrs. Farmer described the work that Dr. Daly does with her and her staff: "She works with them individually and collectively to ensure team success."

Personal regard. Employees show personal regard by going beyond the requirements of a job description or union contract (Bryk \& Schneider, 2003). There were examples of going beyond expectations in the interviews and the expectations of the districts. The PLC model of school improvement is not the norm for American Schools (Huffmann \& Hipp, 2003). Many of the requirements in PLCs call for high personal regard. Personal regard is also described as the willingness to do what it takes to help the organization be successful (Bryk \& Schneider, 2003). The leaders in these districts seem to be working for high personal regard. 
Dr. Chievers stated, "We have a high rate of retention for employees; we only seem to lose those young families that stay home after having a child." Grandview School District has high personal regard. It wasn’t always that way. In Dr. Chievers' words, "The last 2 years of the previous superintendent were very rough. Many battles were waged between the union and the superintendent. In the end, cooler heads prevailed and better relationships were formed." Most of what is being done in the school district is not in the union contract or in the job descriptions of the district, but it has become the norm. Everyone is involved in the PLCs, working weekly in collaboration with colleagues. The superintendent is out and about the district talking to all about their jobs, the students, and the curriculum. Dr. Chievers credits some of the calm to his transparent communication and communication norms. Both Mrs. Marks and Mrs. Red agreed that the principals are building professional development in collaboration with their colleagues, practicing and perfecting presentations, and holding their staff members accountable for the results that are agreed upon. Personal regard in this district comes from all points and together they are completing expectations.

Huntington School District has much the same going on in a little different culture. The superintendent walkthroughs are completed in the same way. The superintendent has a schedule and talks to her employees. The principals work together to develop professional development. In the last 2 years the district has worked on culture in its buildings. Mrs. Jackie stated, "I am very proud of the culture that we have built; Anthony Muhammad would be impressed." The principals also ensure that the teachers are involved in the process of building professional development for the staff. In the Huntington district, the PLC process is presented, taught, and assessed by teachers. 
The sharing of the work and the excellent climate have given the district stability. Mrs. Jackie added,

I have lived downtown for years, others in the district live there also; it's an hour into work and often 2 hours back, but this is such a good place to work I don't think any of us have considered leaving the district.

As previously stated, Huntington has monthly presentations for other districts, and those presentations are completed by teachers. Principals and others ask the staff at Huntington the secret of their success and how they can take it back to their districts. The Huntington staff discusses their processes and the work it takes to complete the process. Dr. Daly stated, "The favorite question is - what can we take back from here that is relatively inexpensive and easy." He added, "The work is not expensive, but there isn't anything that goes with the PLC model that is easy." If a district is looking for a inexpensive quick fix, Huntington doesn't have one. This work is done with personal regard by all employees.

Competence in core responsibilities. To demonstrate competence in core responsibilities, one must understand and have the ability to complete the job (Bryk \& Schneider, 2003). The employees of the two districts who were interviewed for this study were all competent enough to demonstrate understanding of the PLC process. Their colleagues all trusted them. In a word, it seems that everyone had the ability to meet the expectation of competence.

Grandview's administrative team exuded confidence in the understanding of the PLC process. Both Mrs. Marks and Mrs. Red stated that their staffs had high levels of knowledge of the PLC process. It has become not only a part of the district but a part of the district's culture. From superintendent to principals, they openly agreed, "That is how 
things are done around here." The understanding is built from the point that everyone begins to work in the district. In Grandview it is Induction Week, but it doesn't stop there; it continues with the weekly collaborative work with teams, the weekly leadership team meetings for examining data, and the superintendent's walkthroughs. The process that Dr. Chievers and Grandview have created ensures that everyone is involved. The principals believe that working on the process educates everyone.

Huntington has taken the process to a higher state, as previously mentioned. Dr. Daly stated that, "Collaboration is a job requirement." Her expectation for all staff members starts with collaboration. She and her staff members feel that they can teach new employees everything except the willingness to collaborate. An example of this was the student conference before my interview with Mrs. Jackie. Huntington Elementary had a fourth grade student who was performing at the eighth grade level in mathematics. Mrs. Jackie called a conference with the parents and the staff members. Mrs. Jackie explained that, "We had to collaborate and develop a plan for the student's learning. It had to be built for the success of the student." The parents would have been happy to send the student to the middle school for one period a day but, according to Mrs. Jackie, that would not have served the student well. The collaborative group found a solution that supported the student's needs without changing his placement. No job in the district is done alone. The board of education works with the superintendent; the superintendent works with her administrators; the administrators work with the teachers; the teachers work with students and parents.

Personal integrity. According to Bryk and Schneider (2003), "Integrity... demands that a moral-ethical perspective guides one's work" (p. 42). The belief about 
integrity of people moves along to trust (Bryk \& Schneider, 2003). Personal integrity is the fourth part of the concept of relational trust.

The mission of the Grandview School District is to ensure student success. This is the moral and ethical guide of the work in the district, which works daily to accomplish the mission. The vision is to have their students be in the top $10 \%$ of school districts nationwide. The district has set up a system to trust each other to put the interests of the students first. Dr. Chievers stated, "I think it really does start with the development of strong collaborative administrative team that is built upon trust and communication that it contains.” The building administration trusts Dr. Chievers. They have a strong, trustworthy relationship. Mrs. Red believes, "It's more on a personal level versus a big meeting level...really unique to establishing in that trust. We can ask any questions we need request specific supports.”

Huntington School district has a similar mantra. Its mission is to ensure student success. Mrs. Farmer stated,

I think it was just the time that we spent meeting and the time that the superintendent and our other district assistant superintendents and directors spend making sure you are comfortable and good with all those initiatives and everything. I mean, really like laying the background and the why and making us feel comfortable, always lending a hand and supporting us.

This is the moral and ethical guide of the work in the district. The building-level and district-level leadership work together to support each other in getting the work done. Mrs. Jackie believes that "What works really well in terms of trust is when we're all rolling up our sleeves and working together on an equal playing field." The vision is to have their students be in the top $10 \%$ of school districts nationwide, and they work daily to accomplish that mission. 


\section{Summary}

\section{Research Question 1 Findings}

Districts with professional learning communities at the sustaining level have to be systemic and have to establish the six characteristics of PLCs as indicated by the data gathered from the central office and building leadership from the two districts that participated in this study. In the two districts, the relationships between the district-level leadership and building-level leadership are central to the impact and implementation and sustainment of the PLCs. The relationships between the building-level leaders and the central office leaders in Grandview and Huntington School Districts drive the district and are respectful and cordial. In Grandview as well as Huntington, trust is well established. When asked how was trust established, Mrs. Marks stated that Dr. Chievers was everywhere and authentic. He visits the buildings, communicates with staff, and genuinely wants input from everyone. Mrs. Jackie talked about Dr. Daly in the same manner. The people in the position have established trust not only personally but trust in the system and their position. Dr. Chievers stated that he trusts all his principals. He established that trust by working with them side-by-side and individually to assist with their challenges not only in their buildings but in their careers. The relationships in this district between district-level and building-level leadership allow them to ensure that organizational knowledge and information travels to all. The organization is better for it.

The relationships between the district-level and building-level leaderships are well defined in in these sustaining level PLCs. In viewing the districts through the six characteristics, defined autonomy, and deprivatization of practice, it is easy to see the commonalities across the districts. In Grandview and Huntington, the details of the 
relationship and the expectations are developed. The practices include what information will be used for, as in creating the school improvement plan in Grandview and in the Huntington School District. The work is focused on improving student achievement and supporting teachers to enable that improvement.

\section{Research Question 2 Findings}

The systems or practices that are present define the work of the district. Systems at district level and building level are well defined in both districts. Viewing the districts through accountability and capacity building, differences are evident between districts that are sustaining and districts that are implementing. The yearly practice of a school improvement plan development in both Grandview and Huntington school districts focus on data — data from students' learning, data from teachers, and data from administration. The data are used to develop direction and expectations. Once the data are collected and expectations set, the entire staff of the district holds each other accountable according to their roles. As the data are reviewed, the district defines needs and builds the capacity within the district to meet those needs. The districts not only support their teachers, they support their students and district systemically with data that are purposely collected for the process of improving student achievement.

\section{Research Question 3 Findings}

It is evident that relational trust impacts district-level and building-level leadership practices within professional learning communities in the Grandview and Huntington School districts. Both districts have social respect, personal regard, competence in core responsibilities and personal integrity, and those factors guide and improve the relationships between the district and building leadership practices in their PLCs. 


\section{CHAPTER V}

\section{ANALYSIS, FINDINGS, IMPLICATIONS, AND RECOMMENDATIONS}

\section{Introduction}

Chapter $\mathrm{V}$ presents a review of the findings obtained in the study. This chapter is divided into six sections. Section one provides an overview of the study. The second section is the summary of results. Section three provides an overview of the conclusions drawn from the results. Section four reviews the implications for practice and the analysis of the results. Section five outlines the limitations revealed throughout the course of the study. Section six makes recommendations for future studies and implications for future practice.

\section{Overview of the Study}

As stated in Chapter I, research on the role of the school district in school improvement is thin (Firestone, 2009). For this research project, the purpose was describing and discovering the role of relationships between the central office and the building in school district improvement. This research-based project was an attempt to determine how the relationship between district and building leadership affects school improvement as measured by student achievement. In this study, the focus was on school districts that are PLCs at the sustaining stage.

Districts develop distinctive cultures that determine how innovations are implemented. Most districts have a loosely coupled culture in which the district has relatively little influence on school practice (Firestone, 2009). Professional learning 
communities within schools, within districts and district wide PLCs are important because they can reduce intra-school variation (Fullan, 2003). Reform efforts have been fragmented, disjointed, and incoherent with the addition of each new innovation or reform (Fullan, 1996). Sustaining stage district-wide PLCs offer continuous improvement to districts through learning at every level from administration to teacher to student.

The purpose of this study was to explore how district and building leaders work together to affect school improvement in a professional learning community. In this study, school improvement was defined as the purposeful interaction, communication, and connection between school personnel directly related to accomplishing teaching and learning objectives. A professional learning community may be limited to a team of teachers or be as large as a school or district. The sample in this study was districts that had implemented PLCs in the entire district. Understanding the working relationships between the district and building administrators in the PLCs and how the relationships led to school improvement was sought. Insight into how the relationships guided, impeded, or accentuated school improvement successes, failures, challenges, and rewards was explored through this study, and each finding added to the research on PLCs.

The participants in the study were administrators at the district or school level. The districts represented were identified through a three-phase process. In Phase I of the study, the researcher selected elementary school districts with multiple buildings in four counties in northeastern Illinois, because more than $50 \%$ of the state's elementary school districts are located in the four northeastern counties of Cook, DuPage, Lake, and Will (iirc.com). Information from the Illinois Interactive Report Card (IIRC) system was used to identify 134 school districts as multiple building elementary districts. A total of 134 
central office and 782 building level administrators were identified to participate in Phase II of the study.

In Phase II of the study, a survey was administrated to the administrators identified in Phase I of the study to determine the stage of the PLC of the district. Of those identified, 13 central office administrators and 24 building level administrators responded to the survey, a response rate of $9.7 \%$ for central office administrators and $3.1 \%$ for the building administrators, respectively. The 37 respondents included 12 administrators from the same district. Not every district had both a principal and superintendent to complete the survey. The researcher used DuFour's PLCC to sort the multiple building elementary school districts, represented by one or two administrators, into four categories: pre-initiation stage, initiation stage, developing stage, and sustaining stage PLCs. According to the PLCC, this study included 4 pre-initiation stage districts, 6 initiation stage districts, 15 developing stage districts, and 5 sustaining stage districts.

In Phase III of the study, the five districts that were identified as being in the sustaining stage were contacted. Of the five districts, administrators from three (3 central office administrators and 5 building level administrators) agreed to participate in Phase III to examine the relationship of district office and building leaders. I made initial contact by email and sent electronic correspondence to the individual administrators in the districts after gaining permission of the superintendent to set up interviews for the study. Further analysis showed that one of the districts was not a sustaining level PLC, so that district was dropped from the study. This left the study with six administrators, two central office, and four building-level leaders. 
The study began with a general interest in school improvement systems and how they work. Researchers found that district support was necessary for successful school improvement (Rosenholtz, 1989; Ragland, Clubine, Constable, \& Smith, 2002; Snipes, Doolittle, \& Herlihy, 2002; Togneri \& Anderson, 2003; Sappington, Pacha, Baker, Gardner, 2012). As such, this study focused on the relationship of the district and building leaders in sustaining stage PLCs. The qualitative design allowed for rich description of the relationships between central office and building leaders, as seen through the eyes of those leaders.

\section{Summary of Results}

\section{Research Question 1}

How does the relationship between the district-level leadership and the buildinglevel leadership impact the implementation and sustainment of a successful professional learning community?

Leaders in both districts described the relationship between the two levels as trustworthy. The central office leaders and the building leaders in sustaining stage PLCs trust and communicate with each other with ease. The districts have defined expectations through the use of defined autonomy. The role of the central office leaders is to define the goal or "the What" that the district is going to do to improve student achievement. The sustaining stage district PLCs defined "the What" through collaboration with all employees in their districts. The role of the building level leaders is to define the means or "the How" of attaining "the What" that was defined by the district level PLCs. I use the terms of "the What" and "the How" because both sustaining stage districts use these PLC terms. "The What" is taken by the building level leaders to their staff to determine 
the actions necessary to achieve the established goal of the PLC. For instance, according to Mrs. Farmer, 'the district-wide is 'the What' and the building-wide priorities sometimes are considered 'the How." Mrs. Marks stated,

Looking at what central outcomes are targeting, how we are going to be presenting those lessons to kids, how kids are broken up into more homogeneous groupings to meet their needs and we take that - we look at the essential outcome and we'll take the kids that have really method and really dig deeper into some of those common core self-thinking, critical thinking, exchanges....

These are quick examples of "the What" and "the How" used by administrators.

The sustaining stage PLC districts have systems of communication and input that includes everyone in the district. It is described as transparent communication. The districts require that everyone be involved and collaborate. It has become more than a job duty; it has become the culture. It is the way things are done (DuFour \& Eaker, 1998).

Collaboration requires communication. Everyone communicates and knowledge is created. The knowledge of the district is increased by the collaborative work of the entire district. The information that the district finds in collaboration is shared district wide. This makes the knowledge available for use by all employees in the system. The district's organizational memory, shared knowledge base, and information distribution and interpretation all benefit from PLCs. PLCs are a process for continuous improvement used by the leadership of the sustaining level PLCs.

The relationship between district and building level leadership is a large part of becoming a sustaining stage PLC, as was evident in the sustaining level PLCs in this study. In these districts, the two levels of leadership work together to ensure the work of the PLC is completed. The relationship between the district-level leadership and the building-level leadership impacts the implementation and sustainment of successful PLCs 
with their trust, communication, and collaboration. The sustaining stage districts' PLCs in this study had established trust, communication, and collaboration.

\section{Research Question 2}

What district-level and building-level leadership practices within professional learning communities ensure the establishment of a culture of improved student achievement?

The first practice that ensures the establishment of a culture of improved student achievement is defined autonomy. As previously discussed, this practice describes the work and expectations of leadership at both levels. This definition of expectations allows both levels of leadership to do the necessary work according to their roles. In sustaining level districts, the work is completed at the levels as expected, but they also expect input on the two levels: "the What" as defined and "the How" as determined at the building level from all employees.

The second practice is accountability. Accountability in PLCs is based on continuous improvement of the curriculum, which is based on the four questions that drive the curricular work of the community:

5. Exactly what is it we want all children to learn?

6. How will we know when each student has learned it?

7. What happens when students don't learn?

8. How do we respond when students already know it?

The sustaining stage PLCs use the four questions to define their curricular work. The four questions are used to develop and assess every curricular course and expectation. The focus is not on teaching but on ensuring that all students learn. If learning is not 
happening, the group collaborates to find additional solutions. The goal is student learning, which is assessed by the four questions.

The third and final practice is capacity building. Developing and sustaining a sustaining stage PLC requires skilled leaders and focused practice. Employees resign, retire, and are terminated by districts. Institutional knowledge must be kept in the organization and shared if organizations are to be sustained. The sustaining stage districts in this study are constantly working on capacity building. The work includes professional development for staff and training the district employees. While the leaders are gaining knowledge, the district is also looking for places to put those leaders to ensure the district and its work is sustainable. The districts both call this work moving pieces on the chess board. Alan Blankstein (2004) states it this way, "With a clear focus on why we are in the profession... and some information about how to create sustainable communities of learning, there is little that can stand in the way of our success" (p. 213). The work is not easy, but it is required.

The district-level and building-level leadership practices within professional learning communities ensure the establishment of a culture of improved student achievement and include defined autonomy, accountability, and capacity building. The districts in this study have all three practices in place.

\section{Research Question 3}

Does relational trust impact district-level and building-level leadership practices within professional learning communities?

As previously stated, relational trust is composed of social respect, personal regard, competence in core responsibilities, and personal integrity (Bryk, 2003). The two 
sustaining stage PLCs in this study have relational trust in their districts. Both districts demonstrate social respect. The staffs listen and work together to solve issues as they are encountered. The leaders respect each other and each other's positions and responsibilities. The leaders in the two districts show personal regard. They work well with their employees to create a workplace that is positive and focused on student achievement. The district leaders are competent and take their responsibilities seriously. The leadership is trained and capable of completing their responsibilities. Finally, the leadership in both districts is integrous. They work together to improve the academic success of their students. Relational trust impacts how district and building level leadership do their jobs. Relational trust is built through day-to-day social exchanges in a school community while it completes the difficult work of school improvement (Bryk \& Schneider, 2002).

\section{Conclusions}

The research literature and the participants' responses were consistent. Even though different people from different districts were involved, the consistent responses added to the research on PLCs. When asked about trust, all participants trusted those in relationships with them. The participants were able to describe the process of communication and participation in a PLC. The participants see district PLCs as a tool that improves administrative learning, teacher learning, student learning and communication.

\section{Implications for Practice and Analysis of Results}

The study has important implications for both district and building leadership, as well as school boards. The implications include two primary areas for consideration: process and communication. 


\section{Process}

The PLC model describes how things should be done. For the districts in this study, the PLC is almost a culture. According to Schein (2009), “...culture and leadership are two sides of the same coin and one cannot understand one without the other" (p. 3). The PLC teaches process by establishing its six characteristics: (a) mission, vision, values and characteristics, (b) collaborative culture, (c) collective inquiry, (d) action orientation/experimentation, (e) commitment to continuous improvement, and (f) results orientation. The sustaining stage districts have worked to create both process and leadership in their districts. The system provides support for leadership in both the district office and the buildings.

Fullan, Bertani, and Quinn (2004) stated:

District leaders must foster a culture in which school principals are concerned about the success of every school in the district, not just their own. Districts must be concerned about other districts and the overall environment in which they are working. (p. 43)

The districts in this study are working to meet this expectation. The Huntington School district presents on the PLC monthly to other districts and works weekly with JAGs to ensure that principals are concerned about the success of every school in the district. Grandview designs professional development together in their teams to ensure that every building receives the support needed to be successful. The system provides an atmosphere of team over individual.

Fullan (2005) elaborated:

Without attention to the larger system, professional learning communities will always be in the minority, never rising above $20 \%$ in popularity in the nation, and will not last beyond the tenure of those fortunate enough to have established temporary collaborative cultures. (p. 210) 
The only way PLCs will become more common is to be built on a district level. The two sustaining stage districts have developed similar processes for reaching the final stage. These processes may be able to be copied.

\section{Communication}

Bolam et al. (2006) explained: "An effective professional learning community has the capacity to promote and sustain the learning of all professionals in the school community with the collective purpose of enhancing pupil learning” (p. 131). Both of the sustaining stage district-wide PLCs in this study had designed communication systems that required their employees to work together to solve problems. Saphier, King, and D'Auria (2006) stated: “Powerful communication is directly connected with a team's ability to improve instruction" (p. 55). The team in this case is the district, which is made up of many teams and individuals.

A key issue in the development of PLCs is the development of effective and systematic feedback (Thorton, Shepperson, \& Canavero, 2007). The communication systems for the districts are the effective and systematic feedback for the districts. The communication system requires input from all parties. It also requires trust on two levels. The district must trust that once it has identified "the What", the building level can and will implement "the How" that is required to make "the What" successful. The building must trust that the district's What is needed to ensure the success of the students at the building level. In the case of the two sustaining stage districts in the study, they have enhanced trust by requiring input for others in both the What and the How.

Clearly, the implication for educational leaders from this study includes knowledge of PLCs and communication. The districts in this study have successful 
communication systems; their work requires collaboration and communication. The participants in the study all discussed communication and one of them considered it an important factor in PLCs. The superintendents from the sustaining stage PLCs considered it important enough to build and implement a communication plan. The plan is part of the successful sustaining level district-wide PLC.

\section{Limitations}

The small number of participants and the narrowing of the participant pool significantly limited the study. Narrowing was necessary for gathering data, but it also narrowed the generalizability of the resulting data and conclusions. Several limitations that were not anticipated prior to the onset of the study included: survey participation, the difficulty of securing individuals to participate in the study, the amount of time it takes to set up interviews, and accuracy of surveys. The survey return rate in this study was low. Although some people declined to participate, most just didn't return emails, voicemails, or calls. Once the researcher had identified districts for Phase III, several individuals simply did not respond to the invitation to participate, resulting in eight rather than the nine expected participants. Finally, five districts were identified as sustaining level PLCs with the use of PLCC and three of those districts identified agreed to participate in Phase III. In completing the semi-structured interviews, the data showed that one of the districts was not a sustaining level PLC. That district was not included, which reduced the number of individual participants from eight to six.

\section{Recommendations for Future Research}

According to Firestone (2009), "We may never be able to show statistically the school district's contribution to student achievement, but we know the district plays a key 
role in improving teaching and learning” (p. 670). To develop a process for continuous improvement for schools and districts, an understanding of the process of learning for administrators, teachers, and students is required. Sarason (1996) stated, “...if you want change and improve the climate and outcomes of schooling for both students and teachers, there are features of the school culture that have to be changed, and if they are not changed, your...efforts will be defeated" (p. 340). Re-culturing is changing the original culture to a new culture. According to Huffman and Hipp (2003), "Reculturing occurs by developing values, norms, and attitudes that affect the core of the culture of schools, which drives structural change” (p. 15). Vescio (2008) added, “[PLCs]... ultimately require a fundamental change in the institutional structures that have governed schooling, as it has traditionally existed" (p. 80). Organizational learning suggests three features of school culture and practice that have an impact on teachers' ability to sustain an openness to learning: organizational memory, shared knowledge base, and information distribution and interpretation (Louis, Kruse, \& Raywid, 1996). PLCs are designed to help schools with those three features.

Districts create a system of continuous improvement when they move their PLCs from the pre-intiation stage to the sustaining stage. Vescio (2008) stated, "Fueled by the complexities of teaching and learning within a climate of increasing accountability, [PLCs] moves professional development beyond merely supporting the acquisition of new knowledge and skills for teachers" (p. 80). Professional communities are characterized by shared norms and values, reflective dialogue, de-privatization of practice, collective focus on student learning, and collaboration (Louis, Kruse, \& Raywid, 1996). When the culture of an organization is changed, changes in individuals in the 
organization change, which finally changes the culture of the organization. This community of learning can only move to a higher level with the support of the district (Sappington, Baker, Gardner, \& Pacha, 2010). The work of the district is to support the construction of PLCs to build systems of continuous improvement.

This study provided a clear picture of the leadership relationships in a sustaining level PLC. One recommendation for future research is to expand the study to include additional participants representing all four stages of the PLC continuum: Pre-Initiation, Initiation, Developing, and Sustaining. The ability to compare and contrast districts at the different stages can assist districts in moving through the stages. An additional recommendation for expanding the respondent pool would be to remove the criteria in narrowing the initial samples. All types of districts—elementary, secondary, and unitcould be included in the study. Additional studies could be focused on different levels other than elementary. A comparative case study could research different levels, i.e., elementary vs. middle school Also, the original study could be repeated with a significantly higher number of participants, comparing and contrasting the results from that study with the results from this study to identify the leadership relationships in sustaining level PLCs across school districts moving toward the development of grounded theory (Merriam, 2009).

Another direction for this research would include additional information from building and central office level leaders. During the semi-structured interviews, the participants were eager and animated during the discussion of the components of PLCs, which suggested a comfort level that likely provided for genuine and comfortable responses. 
To launch an entirely different yet related study, one could use this research to identify items necessary to move through each of the stages of PLCs on the way to the sustaining level. A study could be developed wherein each stage could be investigated and defined, with the results analyzed in two significant ways: (a) consistency, or lack thereof, of the traits necessary to move through the phases of the PLCC, and (b) patterns of areas for support necessary for districts to be able to move through each of the stages on their way to sustaining level PLCs. Ideally, such information could also be used to help schools and districts develop and understand PLCs at a deeper level. 


\section{REFERENCES}

Barr, R., Dreeben, R., \& Wiratchai, N. (1983). How schools work. Chicago, IL: University of Chicago Press.

Barth, R. (1984). The professional development of principals. Educational Leadership, 42(2), 93-94.

Bennis, W. G. (1993). Beyond bureaucracy: Essays on the development and evolution of human organization. San Francisco, CA: Jossey-Bass.

Bidwell, C. E. (1965). The school as a formal organization. In J. G. March (Ed.), Handbook of organizations (pp. 972-1022). Chicago, IL: Rand McNally.

Bimber, B. A. (1993). School decentralization: Lessons from the study of bureaucracy. Santa Monica, CA: Rand, 1993.

Bjork, L. G. (1993). Effective schools—Effective superintendents: The emerging instructional leadership role. Journal of School Leadership, 3(3), 246-249.

Blankstein, A. M. (2004). Failure is not an option: Six principles that guide student achievement in high-performing schools. Thousand Oaks, CA: Corwin, Hope Foundation.

Blankstein, A. M., Houston, P. D., \& Cole, R. W. (2008). Sustaining professional learning communities. Thousand Oaks, CA: Corwin Press.

Block, P. (2008). Community: The structure of belonging. San Francisco, CA: BerrettKoehler.

Brocato, F. C. (1990). Don't look for a panacea with site based management. Journal of Instructional Psychology, 17(4), 243-251.

Bryk, A. S., \& Schneider, B. L. (2002). Trust in schools: A core resource for improvement. New York: Russell Sage Foundation.

Callahan, R. E. (1962). Education and the cult of efficiency. Chicago, IL: University of Chicago Press.

Conley, D. T. (1993). Roadmap to restructuring policies, practices, and the emerging visions of schooling. Eugene, OR: ERIC Clearinghouse on Educational Management. 
Conzemius, A. E., \& Morganti-Fisher, T. (2011). More than a SMART goal: Staying focused on student learning. Bloomington, IN: Solution Tree Press.

Coopey, J. (1995). The learning organization, power, politics, and ideology introduction. Management Learning, 26(2), 193-213. Doi: 10.1177/135050769502600204

Cowan, D. (2004). Creating co-developers: Linking research and practice. In S. M. Hord (Ed.), Learning together, leading together: Changing schools through professional learning communities (pp. 58-70). New York, NY: Teachers College Press.

Cowan, D. F. (2006). Creating learning communities in low-performing sites: A systemic approach to alignment. Journal of School Leadership, 16(5), 596-609.

Creswell, J. W. (2007). Qualitative inquiry \& research design: Choosing among five approaches. Thousand Oaks, CA: Sage Publications.

Crotty, M. J. (1998). The foundations of social research: meaning and perspective in the research process. Thousand Oaks, CA: Sage Publications.

Cubberley, E. P. (1909). Changing conceptions of education. Chicago, IL: Houghton Mifflin Company.

Cubberley, E. P. (1919). Public education in the United States: A study and interpretation of American educational history: An introductory textbook dealing with the larger problems of present-day education in the light of their historical development. Boston, MA: Houghton Mifflin Company.

Cubberley, E. P. (1929). Public school administration, a statement of the fundamental principles underlying the organization and administration of public education. Boston, MA: Houghton Mifflin.

Dreeben, R., \& Barr, R. (1983). Educational policy and the working of schools. In L. S. Shulman \& G. Sykes (Eds.), Handbook of teaching and policy (pp. 81-94). New York, NY: Longman.

DuFour, R., \& Eaker, R. E. (1998). Professional learning communities at work: Best practices for enhancing student achievement. Bloomington, IN: National Education Service.

Dufour, R., \& Marzano, R. J. (2011). Leaders of learning: How district, school, and classroom leaders improve student achievement. Bloomington, IN: Solution Tree Press.

DuFour, R. (2004). What is a professional learning community? Educational Leadership, 61(8), 6-11. 
DuFour, R., DuFour, R. B., \& Eaker, R. E. (2008). Revisiting professional learning communities at work: New insights for improving schools. Bloomington, IN: Solution Tree.

DuFour, R., DuFour, R., Eaker, R., \& Karhanek, G. (2004). Whatever it takes: How professional learning communities respond when kids don't learn. Bloomington, IN: National Educational Service.

DuFour, R., DuFour, R., Eaker, R., \& Many, T. (2010). Learning by doing: A handbook for professional learning communities at work. Bloomington, IN: Solution Tree Press.

DuFour, R., Eaker, R. E., \& DuFour, R. B. (2005). On common ground: The power of professional learning communities. Bloomington, IN: National Educational Service.

Edmonds, R. R. (1977). Search for effective schools, the identification and analysis of city schools that are instructionally effective for poor children.

Edmonds, R. R. (1982, December). Programs of school improvement: An overview. Educational Leadership, 40(3), 4-11.

Elmore, R. F. (1990). Restructuring schools: The next generation of educational reform. San Francisco, CA: Jossey-Bass.

Elmore, R. F. (2004). School reform from the inside out: Policy, practice, and performance. Cambridge, MA: Harvard Education Press.

Elmore, R. E. (2007). Local school districts and instructional improvement. In W. D. Hawley \& D. L. Rollie (Eds.), The keys to effective schools: Educational reform as continuous improvement $\left(2^{\text {nd }}\right.$ ed., pp. 189-200). Thousand Oaks, C: Corwin Press.

Feger, S., \& Arruda, E. (2008, Spring). Professional learning communities: Key themes from the literature. The Education Alliance Brown University. Retrieved June 20, 2010, from http://www.alliance.brown.edu/pubs/pd/pbs_plc_lit_review.pdf

Firestone, W. A. (2009). Accountability nudges districts into changes in culture. Phi Delta Kappan, 90(9), 670.

Foley, E., \& Sigler, D. (2009, Winter). Getting smarter: A framework for districts. Voices in Urban Education, 5-12.

Fullan, M. G. (1993). Innovation, reform, and restructuring strategies. In Challenges and achievements of American education: The 1993 ASCD yearbook (pp. 116-133). Alexandria, VA: Association for Curriculum and Development. 
Fullan, M. G. (1996). Turning systemic thinking on its head. Phi Delta Kappan, 77, 420423.

Fullan, M. (2003). Change forces with a vengeance. London: RoutledgeFalmer.

Fullan, M. (2005). Leadership \& sustainability: System thinkers in action. Thousand Oaks, CA: Corwin Press.

Fullan, M. (2006). Leading professional learning. School Administrator, 63(10), 10-14.

Fullan, M. (2007). The new meaning of educational change. New York, NY: Teachers College Press.

Fullan, M. (2010). The big ideas behind whole system reform. Education Canada, 50(3), 24-27. Retrieved February 14, 2012, from http://www.cea-ace.ca/educationcanada/article/big-ideas-behind-whole-system-reform

Fullan, M. G., \& Miles, M. B. (1992). Getting reform right: What works and what doesn't. Phi Delta Kappan, 73(10), 744-752. Doi: EJ445727

Fullan, M., \& Stiegelbauer, S. M. (1991). The new meaning of educational change. Toronto, Canada: Ontario Institute for Studies in Education.

Garratt, B. (1987). The learning organization. Fontana.

Garratt, B. (1999). The learning organization 15 years on: Some personal reflections. The Learning Organization, 6(5), 202-207. Doi: 10.1108/09696479910299802

Glanz, J. (1991). Bureaucracy and professionalism: The evolution of public school supervision. Rutherford, NJ: Fairleigh Dickinson University Press.

Good, T. L. (1989). [Foreword]. In Teachers' workplace: The social organization of schools (pp. Ix-Xii). New York: Longman.

Hargreaves, A. (2003). Teaching in the knowledge society: Education in the age of insecurity. New York: Teachers College Press.

Hightower, A. M., Knapp, M. S., Marsh, J. A., \& McLaughlin, M. W. (Eds.). (2002). School districts and instructional renewal. New York, NY: Teachers College Press.

Hill, P. T., \& Bonan, J. (1991). Site-based management: Decentralization and accountability. Education Digest, 57(1), 23-25.

Hipp, K. K., \& Huffman, J. B. (2010). Demystifying professional learning communities: School leadership at its best. Lanham, MD: Rowman \& Littlefield Education. 
Honig, M. I. \& Rainey, L. R. (2012). Autonomy and school improvement: What do we know and where do we go from here? Educational Policy, 26(3), 465-495.

Hopkins, D., Ainscow, M., \& West, M. (1994). School improvement in an era of change. London: Cassell.

Hord, S. M. (1997). Professional learning communities: Communities of continuous inquiry and improvement. Austin, TX: Southwest Educational Development Laboratory.

Hord, S. M., \& Sommers, W. A. (2008). Leading professional learning communities: Voices from research and practice. Thousand Oaks, CA: Corwin Press.

Hubbard, L., Mehan, H., \& Stein, M. K. (2006). Reform as learning: School reform, organizational culture, and community politics in San Diego. New York, NY: Routledge.

Huffman, J. B., \& Hipp, K. (2003). Reculturing schools as professional learning communities. Lanham, MD: Scarecrow Education.

Hughes, S., \& Snauwaert, D. T. (2010). "Brown" policy and the moral pillars of democracy: Exploring justice as the organizing principle of educational studies. Educational Studies: Journal of the American Educational Studies Association, 46(6), 545-559.

Joyce, B. R., \& Showers, B. (1995). Student achievement through staff development: Fundamentals of school renewal. New York, NY: Longman.

Kingston, P. W. (1986). Theory at risk: Accounting for the excellence movement. Sociological Forum, 1(4), 632-656. Doi: 10.1007/BF01107340

Kruse, S., Louis, K. S., \& Bryk, A. (1994). Building professional community in schools. Issues in Restructurying Schools, (6), 3-16. Retrieved December 23, 2011, from http://www.wcer.wisc.edu/archive/cors/issues_in_restructuring_schools/issues_no _6_spring_1994.pdf

Lezotte, L. W., \& Snyder, K. M. (2011). What effective schools do: Re-envisioning the correlates. Bloomington, IN: Solution Tree Press.

Lieberman, A., \& Miller, L. (2008). Contexts and commitments. In A. Lieberman \& L. Miller (Eds.), Teachers in professional communities: Improving teaching and learning (pp. 7-17). New York, NY: Teachers College Press.

Lortie, D. C. (1977). Schoolteacher: A sociological study. Chicago, IL: University of Chicago Press. 
Lortie, D. C. (2007). Schoolteacher: A sociological study; With a new preface. Chicago, IL: University of Chicago Press.

Marzano, R. J., \& Waters, T. (2009). District leadership that works: Striking the right balance. Bloomington, IN: Solution Tree Press.

Marzano, R. J. (2003). What works in schools: Translating research into action. Alexandria, VA: Association for Supervision and Curriculum Development.

Marzano, R. J., Waters, T., \& McNulty, B. A. (2005). School leadership that works: From research to results. Alexandria, VA: Association for Supervision and Curriculum Development.

McLaughlin, M. W., \& Talbert, J. E. (2002). Reforming Districts. In A. M. Hightower, M. S. Knapp, J. A. Marsh, \& M. W. McLaughlin (Eds.), School districts and instructional renewal (pp. 173-193). New York: Teachers College Press.

Moe, T. (2006, July/August). Put to the test: Thriving on failure. Stanford Magazine. Retrieved March 11, 2012, from http://alumni.stanford.edu/get/page/magazine/article/?article_id=33603

Murphy, J., \& Hallinger, P. (1988). Characteristics of instructionally effective school districts. Journal of Educational Research, 81(3), 175-179.

Newmann, F. M. (1994). School-wide professional community. Issues in Restructuring Schools, (6), 1-2. Retrieved December 20, 2011, from http://www.wcer.wisc.edu/archive/cors/Issues_in_Restructuring_Schools/

Newmann, F. M. (1996). Authentic achievement: Restructuring schools for intellectual quality. San Francisco, CA: Jossey-Bass.

Newmann, F. M., Smith, B., Allensworth, E., \& Bryk, A. S. (2001). Instructional program coherence: What it is and why it should guide school improvement policy. Educational Evaluation and Policy Analysis, 23(4), 297-321. doi: $10.3102 / 01623737023004297$

Oliver, D. F. (2003). Assessing schools as PLCs. In J. B. Huffman \& K. K. Hipp (Eds.), Reculturing schools as professional learning communities (pp. 67-74). Lanham, MD: Scarecrow Education.

O'Neil, J. (1995). On schools as learning organizations: A conversation with Peter Senge. Educational Leadership, 52(7), 20-23.

Orton, J. D., \& Weick, K. E. (1990). Loosely coupled systems: A reconceptualization. Academy of Management Review, 15(2), 203-223. 
Oxley, D. (2008). Creating instructional program coherence. Principals Research Review, $3(5)$, pages.

Pedler, M., Boydell, T., \& Burgoyne, J. (1989). The Learning Company. Studies in Continuing Education, 11(2), 91-101. Doi: 10.1080/0158037890110201

Peters, T. J., \& Waterman, R. H. (1982). In search of excellence: Lessons from America's best-run companies. New York, NY: Harper \& Row.

Pfeffer, J., \& Sutton, R. I. (2007). Hard facts, dangerous half-truths, and total nonsense: Profiting from evidence-based management. Boston, MA: Harvard Business School Press.

Purkey, S. C., \& Smith, M. S. (1983). Effective schools: A review. The Elementary School Journal, 83(4), 426-452. doi: 10.1086/461325

Ragland, M. A., Clubine, B., Constable, D., Smith, P. A. (2002). Expecting success: A study of five high performing, high poverty schools. Austin, TX: Council of Chief State School Officers.

Rosenholtz, S. J. (1989). Teachers' workplace: The social organization of schools. New York, NY: Longman.

Rothman, R. (2009). Improving student learning requires district learning. Phi Delta Kappan, 91(1), 44-50.

Rothman, R. (2012). The new "central office". Voices in Urban Education, 22, 2-4. Retrieved July 12, 2012, from http:/www.annenbergnstitute.org/VUE/wpcontent/pdf/VUE22.pdf

Russo, C. J. (2010). Site based management. In T. C. Hunt (Ed.), Encyclopedia of educational reform and dissent (pp. 829-831). Thousand Oaks, CA: SAGE.

Sappington, N. E. (1995). The relationship between the development of learning outcomes in science, as required by the Illinois school accreditation process, and changes in classroom curriculum, instruction, and assessment (Order No. 9633402, Illinois State University) (Unpublished doctoral dissertation). Retrieved April 4, 2013, from http://search.proquest.com/docview/304199618?accountid11578.

Sarason, S. B. (1996). Revisiting "The culture of the school and the problem of change." New York, NY: Teachers College Press.

Schein, E. H. (2004). Organizational culture and leadership. San Francisco, CA: JosseyBass. 
Schlechty, P. C. (1997). Inventing better schools: An action plan for educational reform. San Francisco, CA: Jossey-Bass.

Schlechty, P. C. (2005). Creating great schools: Six critical systems at the heart of educational innovation. San Francisco, CA: Jossey-Bass.

Senge, P. M. (2006). The fifth discipline: The art and practice of the learning organization. New York, NY: Currency Doubleday.

Slavin, R. E., \& Fashola, O. S. (1998). Show me the evidence!: Proven and promising programs for America's schools. Thousand Oaks, CA: Corwin Press.

Snipes, J., Doolittle, F., Herlihy, C., Council of the Great City Schools, W. D., \& Manpower Demonstration Research Corp., N. N. (2002). Foundations for Success: Case Studies of How Urban School Systems Improve Student Achievement.

Strang, D. (1987). The administrative transformation of American education: School district consolidation, 1938-1980. Administrative Science Quarterly, 32(3), 352366.

Sunderman, G. L. (2010). Evidence of the impact of school reform on systems governance and educational bureaucracies in the United States. Review of Research in Education, 34(1), 226-253. doi: 10.3102/0091732X09349796

Supovitz, J. A. (2006). The case for district-based reform: Leading, building, and sustaining school improvement. Cambridge, MA: Harvard Education Press.

Togneri, W., \& Anderson, S. E. (2003). How high poverty districts improve. Leadership, $33(1), 12$.

Tongco, M. C. (2007). Purposive sampling as a tool for informant selection. Ethnobotany Research \& Applications, (5), 147-158.

Tyack, D. B. (1974). The one best system: A history of American urban education. Cambridge, MA: Harvard University Press.

Tyack, D. (2002). Forgotten players: How local school districts shaped American education. In A. M. Hightower, M. S. Knapp, J. A. Marsh, \& M. W. McLaughlin (Eds.), School districts and instructional renewal (pp. 9-24). New York, NY: Teachers College Press.

Van, C. M., Soldwedel, P., \& Many, T. W. (2011). Aligning school districts as PLCs. Bloomington, IN: Solution Tree Press. 
Vescio, V., Ross, D., \& Adams, A. (2008). A review of research on the impact of professional learning communities on teaching practice and student learning $\hat{\tau}$. Teaching and Teacher Education, 24(1), 80-91. doi: 10.1016/j.tate.2007.01.004

Wald, P. J., \& Castleberry, M. S. (2000). Educators as learners: Creating a professional learning community in your school. Alexandria, VA: Association for Supervision and Curriculum Development.

Wayson, W. W. (1988). Up from excellence: The impact of the excellence movement on schools. Bloomington, IN: Phi Delta Kappa Educational Foundation.

Weick, K. E. (1976). Educational organizations as loosely coupled systems. Administrative Science Quarterly, 21(1), 1-19.

Weick, K. E. (1982). Administering education in loosely coupled schools. Phi Delta Kappan, 63, 673-676.

Wells, C., \& Keane, W. G. (2008). Building capacity for professional learning communities through a systems approach: A toolbox for superintendents. AASA Journal of Scholarship and Practice, 4(4), 24-32.

What is Effective Schools Research? (n.d.). Retrieved May 18, 2008, from http://www.mes.org/esr.html 
APPENDIX A

\section{DISTRICT SURVEY}




\section{DISTRICT SURVEY}

\section{Focus}

1. The purpose of the school has not been articulated. Most staff members view the mission of the school as teaching. They operate from the assumption that although all students should have the opportunity to learn, responsibility for learning belongs to the individual student and will be determined by his or her ability and effort.

2. An attempt has been made to clarify the purpose of the school through the development of a formal mission statement. Few people were involved in its creation. It does little to impact professional practice or the assumptions behind those practices.

3. A process has been initiated to provide greater focus and clarity regarding the mission of learning for all. Steps are being taken to clarify what, specifically; students are to learn and to monitor their learning. Some teachers are concerned that these efforts will deprive them of academic freedom.

4. Teachers are beginning to see evidence of the benefits of clearly established expectations for student learning and systematic processes to monitor student learning. They are becoming more analytical in assessing the evidence of student learning and are looking for ways to become more effective in assessing student learning and providing instruction to enhance student learning.

5. Staff members are committed to helping all students learn. They demonstrate that commitment by working collaboratively to clarify what students are to learn in each unit, creating frequent common formative assessments to monitor each student's learning on an ongoing basis, and implementing a systematic plan of intervention when students experience difficulty. They are willing to examine all practices and procedures in light of their impact on learning.

\section{Shared Mission}

6. No effort has been made to engage staff in describing the preferred conditions for the school.

7. A formal vision statement has been created for the school, but most staff members are unaware of it.

8. Staff members have participated in a process to clarify the school they are trying to create, and leadership calls attention to the resulting vision statement on a regular basis. Many staff members
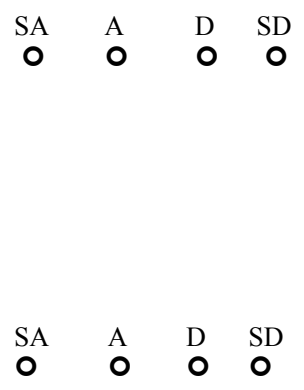

SA A D SD

0000

SA A D SD

0000

$\begin{array}{llll}\text { SA } & \text { A } & \text { D } & \text { SD } \\ 0 & 0 & 0 & 0\end{array}$

question the relevance of the vision statement, and their behavior is generally unaffected by it. 
9. Staff

$\begin{array}{llll}\text { SA } & \text { A } & \text { D } & \text { SD } \\ \text { O } & 0 & 0 & 0\end{array}$

members

have worked

together to

describe the

school are

trying to

create. They

have

endorsed this

general

description

and use it to

guide their

school

improvement

efforts and

their

professional

development.

10. Staff members

can and do

routinely

articulate the

major

principles of

the school's

shared vision

and use those

principles to

guide their

day-to-day

efforts and

decisions.

They honestly

assess the

current reality

in their school

and

continually

seek more

effective

strategies for

reducing the

discrepancy

between that

reality and

they school 
they are working to create.

\section{Collective Commitments (Shared Values)}

11. Staff members have not yet articulated the attitudes, behaviors, or commitments they are prepared to demonstrate in order to advance the mission of learning for all and the vision of what the school might become.

12. Administrators or a committee of teachers have created statements of beliefs regarding the school's purpose and its direction. Staff members have reviewed and reacted to those statements. Initial drafts have been amended based on staff feedback. There is no attempt to translate the beliefs into the specific commitments or behaviors that staff will model.

13. A statement has been developed that articulates the specific commitments staff members have been asked to embrace to help the school fulfill its purpose and move closer to its vision. The commitments are stated as behaviors rather than beliefs. Many staff members object to specifying these commitments and prefer to focus on what other groups must do to improve the school.

14. Staff members have been engaged in the process to articulate the collective commitments that will advance the school toward its vision. They endorse the commitments and seek ways to bring them to life in the school.

15. The collective commitments are embraced by staff, embedded in the school's culture, and evident to observers of the school. They help define the school and what it stands for. Examples of the commitments are shared in stories and celebrations, and people are challenged when they behave in ways that are inconsistent with the collective commitments.

16. No effort has been made to engage the staff in establishing school improvement goals related to student learning.

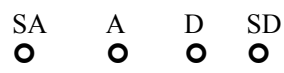

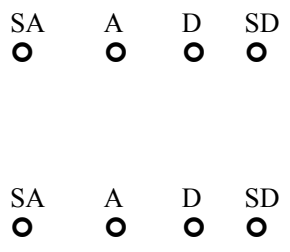


17. Goals for the school have been established by the administration or school improvement team as part of the formal district process for school improvement. Most staff would be unable to articulate a goal that has been established for their school.

18. Staff members have been made aware of the long-term and shortterm goals for the school. Tools and strategies have been developed and implemented to monitor the school's progress toward its-goals. Little has been done to translate the school goal into meaningful targets for either collaborative teams or individual teachers.

19. The school goal has been translated into specific goals that directly impact student achievement for each collaborative team. If teams are successful in achieving their goals, the school will achieve its goal as well. Teams are exploring different strategies for achieving their goals.

20. All staff members pursue measurable goals that are directly linked to the school's goals as part of their routine responsibilities. Teams work interdependently to achieve common goals for which members are mutually accountable. The celebration of the achievement of goals is part of the school culture and an important element in sustaining the PLC process.

\section{Purpose}

21. There is no sense of purpose or priorities. People throughout the school feel swamped by what they regard as a never-ending series of fragmented, disjointed, and short-lived improvement initiatives. Changes in leadership inevitably result in changes in direction.

22. Key leaders may have reached agreement on general purpose and priorities, but people throughout the organization remain unclear. Furthermore, if asked to explain the priorities of the school or the strategies to achieve those priorities, leaders would have difficulty articulating specifics. Staff members would offer very different answers if pressed to explain the priorities of the school.

23. There is general understanding of the purpose and priorities of the school, but many staff members have not embraced them. Specific steps are being taken to advance the priorities, but some staff members are participating only grudgingly. They view the initiative as interfering with their real work.

24. Structures and processes have been altered to align with the purpose and priorities. Staff members are beginning to see benefits from the initiative and are seeking ways to become more effective in implementing it.

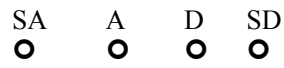

$\begin{array}{llll}\text { SA } & \text { A } & \text { D } & \text { SD } \\ 0 & 0 & 0 & 0\end{array}$

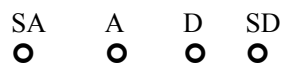

$\begin{array}{llll}\text { SA } & \text { A } & \text { D } & \text { SD } \\ 0 & 0 & 0 & 0\end{array}$

$\begin{array}{llll}\text { SA } & \text { A } & \text { D } & \text { SD } \\ 0 & 0 & 0 & 0\end{array}$

$\begin{array}{llll}\text { SA } & \text { A } & \text { D } & \text { SD } \\ 0 & 0 & 0 & 0\end{array}$

$\begin{array}{llll}\text { SA } & \text { A } & \text { D } & \text { SD } \\ 0 & 0 & 0 & 0\end{array}$

$\begin{array}{llll}\text { SA } & \text { A } & \text { D } & \text { SD } \\ 0 & 0 & 0 & 0\end{array}$ 
25. There is almost universal understanding of the purpose and priorities of the school. All policies, procedures, and structures have been purposefully aligned with the effort to fulfill the purpose and accomplish the priorities. Systems have been created to gauge progress. The systems are carefully monitored, and the resulting information is used to make adjustments designed to build the collective capacity of the group to be successful.

\section{Communication}

26. There is no sense of purpose and priorities. Different people in the school seem to have different pet projects, and there is

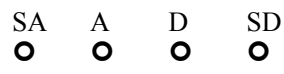
considerable in-fighting to acquire the resources to support those different projects.

27. Leaders can articulate the purpose and priorities of the school with a consistent voice, but their behavior is not congruent with their words. The structures, resources, and rewards of the school have not been altered to align with the professed priorities.

28. The school has begun to alter the structures, resources, and rewards to better align with the stated priorities. Staff members who openly oppose the initiative may be confronted, but those confronting them are likely to explain they are doing someone else's bidding. For example, a principal may say, "The central office is concerned that you are overtly resisting the process we are attempting to implement."

29. People throughout the school are changing their behavior to align with the priorities. They are seeking new strategies for using resources more effectively to support the initiative, and are willing to reallocate time, money, materials, and people in order to move forward. Small improvements are recognized and celebrated. Leaders confront incongruent behavior.

30. The purpose and priorities of the school are evident by the everyday behavior of people throughout the school. Time, money, materials, people, and resources have been strategically allocated to reflect priorities. Processes are in place to recognize and celebrate commitment to the priorities. People throughout the school will confront those who disregard the priorities.

31. Teachers have been provided with a copy of state, provincial, and/or national standards and a district curriculum guide. There is no process for them to discuss curriculum with colleagues and no expectation they will do so.

32. Teacher representatives have helped to create a district curriculum guide. Those involved in the development feel it is a useful

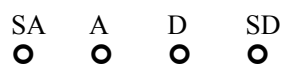

SA $\quad$ A $\quad$ D $\quad$ SD

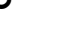

$\begin{array}{llll}\text { SA } & \text { A } & \text { D } & \text { SD } \\ 0 & 0 & 0 & 0\end{array}$ resource for teachers. Those not involved in the development may or may not use the guide. 
33. Teachers are working in collaborative teams to clarify the essential learning for each unit and to establish a common pacing guide. Some staff members question the benefit of the work. They argue that developing curriculum is the responsibility of the central office or textbook publishers rather than teachers. Some are reluctant to give up favorite units that seem to have no bearing on essential standards.

34. Teachers have clarified the essential learning for each unit by building shared knowledge regarding state, provincial, and/or national standards; by studying high- stakes assessments; and by seeking input regarding the prerequisites for success as students enter the next grade level. They are beginning to adjust curriculum, pacing, and instruction based on evidence of student learning.

35. Teachers on every collaborative team are confident they have established a guaranteed and viable curriculum for their students. Their clarity regarding the knowledge and skills students must acquire as a result of each unit of instruction, "and their commitment to providing students with the instruction and support to achieve the intended outcomes, give every student access to essential learning.

\section{Teaming}

36. Each teacher establishes his or her own criteria for assessing the quality of student work.

37. Teachers have been provided with sample rubrics for assessing the quality of student work.

38. Teachers working in collaborative teams are attempting to assess student work according to common criteria. They are practicing applying the criteria to examples of student work, but they are not yet consistent. The discrepancy is causing some tension on the team.

39. Teachers working in collaborative teams are clear on the criteria they will use in assessing the quality of student work and can apply the criteria consistently.

40. Collaborative teams of teachers frequently use performance-based assessments to gather evidence of student learning. Members have established strong inter-rater reliability and use the results from these assessments to inform and improve their individual and collective practice. The team's clarity also helps members teach the criteria to students, who can then assess the quality of their own work and become more actively engaged in their learning.
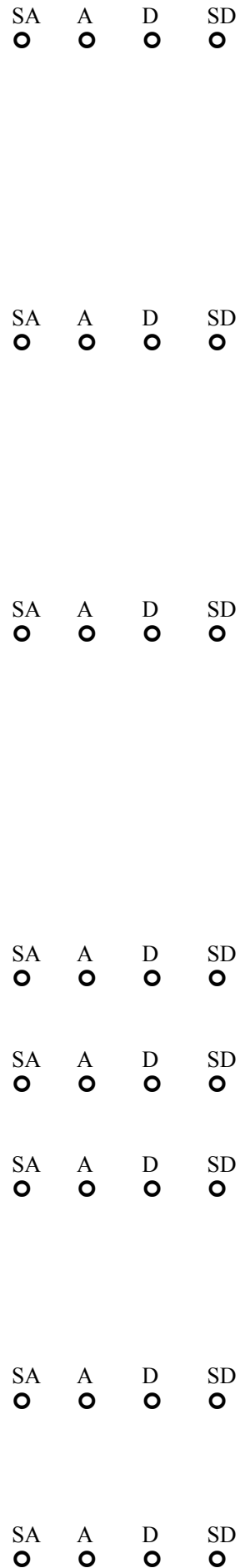


\section{Monitoring}

41. Each teacher creates his or her own assessments to monitor student learning. Assessments are typically summative rather than

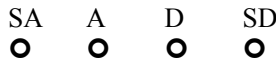
formative. A teacher can teach an entire career and not know if he or she teaches a particular skill or concept better or worse than the colleague in the next room.

42. The district has established benchmark assessments that are administered several times throughout the year. Teachers pay little attention to the results and would have a difficult time explaining the purpose of the benchmark assessments.

43. Teachers working in collaborative teams have begun to create common assessments. Some attempt to circumvent the

$\begin{array}{llll}\text { SA } & \text { A } & \text { D } & \text { SD } \\ 0 & 0 & 0 & 0\end{array}$
collaborative process by proposing the team merely use the quizzes and tests that are available

\section{Intervention}

44. What happens when a student does not learn will depend almost exclusively on the teacher to whom the student is assigned. There $\begin{array}{llll}\text { SA } & \text { A } & \text { D } & \text { SD } \\ 0 & 0 & 0 & 0\end{array}$ is no coordinated school response to students who experience difficulty. Some teachers allow students to turn in late work; some do not. Some teacher's allow students to retake a test; some do not. The tension that occurs at the conclusion of each unit when some students are proficient and ready to move forward and others are failing to demonstrate proficiency is left to each teacher to resolve.

45. The school has taken steps to provide students with additional time and support when they experience difficulty. The staff is grappling with structural issues such as how to provide time for intervention during the school day in ways that do not remove the student from new direct instruction. The school schedule is regarded as a major impediment to intervention and enrichment, and staff members are unwilling to change it. Some are concerned that providing students with additional time and support is not holding them responsible for their own learning.

46. The school has taken steps to provide students with additional time and support when they experience difficulty. The staff is grappling with structural issues such as how to provide time for intervention during the school day in ways that do not remove the student from new direct instruction. The school schedule is regarded as a major impediment to intervention and enrichment, and staff members are unwilling to change it. Some are concerned that providing students with additional time and support is not holding them responsible for their own learning. 
47. The school has a highly coordinated system of intervention and enrichment in place. The system is very proactive. Coordination with sender schools enables the staff to identify students who will benefit from additional time and support for learning even before they arrive at the school. The system is very fluid. Students move into intervention and enrichment easily and remain only as long as they benefit from it. The achievement of each student is monitored on a timely basis. Students who experience difficulty are required, rather than invited, to utilize the system of support. The plan is multilayered. If the current level of time and support is not sufficient to help a student become proficient, he or she is moved to the next level and receives increased time and support. All students are guaranteed access to this system of intervention regardless of the teacher to whom they are assigned. The school responds to students and views those who are failing to learn as "under-supported" rather than "at risk." 
APPENDIX B

RECRUITMENT E-MAIL 
March 10, 2014

Dear

I am a practicing district administrator and a doctoral student at Illinois State University. I am currently working on my dissertation under the direction of Dr. Neil Sappington. I am contacting you to seek your assistance with my dissertation research. In order to add to the body of knowledge regarding professional learning communities, my research study will explore the factors concerning relationships between building and district leadership. I obtained your contact information from your district website and am hopeful you'll consider participating in this study. Your participation is entirely voluntary and would be greatly appreciated.

I am requesting your participation, which will involve one audio-taped interview with me that will take place in a location convenient to you. I expect the interview will last approximately 45-60 minutes. The questions will relate to your thoughts on the relationships between building and district administration. Your responses will be kept confidential, and pseudonyms will be assigned. The only risk to you is the breach of confidentiality of this researcher. I can assure you, your information will remain confidential. At no time will your name, the name of your school, or your district be identified in this research or at any time in the future.

While time is at a premium for all school leaders, research of practices in the field of education is invaluable in continuing to improve the service we all provide to students and their communities. Reflecting on one's practice through participation in this type of research can also help individuals increase their knowledge and understanding. May I send you more information regarding participation in this study through a Letter of Consent approved by both my Principal Investigator and the Illinois State University Institutional Review Board? If you are willing to participate in this research study, please contact me via email at with your name, a contact phone number, and a good time to reach you. Once you've volunteered, I will respond to you within 2-3 days to schedule a convenient time for the interview within the next few weeks.

In case this email does not reach you, I may also make one phone attempt (using the work contact number provided on your district's website) to contact you and request your participation. Please also feel free to contact me if there is any additional information I may provide to help you decide if you're willing to participate in this study

If at any time throughout the process of this study you have any questions concerning the research, please feel free to contact me at ( If you have any additional questions about your rights as a potential subject or participant in this research, or if you feel you have been placed at risk, you can contact the Research Ethics \& Compliance Office at Illinois State University at (309) 4388451. If you have any other questions, you may contact the Principal Investigator of this study Dr. Neil Sappington at Illinois State University at (309) 438-5238 or via email at nesappi@ilstu.edu. This information will all once again be provided to you in the Letter of Consent.

I appreciate you taking time and consideration this morning/afternoon and I look forward to contacting you again regarding the content and your potential participation in this research study.

Sincerely,

Nathaniel Cunningham Jr.

Doctoral Candidate

Illinois State University

Phone: ()

Email: 
APPENDIX C

RECRUITMENT PHONE SCRIPT - IF INDIVIDUAL ANSWERS PHONE 
September 10, 2013

$\mathrm{Hi}$, is available?

My name is Nate Cunningham, and I am a practicing district administrator and a doctoral student at Illinois State University. I am currently working on my dissertation, a research study exploring the factors concerning relationships between building and district leadership in a professional learning community.

I am calling to request your participation, which will involve one audio-taped interview with me that will take place in a location convenient to you. I anticipate the interview will last approximately 45-60 minutes. . The questions will relate to your thoughts on the relationships between building and district administration.

While time is at a premium for all school leaders, research of practices in the field of education is invaluable in continuing to improve the service we all provide to students and communities.

Your participation is entirely voluntary and would be greatly appreciated. Do you have any questions about this study? Are you willing to participate in this research study?

[If yes, schedule appointment for time and location convenient to participant.] [If no, thank individual for his/her time and wish him/her a good day.] 
APPENDIX D

RECRUITMENT PHONE SCRIPT—IF LEAVING VOICEMAIL 
September 10, 2013

Hi, my name is Nate Cunningham, and I am a practicing district administrator and a doctoral student at Illinois State University. I am currently working on my dissertation, a research study exploring the factors concerning relationships between building and district leadership in a professional learning community.

I am calling to request your participation in a research study that would be a one-time interview. If you might be available and interested, please contact me at

[Follow phone script when individual returns phone call.] 
APPENDIX E

INFORMED CONSENT LETTER 
Dear

I am a practicing district administrator and a doctoral student at Illinois State University and am currently working on my dissertation, a research study exploring the factors concerning relationships between building and district leadership in a professional learning community.

I am requesting your participation, which will involve one audio-taped interview with me that will take place in a location convenient to you. I expect the interview will last approximately 4560 minutes. The questions will relate to your thoughts on the factors that are important in the relationships between building and district leadership in professional learning communities.

Your participation is entirely voluntary and is greatly appreciated. If you choose not to participate or to withdraw from the study at any time, there will be no penalty of any kind. Some individuals may be concerned that commenting on their district and building relationships may negatively affect their employability; however, I am taking multiple precautions to keep all data confidential and to ensure the identities of the study participants are not known by others. Pseudonyms will be used during the interview and the final report. You may decline to answer any questions within the study. Your participation will remain confidential, and no identifying information will be shared with your employer. While the results of the research study may be published, your name will never be used. The recording of our interview will be destroyed after it is transcribed, which will be done within one month of the interview.

Although there may be no direct benefit to you from the study itself, the possible intrinsic benefit of your participation would be to reflect on the student teacher placement process overall and the individual role you play within the field of education.

If you have any questions concerning the research study, please call me at ( $\square$, or you may contact my study advisor, Dr. Neil Sappington at 309-438-2058.

Sincerely,

Nathaniel Cunningham Jr.

I give consent to participate in the above study. I understand that my interview will be audiotaped.

Signature

Date

If you have any questions about your rights as a subject/participant in this research, or if you feel you have been placed at risk, you can contact the Research Ethics \& Compliance Office at Illinois State University at (309) 438-2529 and/or rec@ilstu.edu. 


\section{APPENDIX F}

THANK YOU NOTE 
April 1, 2014

Dear

Thank you for participating in my research project through Illinois State University. I appreciate you taking the time to meet with me and to share your thoughts about the field of education.

Best wishes in your future endeavors.

Sincerely,

Nathaniel Cunningham Jr. 
APPENDIX G

CONFIRMATION EMAIL-DEMOGRAPHIC QUESTIONS

TO COMPLETE PRIOR TO INTERVIEW 
Thank you for agreeing to participate in my research study. Please gather the following information prior to our interview, which is scheduled for at $\mathrm{am} / \mathrm{pm}$ at

\section{$\underline{\text { Respondent }}$}

Job Title:

Primary Areas of Responsibility:

How may staff members are affected by your leadership?

What are your district goals?

\section{$\underline{\text { School or District Context }}$}

Student enrollment:

\# of Certified Teachers:

\# of Administrators in the district 
APPENDIX H

INTERVIEW GUIDE: BUILDING LEADERSHIP INTERVIEW

QUESTIONS BASED ON THE RESEARCH PROBLEM 


\section{Introductions \& Building Rapport}

Review information from the previously completed information sheet (Attachment 6). What are your district goals?

Do you know how they were developed?

Statement of the Problem: This research-based project is an attempt to determine how the relationship between district and building leadership affects school improvement as measured by the components of the professional learning community as described by Hord (1997).

\section{$\underline{\text { Research Question }}$}

1. How does the relationship between the district-level leadership and the building-level leadership impact the implementation and sustainment of a professional learning community?

\section{Interview Questions}

1. What is the District Vision

a. How was the vision established?

b. Who was involved in building the vision?

c. Does the district require building level vision statements?

2. What is the District Mission?

a. How was the mission established?

b. Who was involved in building the district mission?

c. Does the district require building level mission statements?

3. What are the District's Values?

a. How were the values established?

b. Who was involved in building the district's values?

c. Does the district require building level value statements?

4. How were/are the three top priorities of your district-wide PLC established?

a. What is the role of building level leadership in establishing the goals of the district-wide PLC?

b. What is the role of district level leadership in establishing the goals of the each building PLC?

5. How are the three top priorities of building level PLCs established?

a. How did building-level leadership establish trust with district-level leadership?

\section{Artifacts}

1. Copies of goal document and development process.

2. Copies of goal document and development process

3. Copies of goal document and development process

4. Agendas for district administrative meetings

5. Agendas for district administrative meetings 
6. How is building level leadership involved in the development of the plan for resource allocation?

7. How is district level leadership involved in the development for building level plans for resource allocation?

8. How is building level leadership involved in district-wide scheduling?

9. How is building level leadership involved in planning professional development?

10. How does district level leadership ensure building level professional learning, promote district goals, and allow building level autonomy?

11. Do you trust district level leadership?

a. If yes, how did district level leadership establish trust?

b. If no, how did district level leadership undermine trust?

12. Does your school have a strong knowledge base concerning PLCs supported by staff development?

a. If yes, how did district level leadership establish the knowledge base?

b. If no, how did district level leadership undermine the knowledge base?

13. Does your school have an understanding of the importance of group goals and commitments as they relate to successful PLCs?

a. If yes, how did district level leadership help establish the importance of group goals and commitments?

b. If no, how does district level leadership undermine the importance of group goals and commitments?

14. How was the PLC established and sustained? a. What role does the district level leadership play in this process?

b. What role does the building level leadership play in this process?

15. How does the mission affect your daily work as an administrator?
6. District resource allocation plan that includes process and participants.

7. District resource allocation plan that includes process and participants.

8. District scheduling plan that includes process and participants.

9. District professional development plan that includes process and participants.

10. Has the building decision-making structure or governance structure changed since Quality Review work started? If so, how has it changed?

11. Copies of district communication concerning mission, vision, and goals.

12. Copies of in-service sessions on PLCs.

13. Copies of in-service sessions on PLCs.

14. District documents on the PLC process.

15. Memos from principal or head teacher. 


\section{Research Question}

2. What district-level and building-level leadership practices within professional learning communities ensure the establishment of a culture of improved student achievement?

\section{Interview Questions}

1. Does district level leadership have a succession plan for building level leadership?

a. If yes, is the plan communicated to building level leadership?

b. If no, does district level leadership do something else to promote stability?

2. Does district level leadership have a succession plan for district level leadership?

a. If yes, is the plan communicated to building level leadership?

b. If no, does district level leadership do se to promote stability?

3. What does the district leadership do to promote stability?

4. What does the building leadership do to promote stability?

5. Are the district succession plans compatible with the building-level succession plans?

6. Are you aware of the PLC goals for the district and how they relate to the following?

- What do we want students to learn?

- How will we know when they have learned it?

- What will we do when they don't learn it?

7. Are there specific commitments building administration must honor to achieve district and building purpose and vision?

8. Is there a feedback process that identifies tasks required by the district that building administration would like to be simplified or? eliminated to give them more time to focus on student achievement?

9. Is there a process that identifies supports that need to be changed, restructured or created to enhance building school improvement efforts?

10. What are the districts non-negotiables as related to the PLC process?

a. How are the non-negotiables communicated to building administration?

b. Does district administration support the nonnegotiables by word, deed, and action?
Artifacts
1. Copies of district and building
administrative succession plan.

2. Copies of district and building administrative succession plan.

3. Copies of district and building administrative succession plan.

4. Copies of district and building administrative succession plan.

5. Copies of district and building administrative succession plan.

6. Copy of district's mission, vision, values, and goals.

7. Copy of district's mission, vision, values, and goals.

8. Copy of district's mission, vision, values, and goals.

9. Copy of district's mission, vision, values, and goals.

10. Copy of district's mission, vision, values, and goals. 


\begin{abstract}
APPENDIX I
INTERVIEW GUIDE: DISTRICT LEADERSHIP INTERVIEW

QUESTIONS BASED ON THE RESEARCH PROBLEM
\end{abstract}




\section{Introductions \& Building Rapport}

Review information from the previously completed information sheet (Attachment 6). What are your district goals?

Do you know how they were developed?

Statement of the Problem: This research-based project is an attempt to determine how the relationship between district and building leadership affects school improvement as measured by the components of the professional learning community as described by Hord (1997).

\section{Research Question}

1. How does the relationship between the district-level leadership and the building-level leadership impact the implementation and sustainment of a professional learning community?

\section{Interview Questions}

1. What is the District Vision

a. How was the vision established?

b. Who was involved in building the vision?

c. Does the district require building level vision statements?

2. What is the District Mission?

a. How was the mission established?

b. Who was involved in building the district mission?

c. Does the district require building level mission statements?

3. What are the District's Values?

a. How were the values established?

b. Who was involved in building the district's values?

c. Does the district require building level value statements?

4. How were/are the three top priorities of your district-wide PLC established?

a. What is the role of building level leadership in establishing the goals of the district-wide PLC?

b. What is the role of district level leadership in establishing the goals of the each building PLC?

5. How are the three top priorities of building level PLCs established?

a. How did building-level leadership establish trust with district-level leadership?

\section{Artifacts}

1. Copies of goal document and development process.

2. Copies of goal document and development process

3. Copies of goal document and development process

4. Agendas for district administrative meetings

5. Agendas for district administrative meetings 
6. How is building level leadership involved in the development of the plan for resource allocation?

7. How is district level leadership involved in the development for building level plans for resource allocation?

8. How is building level leadership involved in district-wide scheduling?

9. How is building level leadership involved in planning professional development?

10. How does district level leadership ensure building level professional learning, promote district goals, and allow building level autonomy?

11. Do you trust district level leadership?

a. If yes, how did district level leadership establish trust?

b. If no, how did district level leadership undermine trust?

12. Does your school have a strong knowledge base concerning PLCs supported by staff development?

a. If yes, how did district level leadership establish the knowledge base?

b. If no, how did district level leadership undermine the knowledge base?

13. Does your school have an understanding of the importance of group goals and commitments as they relate to successful PLCs?

a. If yes, how did district level leadership help establish the importance of group goals and commitments?

b. If no, how does district level leadership undermine the importance of group goals and commitments?

14. How was the PLC established and sustained? a. What role does the district level leadership play in this process?

b. What role does the building level leadership play in this process?

15. How does the mission affect your daily work as an administrator?
6. District resource allocation plan that includes process and participants.

7. District resource allocation plan that includes process and participants.

8. District scheduling plan that includes process and participants.

9. District professional development plan that includes process and participants.

10. Has the building decision-making structure or governance structure changed since Quality Review work started? If so, how has it changed?

11. Copies of district communication concerning mission, vision, and goals.

12. Copies of in-service sessions on PLCs.

13. Copies of in-service sessions on PLCs.

14. District documents on the PLC process.

15. Memos from principal or head teacher. 


\section{Research Question}

2. What district-level and building-level leadership practices within professional learning communities ensure the establishment of a culture of improved student achievement?

\section{Interview Questions}

1. Does district level leadership have a succession plan for building level leadership?

a. If yes, is the plan communicated to building level leadership?

b. If no, does district level leadership do something else to promote stability?

2. Does district level leadership have a succession plan for district level leadership?

c. If yes, is the plan communicated to building level leadership?

d. If no, does district level leadership do se to promote stability?

3. What does the district leadership do to promote stability?

4. What does the building leadership do to promote stability?

5. Are the district succession plans compatible with the building-level succession plans?

6. Are you aware of the PLC goals for the district and how they relate to the following?

-What do we want students to learn?

- How will we know when they have learned it?

-What will we do when they don't learn it?

7. Are there specific commitments building administration must honor to achieve district and building purpose and vision?

8. Is there a feedback process that identifies tasks required by the district that building administration would like to be simplified or? eliminated to give them more time to focus on student achievement?

9. Is there a process that identifies supports that need to be changed, restructured or created to enhance building school improvement efforts?

10. What are the districts non-negotiables as related to the PLC process?

a. How are the non-negotiables communicated to building administration?

b. Does district administration support the nonnegotiables by word, deed, and action?

\section{Artifacts}

1. Copies of district and building administrative succession plan.

2. Copies of district and building administrative succession plan.

3. Copies of district and building administrative succession plan.

4. Copies of district and building administrative succession plan.

5. Copies of district and building administrative succession plan.

6. Copy of district's mission, vision, values, and goals.

7. Copy of district's mission, vision, values, and goals.

8. Copy of district's mission, vision, values, and goals.

9. Copy of district's mission, vision, values, and goals.

10. Copy of district's mission, vision, values, and goals. 


\section{APPENDIX J}

RECORDING-VIDEO, AUDIO, STILL IMAGE, DIGITAL 
Recording an individual's voice and/or image creates unique handling and storage issues, particularly if the content may be considered sensitive. Subjects must be informed ahead of time that such recording will occur. Subjects must also be provided with information about the storage, confidentiality, and future use of the resulting tape. Only what is necessary for the purpose of the study should be recorded.

If a research protocol involves the recording of research subjects, complete the questions listed below:

1. What type of recording will be utilized?

The interviews will be audiotaped using a digital recorder.

2. What identifiers will be recorded, e.g., partial facial features, full facial features, subject's name?

Only voices will be recorded, and pseudonyms will be used during the recordings.

3. Is the recording necessary for participation in the research? If so, why?

The recording is necessary to ensure the comments of the participants are captured accurately. This will ensure the coding of the data will result in more accurate summarization.

4. What additional risks to the subject may arise from the recording?

None.

5. Who will have access to the recording(s)?

The only individuals who will have access to the recordings will be the Principal Investigator and the Co-Principal Investigator.

6. How will the recording(s) be used, e.g. educational or commercial purposes, analysis by the research team, future unspecified use? Please note that any public use of the recordings requires separate, explicit consent for such use.

The recordings will be used for only this dissertation and research and documentation that may result directly from this dissertation, as conducted by the Co-PI.

7. What mechanisms in place to protect the confidentiality of the person(s) being recorded?

The recording will only be audio, so the individuals will not be visually recognizable. Pseudonyms will also be assigned to participants prior to the beginning of each recording, so their true names will not be part of the recorded evidence. 
8. Will the recording( $\mathrm{s}$ ) be kept indefinitely? If not, provide a clear indication of when and how they will be destroyed.

The recordings of the interview will be transcribed within one month of the interview, and the recordings will be destroyed when the transcriptions are completed.

9. Will the subjects receive any compensation for allowing themselves to be taped? If so, describe the amount and the method of compensation.

No.

Additional Informed Consent Requirements: In addition to the standard elements of informed consent, consent forms for projects involving recordings must make specific mention of the elements included above.

$\square \quad$ If the recording is an optional procedure, the subject must have the choice of participating in the recording. The consent for this is separate and distinct from consent to participate in the project, therefore separate signature and date lines are required.

$\square \quad$ If the recording is an integral part of the research and not an optional procedure, a separate informed consent document is not required. However, documentation of the considerations listed above must be still be included within the body of the informed consent document, as well as any additional risks that may arise due to the recording. 